\title{
Failures and Interventions on Agricultural Markets at the International, National and Regional Scale
}

\author{
Dissertation \\ zur Erlangung des Doktorgrades \\ der Fakultät für Agrarwissenschaften \\ der Georg-August-Universität Göttingen
}

vorgelegt von

Thomas Kopp

geboren in Gräfelfing

Göttingen, März 2015 
1. Referent: Prof. Dr. Bernhard Brümmer, Professur für Landwirtschaftliche Marktlehre, Fakultät für Agrarwissenschaften

2. Korreferent: Prof. Dr. Stephan von Cramon-Taubadel, Professur für Agrarpolitik, Fakultät für Agrarwissenschaften

Tag der mündlichen Prüfung: 13. Mai 2015 
Kopp, T. (2015): Failures and Interventions on Agricultural Markets at the International, National and Regional Scale. Dissertation at the Department of Agricultural Economics and Rural Development, Georg-August University of Göttingen. 



\section{Acknowledgements}

This thesis would not have been possible without the support and encouragement of many different persons. Therefore, I am very glad that I have here the possibility to express my deep gratitude. As there are too many to name them all, I would like to highlight some persons.

First of all I would like to thank my supervisor Prof. Dr. Bernhard Brümmer for his guidance and trust. I always felt that I could conduct this research independently, and at the same time rely on his support, which contributed to the eventual success of this work.

I also thank my second examiners Prof. Dr. Stephan von Cramon-Taubadel and Prof. Dr. Meike Wollni for their readiness to take over this task.

I would like to take this opportunity to also thank my co-authors for fruitful collaborations. Dr. Sören Prehn has already been my teacher before I even considered doing a PhD. Prof. Dr. Zulkifli Alamsyah and Ibu Raja Sharah Fatricia did not only co-author the second paper but also provided fundamental support during the data collection phase in Jambi.

I would like to thank all my friends and colleagues at Göttingen University. These include the colleagues from our working group for listening to many many presentations of mine and giving valuable feedback. I especially mention Dr. Tinoush Jamali Jaghdani for his help with questionnaire design and data bank set-up. Credit also goes to Dr. Elisabeth Waldmann, Dr. Juliane Manitz, Benjamin Säfken and Holger Reulen for support in statistical questions. I thank my co-discussants Dr. Friederike Greb and Dr. Vijesh Krishna, as well as the participants at the Doctoral Seminar of the Department for Agricultural Economics and Rural Development for valuable input and comments on my presentations.

I also thank my colleagues from the CRC990 for a lot of support and companionship 
during the hardships of the data collection phase (and some fun time in between). A particular thank you goes to Anna-Mareike Holtkamp, Stefan Moser, Michael Euler, and Dr. Vijesh Krishna for close cooperation during these days in the villages, as well as the staff of the CRC office in Jambi, especially Rizky Febrianty who was probably one of the most stressed out people in the initial phase of the project.

Moreover, I thank all the research- and student assistants whose work was essential for conducting my research and compiling this dissertation: these are the assistants in Jambi to whom I am grateful for their hard work and many overtime hours during the data collection: Meriussoni Zai, Viverani Desmera, Anna-Carina Kruse, Khoiriana, Muhammad Beni Saputra, Nesar Budi Cahyo Laksono, Nursanti, Redha Illahi, Reny Dwijayanti, Rini Atopia, Rio Handoko, Rio Yudha, and Sri Muryati. My gratitude also goes to my assistants in Göttingen for their diligent work of data entry: Rakhma Sujarwo, Angga Yudhistira, Fuad Nurdiansyah, and Krystal Lin. Jurij Berger assisted me during the compilation of the final manuscript.

For proofreading and valuable comments I would like to thank Dr. Daniel Castro, Katharina Trapp, Steffen Lange, Nikolai Deuschle, and especially Adam Walker for his reliable and brilliant English language proofreading, as well as often being available on very short notice.

I would like to thank my friends in Germering, Berlin and Göttingen, as well as my friends from the video project Ecapio from whom I drew more energy than they probably assume.

My research has been made possible by generous funding by the German Research Foundation (DFG) within the Collaborative Research Centre 990 'Ecological and Socioeconomic Functions of Tropical Rainforest Transformation Systems in Sumatra, Indonesia' (EFForTS).

Most of all I would like to thank Mariana who always supported me during these years. She was my backing in difficult phases, went with me during the long phase of separation during the initial phase, and tolerates frequent instances of mental absence.

Last but not least, a special thank you goes to my family: my parents, Ulla and Hans Kopp who always supported me during my studies and enabled me to get to this stage, as well as my brother Roland who will always be my brother. 
For Elisabeth Meyer.

I miss you. 



\section{Contents}

\begin{tabular}{ll}
\hline Acknowledgements & i
\end{tabular}

Contents

List of Figures $\quad$ vii

List of Tables viii

$\begin{array}{llr}1 & \text { Introduction } & 1\end{array}$

1.1 Distortions on agricultural markets . . . . . . . . . . . . . . 2

1.2 Relevance and contribution . . . . . . . . . . . . . . . . . 4

1.3 Theoretical background $\ldots \ldots \ldots \ldots$. . . . . . . . . . . 5

1.4 Application of the theoretical framework . . . . . . . . . . . . 10

2 Traders and Credit Constrained Farmers: Market Power along $\begin{array}{ll}\text { Indonesian Rubber Value Chains } & 21\end{array}$

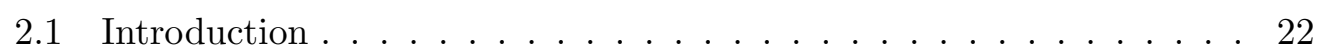

2.2 Data . . . . . . . . . . . . . . . . . . . . . . . . . . 24

2.3 Background: rubber in Jambi . . . . . . . . . . . . . . . . . . . . . . 24

2.4 Methodology $\ldots \ldots \ldots \ldots$

2.5 Results and discussion . . . . . . . . . . . . . . . . . . . . . 35

2.6 Conclusions $\ldots \ldots \ldots \ldots$

3 Have Indonesian Rubber Processors Formed a Cartel? Analysis of Intertemporal Marketing Margin Manipulation 45

3.1 Introduction . . . . . . . . . . . . . . . . . . . . . . . . 46

3.2 Background $\ldots \ldots \ldots \ldots$. . . . . . . . . . . . . . . . . . . . . . . 49

3.3 Methodology . . . . . . . . . . . . . . . . . . . . . 51

$3.4 \quad$ Data $\ldots \ldots \ldots \ldots \ldots \ldots \ldots$ 
3.5 Results. . . . . . . . . . . . . . . . . . . . . . . . 58

3.6 Discussion . . . . . . . . . . . . . . . . . . . . . . 62

$3.7 \quad$ Conclusions $\ldots \ldots \ldots \ldots \ldots$. . . . . . . . . . . . . . . 67

4 Preference Erosion - the Case of Everything But Arms and Sugar 71

4.1 Introduction . . . . . . . . . . . . . . . . . . . 73

4.2 Political background $\ldots \ldots \ldots \ldots \ldots$. . . . . . . . . . . 75

4.3 Methodological issues . . . . . . . . . . . . . . . . . . 80

4.4 Data $\ldots \ldots \ldots \ldots \ldots$

4.5 Results and interpretation . . . . . . . . . . . . . . . . . 88

4.6 Conclusion . . . . . . . . . . . . . . . . . . . . . . . . . . . . . 91

5 Discussion of Results and Open Questions 95

5.1 Overview . . . . . . . . . . . . . . . . . . . 96

5.2 Welfare- and policy implications across scales . . . . . . . . . . . 98

5.3 Limitations . . . . . . . . . . . . . . . . . . . . . . 100

5.4 Relevance and wider implications . . . . . . . . . . . . . . . . 104

\begin{tabular}{lr}
\hline Bibliography & 109
\end{tabular}

\begin{tabular}{ll}
\hline Appendix & 123
\end{tabular}

(1) Appendix to chapter two . . . . . . . . . . . . . . . . . 123

(2) Appendix to chapter three . . . . . . . . . . . . . . . . . . . 126

(3) Questionnaire . . . . . . . . . . . . . . . . . . . . . 128 


\section{List of Figures}

$2.1 \quad$ Global rubber production in $2012 . \quad \ldots \ldots \ldots$. . . . . . . . . 25

2.2 Trade flows of rubber in the Jambi Province. . . . . . . . . . . . . . 26

2.3 Position of respondents in the value chain, starting from the factory. $\quad 27$

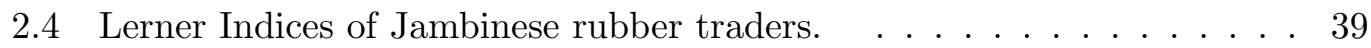

3.1 Marketing channels for rubber. . . . . . . . . . . . . . . . . . . . . . 49

3.2 Intuition of asymmetric price transmission. . . . . . . . . . . . . 52

3.3 Symmetric error correction (continuous line) and asymmetric error correction (dotted line). . . . . . . . . . . . . . . . 54

$3.4 \quad$ Welfare effect during adjustment process after shock at $\mathrm{t}=0$. . . . . 56

3.5 Time series of buying and selling prices. $\ldots \ldots \ldots$. . . . . . 58

3.6 Distribution of ect values. . . . . . . . . . . . . . . 60

3.7 Penalized splines. $\ldots \ldots \ldots \ldots 1$

3.8 Results of one-dimensional grid search. . . . . . . . . . . . . . 62

3.9 Correction of shocks over time. $\ldots \ldots \ldots$. . . . . . . . . . 64

4.1 Price development. . . . . . . . . . . . . . . . . . . . . . . . . . . . . . . 79

4.2 Welfare effects of policy changes. $\ldots \ldots \ldots \ldots$. . . . . . . 79

4.3 Development of $P M$ in ACP countries. . . . . . . . . . . . . . 83

4.4 Aggregate exports in millions of Euros. . . . . . . . . . . . . . . 88

5.1 Network structures. . . . . . . . . . . . . . . . . . . . . . . . . 101 


\section{List of Tables}

1.1 Matrix of distortions and scales. . . . . . . . . . . . . 3

2.1 Spearman's rank correlation coefficients between buying and selling prices, and the traders' positions in the value chains. . . . . . . . . . . . 27

2.2 Regression of estimated dry rubber contents on credits given. . . . . . . 35

2.3 Variables entering the production function. . . . . . . . . . . . 35

2.4 Possible determinants of market power. . . . . . . . . . . . . . 36

2.5 Regression results of revenue function. . . . . . . . . . . . . . . 38

2.6 Determinants of market power that is exercised by traders. . . . . . . . 40

3.1 Estimates of long-run relation. . . . . . . . . . . . . . . . . 60

3.2 Results of Akaike Information Critereon. . . . . . . . . . . . . . . . . . 61

3.3 Results of all models discussed. . . . . . . . . . . . . . . . . . . . . 63

4.1 Development of EU sugar policies. . . . . . . . . . . . . . . . . . 80

4.2 Estimation results . . . . . . . . . . . . . . . . . . . . . . . . . . . . . . . . . . . . 8

viii 


Chapter 1

\section{Introduction}




\subsection{Distortions on agricultural markets}

For a long time, economic thought has been based on the assumption that efficient, perfectly competitive markets are the normal case (Cassels, 1937), and that the best policy is not to intervene in markets. This early assumption has, in many instances, proven to not hold. Malfunctions do exist in various forms, and policy interference is common. Agricultural markets are especially prone to malfunctioning due to a number of characteristics specific to the sector. These include the wide geographical spread of many small firms (Hallet, 1981) and relatively high levels of uncertainty (Runge and Myers, 1985). Both lead to a greater volatility of output in agriculture than in other sectors of the economy (Nedergaard, 2006). Hagedorn identifies a systematic "economic disadvantage for the farm sector" (Hagedorn, 1983, p. 310): the introduction of a new technology at the individual farm level does not lead to an advantage in the market, but rather diverts disadvantages from the farm. This is in contrast to the industrial sector, where a new technology usually enables the generation of profits. The reason is a great homogeneity between producers and again - their large number (Hagedorn, 1983).

Gaining a deeper understanding of these distortions is crucial. A clear comprehension of the underlying mechanisms that result in a malfunction in a certain market is the exclusive basis from which the best reaction can be developed. Likewise, it is important to understand the effects of a certain policy, identifying the groups of stakeholders who are actually affected, and anticipating their reaction. Agricultural policies are influenced at an above-average level by lobby groups due to the characteristics laid out above. The large number of rather homogenous producers share very similar interests, fostering political coordination. The sector has indeed been successful in organising itself, as well as in influencing political processes (Hagedorn, 1983). With deeper knowledge on these processes, an estimate of the consequences to a society's welfare from any distortion in agricultural markets can be predicted, and eventually normatively assessed.

Two kinds of distortions observed on the markets of agricultural goods are discussed in this work: a) the distortions that stem from a malfunction of the market, and b) the ones that are policy-driven and have the target of changing the market outcome (independent of whether market failure is present or not). The lack of market functioning refers to non-competitive markets, i. e. the presence of market power on either the demand side (mono-/oligopsony) or the supply side (mono-/oligopoly), as well as to market failure 1

The market distortions are categorised according to their nature and along the

\footnotetext{
${ }^{1}$ Examples for each aspect of the theoretical framework are provided below.
} 
scale dimension. A brief overview of the theoretical framework along which the analyses are organized is presented in Table 1.1 .

Table 1.1: Matrix of distortions and scales.

\begin{tabular}{|c|c|c|c|}
\hline & \multicolumn{2}{|c|}{ Scale } \\
\hline & & Micro & Meso \\
\hline \multirow{2}{*}{$\begin{array}{c}\text { Kind } \\
\text { of } \\
\text { Distortion }\end{array}$} & $\begin{array}{c}\text { Market } \\
\text { functioning }\end{array}$ & $\begin{array}{l}\text { Malfunctioning on } \\
\text { disaggregated level }\end{array}$ & $\begin{array}{c}\text { Sector-wide } \\
\text { malfunctioning }\end{array}$ \\
\hline & $\begin{array}{c}\text { Policy } \\
\text { Intervention }\end{array}$ & $\begin{array}{l}\text { Specific } \\
\text { measures }\end{array}$ & $\begin{array}{l}\text { Sector-wide } \\
\text { interventions }\end{array}$ \\
\hline
\end{tabular}

Source: own production.

This introducing chapter provides the theoretical framework for the thesis, gives a short summary of each of the three scientific articles, and puts them into a greater context to highlight their relevance.

\section{Target of this work}

While there is a body of literature on market malfunctioning on the micro- and the meso-/macro-scale, the scale dimension itself is often not explicitly expounded. However, it makes sense to differentiate not only between the kinds of distortions, but also along the scale dimension, since effects of micro-distortions (restricted to one product, one market-segment, one geographic area, etc.) usually have immediate effects at the local scale, but less tractable impacts at a more aggregated scale. Likewise, the effects of distortions on a greater scale may trickle down to the individual stakeholder at a quick rate, or on the other extreme, hardly be recorded. A comprehensive report of market distortions must therefore account for the differences in scale. This is not a negligible undertaking, since the functioning of a market can be critically influenced by lower-level processes or constrained by higher-level requirements. Examples can be found for every kind of distortion on every level of aggregation. For the different combinations, examples are provided in the course of this elaboration.

The choices made on the household level in a rural context are, for example, influenced by the social, economic, and legal environment. This framework of constraints and opportunities is present at all scales, be it local (customary) or national law, socioeconomic indicators on a local scale or at the national level, such as taxation, energy policy, or output prices on a global level (World Bank, 2007). 
The reconciliation of the meso-/macro-perspective with the understanding of microeconomic dynamics has been a challenge for economists of different sub-disciplines during the last few decades (Kojima and Ozawa, 1984 foreign direct investment; Chetty et al., 2011: labour supply; Robinson, 1991: structural adjustment; Bloom and Canning, 2005: economic growth; Robilliard and Robinson, 2003: rural household income).

The target of this work is to discuss three of the four possibilities of the matrix shown in Table 1.1 at one example, respectively. The key questions that each of the papers attempt to answer by scrutinising the different kinds of distortions are as follows: are market malfunctions present (chapters two and three)? What are the distributional consequences: who wins and who loses? What are the net costs to society? The replies to these questions are addressed in each of the papers, using the examples of the rubber market in Jambi (Indonesia) and the European Union's (EU) sugar market order and will be condensed in chapter five.

\subsection{Relevance and contribution}

The agricultural sector is home to some of the most prominent examples of malfunctioning markets. These markets malfunction due to a variety of reasons, such as externalities or market concentration, for example. With the 'industrialisation' of the agricultural sector during the second half of the 20th century (e.g. mechanisation, increased application of synthetic fertilisers and pesticides, separation of crop and livestock), its effects on the environment have increased tremendously (Conway and Pretty, 1991). This can be observed both in industrialised and in economically less developed countries. The industrialisation in agriculture led to an increase of water and air pollution due to pesticides, fertilisers, residuals from onfarm processing, and climate gas emissions, amongst others (Conway and Pretty, 1991). These externalities have the potential to affect the health of individuals and the environment, and therefore the welfare of a given society. Market concentration can be observed at many levels (e.g. the German beer industry, EU sugar processors, or global dairy production) and often reduces total welfare (see below). This is especially relevant in the context of economically less developed countries, where markets exhibit imperfections on various levels. Since many farmers have little bargaining power with their buyers, the increase of the total wealth to be distributed (due to rising prices for agricultural products) does not necessarily lead to increasing rural incomes. The resulting increased levels of inequality in rural areas, which is contrary to the target of many rural development policies, lead in turn to a higher pressure on the surrounding environment. A good example of this 
is poor households who engage in logging activities in areas covered by rainforest (Dauvergne, 1993).

Policy intervention is also widespread in the agricultural sector - as a reply to market failure, or as a measure of redistribution. The biggest part of the EU budget, for example, has always been reserved for the Common Agricultural Policy. One factor of it has been the Common Market Order for sugar.

Both kinds of distortions - failures and interventions - always create winners and losers. This is independent of the total societal welfare. A distortion can cause an increase, decrease or have no effect on welfare. This does not only depend on the actual distributional effects of the distortion, but also on the underlying definition of welfare, for example whether a certain amount of money is valued depending on the income level of the group that holds it in their hands.

This dissertation contributes to the literature by presenting a review of distortions of different scopes and scales. It includes two papers that broaden the horizon concerning the (mal-)functioning of one specific market, covering the complex networks and interactions in great detail, and one piece that illustrates with a powerful example how interventions can pile up until a complex system of (partly conflicting) policies is built by policymakers under the pressure of the public, influenced by lobbyists and constrained by obligations from multilateral agreements.

\subsection{Theoretical background}

\section{Non-competitive markets}

Gabszewicz and Thisse (2000) summarise the four conditions which have to be met for a market to be competitive:

- The number of firms active in the market is sufficient in the sense that the decisions of one firm do not have an influence on the market price (firm size and number)

- No barriers exist for new (existing) firms to enter (leave) the market (free entry/exit)

- Goods are homogeneous, leading to perfect substitutability between the products provided by two firms active on that market (product homogeneity)

- Every participant of the market has all information on the market prices of all goods traded (perfect information) 
The discussion of underlying reasons for malfunctions on one specific agricultural market presented in part 1.4 of this introduction goes along the lines of Gabszewicz's and Thisse's (2000) conceptualisation of these four characteristics of perfectly competitive markets.

Models that are based on the assumption of competitive markets have been criticised for 'widen[ing] rather than to narrow the gap that has always existed between the worlds of theory and of practice' (Cassels, 1937). The first one to challenge the assumption of competitive markets was Cournot in the book "Recherches sur les principles mathémathiques de la théorie des richesses" from 1838, in which he introduced the concept of market power (Gabszewicz and Thisse, 2000). After Cournot, there had been relative silence on the issue for nearly a century until the 'Imperfect Competition Revolution' took place in the 1920s and '30s (Gabszewicz and Thisse, 2000). It was started by Piero Sraffa who rejected the concept of competitive markets, stating that these are the exception rather than the rule (Sraffa, 1926). The reasons for his rejection are inconsistencies in the theory, as well as contradictions with observations made in the real world. These inconsistencies and contradictions refer to the fact that only a minority of enterprises/industries have cost structures which fulfil the assumptions that the supply functions in economic theory rely upon:

Business men [...] would consider absurd the assertion that the limit to their production is to be found in the internal conditions of production in their firm, which do not permit of the production of a greater quantity without an increase in cost. The chief obstacle against which they have to contend when they want gradually to increase their production does not lie in the cost of production [...] but in the difficulty of selling the larger quantity of goods without reducing the price. (Sraffa, 1926 , p. 543)

Instead, Sraffa understands the market not as a competition between identical firms, but rather as one between many monopolies. Joan Robinson followed up on that, and suggested a more general theory which incorporates perfect competition as one special case (Robinson, 1959, first edition: 1933). At the same time, Edward H. Chamberlin (1958, first edition: 1933) arrived at similar conclusions: consumers' preferences towards single brands and willingness to substitute with similar (not identical) products of another brand result in elastic demands faced by every single firm, i. e. their decisions on production quantities influence the prices of their products. 
As an empirical approach for analysing and quantifying market power, StructureConduct-Performance (SCP) analyses of markets have been available since the 1940s (Schmalensee, 1989; Perloff et al., 2007). The 'structure' refers to the observable distribution of firms in a market, such as firm concentration and market shares, as captured, for example, by the Herfindahl-Hirschman Index (Hirschman, 1964). The 'performance' indicates the proximity of the market outcome to the one under perfect competition. 'Conduct' stands for the behaviour of all stakeholders active in the market, which is determined by the structure and results in the performance. It is hence this unobservable element of the theory which connects the observable characteristics of a market with the economic outcome.

More recent works have turned toward the modelling of decisions of economic agents. Gabszewicz and Thisse (2000) observe an expansion of these game-theoretical approaches since the 1970s. They summarise the game-theoretical implications of the four conditions (that are presented above) which are to be fulfilled by a market to be perfectly competitive. Perloff et al. (2007) differentiate between static and dynamic models of game theory. While the static models assume that future developments have no effect on current decisions, the dynamic ones model the strategy of agents who maximize not only current profits, but also the present value of future profits. In the dynamic models framework, the current decisions can be based on two motivations. The first one is the target to change the 'fundamentals' (i. e. the future competitive environment), for example via investments into marketing, the capital stock, etc. The alternative motivation is based on 'strategic' considerations. They refer to actions that have the target to affect the belief of other firms about the own behaviour in the future, such as the credibility of threats (Perloff et al. 2007).

The analysis in chapter two is based on an SCP approach. Ideas for a more sophisticated extension to the analysis conducted in chapter three with a game-theoretical framework are laid out in chapter five.

\section{Market failure}

While Arthur C. Pigou did not invent the concept of externalities and market failure, he was the first to formally represent them in an economic model (Groenewegen, 2009, Pigou, 1932). His concept of market failure associated with externalities has been at the core of welfare economics ever since. Pigou assumed perfect competition (Marcuzzo, 2009), so in his view market failure can be found in otherwise perfectly competitive markets.

Externalities exist if the production or consumption of a good generates effects 
on other individuals which are not reflected in the product price. These effects can increase other individuals' utility or income ('positive externalities') or impose costs on them ('negative externalities'). The externalities do not need to take effect at the point of time of their emission but may kick in with some delay. Typical examples for negative externalities include soil and air pollution (delayed effect), or noise (immediate effect), and for positive externalities bee-keeping and pollination (immediate effect) or technology spillovers (delayed effect).

Another failure - apart from externalities - that can often be observed in rural areas of economically less developed countries, is the lack of a (formal) capital market. The reasons for the absence of a capital market lie firstly in the relatively high fixed costs of establishing branches of formal lending institutions in rural areas; this is primarily due to the fact that there are few potential customers per branch due to low population density. Secondly, collateral is often not available, for example due to a lack of formal land titles. Thirdly, the difficulty of acquiring information on the potential borrowers, paired with low contract enforceability, increases the risk of defaults.

It is important to note that failure in one market can be transmitted to another market (Subramanian and Qaim, 2011). This is especially true for situations in which markets are interlinked, as for example through complex networks of reciprocal exchanges in rural societies of low income countries (Ellis, 2000). One example for these reciprocal exchanges can be found in the credit market. Ellis (2000) notes that, especially in Asia, private sector money lending can often be found but is often interlocked with other markets, which puts the borrower in a disadvantaged negotiation position on the other market with the provider of his or her credit.

Other market characteristics leading to market failure include high transaction costs, the existence of public goods due to non-excludability of consumers, government corruption, the failure of the government to provide a stable currency, rule of law, and the protection of property rights ${ }^{2}$

Pigou's concept of market failure also incorporates the maldistribution of income and the creation of business cycles which result in instability in incomes and consumption (Medema, 2009). Other authors, however, employ different definitions of market failure. Following Koester (2011), for example, only divergences between the public and private willingness to pay qualify as failures of the market mechanism while distributional considerations are not part of the concept.

\footnotetext{
${ }^{2}$ While these sources of market failure are mentioned here for the sake of completeness, they are of limited relevance in the subsequent chapters, and are therefore not elaborated upon more extensively at this point.
} 


\section{Scales of market malfunctions}

The units of analysis for identifying malfunctioning on a micro- or local- scale are households, small-scale traders/middlemen, small businesses, and the like. These can be summarised as single stakeholders, whose individual actions do not have a significant influence on a larger scale. (If many stakeholders behave in a similar way, their actions of course have a combined effect that is also significant on a larger scale.)

Analyses on a meso- or macro-scale are carried out in the form of aggregates over different dimensions, such as geographically (regional, national, international) or the product-range (within one or across many industries).

In many cases the scale of analysis depends on the wider context of market failures, for example institutional issues, (e.g. the functioning of land markets, World Bank, 2007), corruption levels, village dynamics, or (lacking) infrastructure. The observed characteristic might be common on a larger scale (macro), or only in exceptional cases (micro). The same is true for the level at which the corresponding effects are witnessed, which can be at an individual basis, or throughout a whole industry.

\section{Policy responses}

The target of policy intervention is to correct the lack of a desired outcome in a possibly (but not necessarily) well functioning market or to achieve other, noneconomic, political goals. The rationale behind this is that even perfectly functioning markets can produce politically undesirable outcomes (Koester, 2011).

The policy which is best suited to correct for a certain malfunction depends on its nature. The presence of negative (positive) externalities that arise with the production of a good can, for example, be compensated for by a lump-sum tax (subsidy) on its production, in order to internalise the externality. If the main failure is one of asymmetric information, the government can introduce an information system if prices are intransparent, or a technical standard if information on unobservable product characteristics is lacking.

In summary, policy can either be a response to market failure or an initial distortion. This partly depends on the definition of 'failure'. Koester for example, lists redistribution as an additional motivation for policy intervention besides market failure, as mentioned above (Koester, 2011). Pigou's concept of market failure, on the other hand, includes issues of distribution, so a policy that aims for redistribution would be categorized under the umbrella of correcting market failures. This means that the concentration of capital (which may lead to social friction) is also 
understood as a market failure, which requires measures of redistribution from the richer members of society to the poorest. Political goals in the agricultural sector include, amongst many others, the conservation of a traditional lifestyle in rural areas and self sufficiency of a particular region (Koester, 2011). Another possible justification for a policy intervention is to rectify the (possibly unintended) sideeffects of older interventions, or the adjustment of a policy in anticipation of a changed context. According to Constanza et al. (2001), one requirement that a planned intervention has to fulfil is its social acceptance, i. e. the distributional consequences, as well as its compatibility with international agreements. Many policy instruments employed in agricultural markets have side effects, i. e. the influence on markets other than the one primarily targeted with the intervention (Koester, 2011). As will be demonstrated later, this is not always given, and might therefore require additional regulation. It will be of particular concern in chapter four.

\section{Scales of policy interventions}

Policy interventions in the agricultural sector can take two forms: a) regulative laws - such as bans and rules - which are hereafter referred to as micro policies or b) incentive based measures (Constanza et al., 2001). The latter market-wide interventions are less specific and referred to as macro-policies hereafter. They include measures such as subsidies, taxes, and quotas which are applied to production, imports, or exports and have the potential to affect prices, as well as the quantities that are produced and traded (Koester, 2011).

The micro policies (rules and bans) are very specific measures that are applied on farm level. They concern production requirements and have to be followed by every single farmer on each of his/her fields. Basically, all cross compliance regulations of the Common Agricultural Policy (CAP), such as the fertilisation ordinance, the direct payments obligation regulation (humus balance, green corridors, nitrogen balance, crop rotation) fall into this category. It also includes measures that are constrained by narrow geographical boundaries, such as the Bavarian corn rootworm management regulation ("Maiswurzelbohrerbekämpfungsverordnung").

Both kinds of policies can have the target of redistribution or of correcting market failure.

\subsection{Application of the theoretical framework}

Instead of providing systematic analyses of all cases (all possible combinations, all aspects) included in the general framework, this work gives exemplary illustrations for three of the general issues. Firstly, two cases of market failure are presented, 
both taking place in the Jambi Province on Sumatra, Indonesia. More specifically, the illustrations relate to the rubber sector. Chapter two focuses on the underlying dynamics at the micro-scale (village level), while chapter three delves into the implications of a great concentration of this sector on a meso-level, i.e., at the processor stage. These two cases are followed by one of policy intervention on a meso-scale: The fourth chapter discusses the Sugar Market Order of the European Union 3

The analyses carried out are based on quantitative research methods. Three approaches are applied as required by the different scales and scopes of the analyses: in the first paper production functions are estimated, the second one follows a price transmission approach, and in the third paper a gravity model is employed. More information on the methodology is provided in the following subsections that are dedicated to the individual articles. The different methodological approaches represented in the following three chapters also require the employment of different kinds of data, so little can be generalised here: the most fundamental data that all papers are based upon are information on trade flows, including traded quantities, values, prices, and buyer-seller pairs. More exhaustive information on data and their collection is provided in the respective sections.

\section{Failures on the rubber market in Jambi, Indonesia}

\section{The Jambinese rubber value chain}

Rubber production in Indonesia is predominately carried out by small scale farmers. Their output consists of slabs of coagulated rubber of around 50kg. ${ }^{4}$ In the Jambi Province on Sumatra Island, the vast majority of the rubber is delivered to processors via a network of small- and medium-sized traders. The processors - crumb rubber factories - clean and press the slabs into rubber blocks, following the international product standard 'Technically Specified Rubber' (TSR). This rubber is then exported all over the world for further processing, mainly in the tyre industry.

Jambi is one example of a province that crucially depends on its agricultural sector. It also represents a typical rubber production area. $52 \%$ of the workforce is employed in the agricultural sector and $48 \%$ of arable land is dedicated to rubber production, of which $99.6 \%$ is cultivated by smallholders (Regional Account and

${ }^{3}$ The analysis of the EU CMO for sugar cannot be called a macro policy in the strict economic meaning, since the focus is only on one sector of the economy. Nevertheless, the analysis is on a very aggregated level, and includes all countries that are active on the international sugar market.

${ }^{4}$ References to the information provided in these paragraphs can be found in chapters two and three 
Statistical Analysis Division, 2012). Although Jambi is not, on average, an exceptionally poor province, the rural population is still disadvantaged compared to the populations in other parts of Indonesia.

The Jambinese rubber market is dominated by market power on the demand side on all scales. The market structures tend to be oligopsonistic or monopsonistic competition - the demand-side equivalents of monopolistic competition and oligopoly. The processors exercise market power towards their suppliers (traders and some large farmers), and the traders in the villages towards farmers and smaller traders. Violations of all four preconditions for a competitive market as defined by Gabszewicz and Thisse (2000) can be found at the different scales: symmetric information, small firms, absence of entrance barriers, and product homogeneity.

Analysis on the micro scale has been carried out at the level of single individuals via a representative survey of traders. The units of analysis at the meso-level are the average price of five rubber processing firms and international prices.

\section{Paper one: village level traders (micro scale)}

When looking at the market performance on the micro scale, one can observe that the prices paid by traders for their rubber input are below marginal value products (MVP). Varian (1987) describes first-degree price discrimination (or 'perfect discrimination') of a monopolist as the selling of a product to each consumer at the maximum price that he or she is willing to pay. By doing so, the monopolist receives the whole possible rent, and the consumer none (note that under perfect discrimination, the pareto-efficient quantity of a good is produced and sold). In the case of demand sided market power, perfect discrimination means that the monopsonist pays the lowest price for an input that each provider of this input is willing to accept. Varian observes that "there are very few real-life examples of perfect price discrimination" (Varian, 1987, p. 431). It might be the case that the Jambinese rubber market is one of these rare examples, since most traders pay different prices to each of their providers.

The structure of the Jambinese rubber market at the village level varies for different geographic regions, but generally lies on the continuum between oligopsony and monopsonistic competition. Bhaskar et al. 2002, p. 156) define monopsonistic competition as an "oligopsony with free entry, so that $[\ldots]$ profits are driven to zero." It is the demand-side equivalent to monopolistic competition as first described by Chamberlin (1958). In some villages, true monopsonies can be found.

The results of the analysis carried out in chapter two show that the traders' input prices for rubber lie significantly below this input's MVPs which is a strong indi- 
cator for the presence of market power. This was concluded from the estimation of the traders' production functions, and the subsequent calculation of the rubber input's MVP. These differ significantly from the observed prices that traders pay for this input. The deviation of the observed prices from the MVPs were normalised by calculating Lerner Indices. The average of the Lerner Indices is 0.29 (standard deviation: 0.27 ) which means that the average trader pays $29 \%$ below the MVP. The reasons for the weak performance of this market lie in the violation of several prerequisites for a competitive market, as well as market failures.

Product homogeneity: One could argue that raw rubber is a rather homogenous good, so the theory of imperfect competition in this sector would not be supported. While this argument would be effective for the monopoly case, it is not valid for market power on the demand side because the services that are offered by the buyers (traders) are not homogeneous. The most important reasons for this are the personal relations that have often been ongoing for a long time, resulting in mutual trust. The exchanges on the market are therefore not anonymous as often implicitly assumed in economic theory.

The product itself is subject to artificially imposed heterogeneity that is associated with different demands by every trader: at the moment of purchasing rubber, the trader assesses its quality by estimating the 'dry rubber content' (DRC), a measure of purity 5 Since there is a lot of scope for manipulation, these DRC estimations are often subject to a bias.

Gabszewicz and Thisse (2000) also note that different geographic locations have implications for market power similar to product differentiation. The importance of the geographic location is associated with the availability and quality of transport infrastructure (road network), which is at a sub-optimal level in many parts of the Jambi Province.

Free entry: The following three conditions must be fulfilled to guarantee free entry to a market, as described by Bain (1956) for the monopoly case.

a) Possible entrants do not have higher costs than established firms.

b) The hypothetical size of firms under conditions of perfect competition is 'small', with regards to their share of total industry output and ability to influence prices.

\footnotetext{
${ }^{5}$ This does not mean, that all differences of DRC estimations are due to manipulation. The estimations does account partly for existing quality differences.
} 
c) The products of the established firms do not have an advantage based on product differentiation, such as brand loyalty.

For the monopsonistic case, condition b) is changed slightly (total industry output becomes input), and conditions a) and c) are exchanged: condition a) requires possible entrants to face the same output prices as established firms, and in order to fulfill c), the suppliers of the input should feel no loyalty towards the established firms, but be able to freely switch to an entrant. In Jambi, condition a) is not likely to be fulfilled because the access to rubber factories for selling is limited, since supply is often larger than the factories can handle (see chapter three) and the traders who have established personal relations are advantaged. It is difficult to assess condition b) in general, since the concentration of the trading varies across villages. Condition c) is certainly not fulfilled: the differentiation of demand is based upon the ongoing personal relationship between seller and buyer (see elaboration above). These close ties are amplified by the linkage of the trading business with the credit market (see next point).

Credit constraint (failure): Since Jambinese farmers are constrained to receive credit from formal lending institutions for the reasons laid out above (Ellis, 2000 Subramanian and Qaim, 2011), traders assume the role of informal providers of credit. For cultural reasons, the credit that traders provide to their suppliers comes (predominantly) at a zero interest rate. Whether a farmer is indebted with a trader, and - if yes - the size of the credit significantly affect the estimation of the DRCs of the delivered rubber. As we will see, however, credits do not actually affect the Lerner Index. This indicates that the correlation between DRC estimation and credit given reflects only the traders' own costs of providing liquidity in the form of credit. This does not mean, however, that the DRC estimation is free from manipulation on other grounds (see below).

Imperfect information: The costs for obtaining information on the prices that different traders are paying for rubber are relative low for individual farmers. They can be obtained via their personal networks, supported by mobile telecommunication technology. However, since the estimation of the DRC content is done on an ad hoc basis and characterised by some arbitrariness, the farmer does not know about it before selling to a new trader. The DRC estimations of his or her current trader, on the other hand, can be predicted based on previous experience. The farmer might have an idea of the distribution of possible DRC estimations given by different alternative traders, but as demonstrated by Gabszewicz and Thisse (2000), this information does not help and the trader can offer the monopson price. 
Market power (performance): Due to the nature of the product, the rubber supply of an individual farmer, and thus the total supply on the market, is very inelastic $\sqrt{6}$ This means that market-wide, there is a lot of scope for pricing below marginal revenues. In a Bertrand-fashioned competition, traders are setting the prices, and not the quantities (Bertrand, 1883, referred to in Gabszewicz and Thisse, 2000). In essence, all the rubber that is available at a certain price will be purchased.

For the analysis on the level of individual traders, the loyalty of providers needs to be considered. They prefer continuing the business relationships with the traders with whom they have established relations. This results in a willingness to accept a certain price disadvantage. If the disadvantage exceeds a certain level, the farmer might switch to another trader. From the trader's perspective, the aggregation of these behaviours of individual suppliers results in an upward-sloping supply curve faced by the trader.

The aspect of perfect discrimination that was mentioned above could be implemented via the manipulation of the DRC estimations which is different for every farmer. However, it must be made clear that the estimation of the DRC is not only determined by market power. The DRC reflects the de facto quality differences and is also systematically underestimated in order to recover credit costs, and only partly according to non-observable characteristics of the farmer (which would reflect his or her individual willingness to sell at a certain price).

\section{Paper two: processors (meso scale)}

As the second study (chapter three) reveals, the five crumb rubber factories located in Jambi City exercise market power vis-à-vis their providers. A time series analysis of co-movements of input- and output-prices shows that these processors engage in asymmetric price transmission. Their market power manifests itself in an intertemporal manipulation of marketing margins.

A look at the structure of the processing industry reveals at least monopsonistic competition, in which "competition takes place among the few", as Gabszewicz and Thisse (2000) put it, or possibly even an oligopsony.

The identification of underlying dynamics is straightforward in this case. According to Gabszewicz and Thisse (2000), established firms might find it profitable to erect barriers against entry. These barriers can be of a technological nature, but may also exist on a legal basis. This is the case for the Jambinese market of rubber

\footnotetext{
${ }^{6}$ This is only true for the short-term perspective. The production decisions (e.g. cultivation of rubber vs. oil palm) of farmers are taken as given and not subject to change within the time horizon of this analysis.
} 
processing, where entry to the market (i. e. construction of another factory) is not only very costly but actually impossible in the literal sense. While the barriers to entering (or leaving) a market are frequently associated with high fixed costs, in this case they are based on legislative grounds. The Jambinese factories have an amount of political power which is great enough to deter the government from permitting the establishment of new factories. Since these barriers are a success of political lobbying, they are high investments/sunk costs. These costs would of course - not be incurred by new entrants if the market was free. In effect, this artificially constrains the demand for the rubber (the number of factories is below its optimal level), resulting in a price for the raw rubber input that is below the optimal level.

The international rubber prices are provided by the Jambinese government, and can be accessed via a mobile phone query (smartphones are not required). While this is not very well known throughout the population in Jambi, it might not be relevant for the suppliers' assessment of the factory-prices anyway, since the factories' processing costs are unknown to the suppliers. The prices that the different factories pay for the rubber input is transparent to the providers, so the market mechanism can be assumed to function in this respect.

The condition of product homogeneity is also fulfilled. The processing of rubber in Jambi is homogenous in input and output, since no extra services are provided to suppliers and all factories sell the same product, according to the international standard TSR.

As mentioned above, the results of this analysis show that the rent that is redistributed from the suppliers to the factories due to intertemporal marketing margin manipulation is substantial: around three million U.S. Dollars are annually redistributed from Jambinese farmers to factories. Compared to a non-oligopsonistic market situation, the farmers have missed out on an income from rubber production of $7 \%$. The total redistribution that has been generated in the process could not be quantified in this analysis (due to missing information on the price elasticities on the supply and demand sides), but can be assumed to be substantial.

\section{Methods and data}

Paper one: The collection of the data required for this analysis was exercised as a survey with agricultural traders in the Jambi Province from September until December 2012. The targeted sample consists of all traders in 40 villages that are representative for the rubber- and palm oil-producing regions in the province. A response rate of $71 \%$ was achieved. The data obtained include prices and quantities 
of inputs and outputs, credit sizes given to individual farmers, as well as many other business-related and personal characteristics of the respondents (see Appendix [3)]. Based on these data, a translog production function was estimated which was used to calculate the MVP and subsequently the Lerner Indices. The Lerner Index captures deviations of prices from the MVP. In a subsequent step, determinants of this measure of market power were estimated.

Paper two: This paper employs an approach of time series analysis in order to circumvent the problem of aggregating data over time which ignores the dynamic nature of price setting processes. The analysis of price transmission enables the assessment of the integration of markets. At the core of the empirical part of this study lies the estimation of an Auto-Regressive Asymmetric Threshold Error Correction Model. In order to understand the nature of the error correction process without the need for restrictive a priori assumptions, the non-parametric estimation technique of penalised splines is employed. The analysis is carried out based on price data because they are - as in many other cases, too - the only data that are available at the high frequency required for time series analysis. More specifically, the factories' buying and selling prices from 2009-2012 were used. The buying prices were provided by GAPKINDO, the rubber processors' association who collect these data for their own purposes, and the selling prices stem from a Jakarta-based marketing company which publishes the results of rubber auctions on a daily basis.

\section{Policy interventions}

\section{Paper three: policy interventions on the EU sugar market (meso scale)}

The third paper provides an example of a policy intervention designed to tackle a market outcome that was not politically desired (or market failure, if one follows Pigou's definition of the same, which includes aspects of distribution). A gravity analysis of monodirectional trade flows of sugar from all sugar producing countries to the EU showed that countries that had been enjoying preferential access to the protected European sugar market had been negatively affected by the reduction of the intervention price for sugar between the years 2006 and 2009.

Behind the European sugar regime stands the political will to support producers in the EU and in economically less developed third countries. The initial policy targeted the redistribution of rents from EU consumers to producers for several reasons, including self-sufficiency (i. e. independence from imports from noncommunity countries) and the support of rural livelihoods. As laid out above, a policy intervention is justified if it enables the achievement of overall economic or 
sectoral policy targets (Koester, 2011). These measures of redistribution were then also applied to formerly colonised countries, and subsequently also to the poorest countries in the world as a response to the non-desired market outcome of a development gap between the Global North and South.7 These policies were implemented via the Common Market Order (CMO) for sugar, followed by the Sugar Protocol (SP), which is an annex to preferential trade agreements with the African, Caribbean, and Pacific (ACP) countries, a conglomeration of formerly European colonised countries, and eventually the Everything But Arms (EBA) agreement with the Least Developed Countries (LDC) on earth.

The CMO for sugar consisted of an intervention price and a quota. So the bill for the producer support was paid by European consumers, and partly by the European taxpayer who had the burden to pay export subsidies because the sugar produced under the quota, together with the imports from ACP countries and LDCs were a multiple of what the domestic demand would absorb. The expected huge amount of exports - caused partly by the introduction of unlimited access for the LDCs - was the reason why the intervention price had to be strongly reduced over the years from 2006 until 2009.

This reduction affected not only the European farmers, but also the ones that were profiting from the high intervention price, too, namely the sugar producers located in ACP countries. Since their preferential access lost part of its value, this process is termed 'Preference Erosion'. The work presented in chapter four quantifies this erosion of preferences, as well as the impact of the changed CMO on the other affected, non-European stakeholders. These are the LDCs, as well as countries that are members of both the LDC and ACP groups. The results show that Preference Erosion did occur. The ACP countries were indeed negatively affected by the expected consequences of the introduction of the EBA.

\section{Methods and data of paper three}

The quantitative analysis is based on the empirically successful gravity model, whose microeconomic foundation has been developed by Bergstrand (1985). The estimation is carried out with the scale-independent Negative Binomial Quasi Generalised Pseudo Maximum Likelihood estimator in order to account for excess zeros in the underlying data. These data include the monodirectional trade flows in terms of values from all sugar producing countries to the EU, as well as other variables required by the gravity specification, such as bilateral distance and mutual resistance terms. Instead of capturing the policy via a dummy variable, the

\footnotetext{
2013

${ }^{7}$ The terms 'Global North' and 'Global South' are used in this work as defined in Bendix et al.
} 
'preference margin' is employed in order to solve the problem of identification. It measures the use that a country is making of its tariff-free quota. The data that this analysis is based on stem from various sources. The allocated quotas and trade quantities/values were provided by the European commission, the data indicating political systems and distance between countries were generated by research institutes and information on total production quantities and exchange rates were extracted from databases of international agencies. 

Chapter 2

Traders and Credit Constrained Farmers: Market Power along Indonesian Rubber Value Chains 


\title{
Traders and Credit Constrained Farmers: Market Power along Indonesian Rubber Value Chains
}

\author{
Thomas Kopp ${ }^{1}$ and Bernhard Brümmer ${ }^{1}$ \\ ${ }^{1}$ Georg August University, Göttingen, Germany
}

\begin{abstract}
While traders of agricultural products are known to often exercise market power, this power has rarely been quantified for developing countries. In order to derive a measure, we estimate the traders' revenue functions and calculate the Marginal Value Products directly from them. We subsequently find determinants affecting their individual market power. An exceptional data set with detailed information on the business practices of rubber traders in Jambi, Indonesia is employed. Results show that market power at the traders' level exists and is substantial. This market power is amplified in situations of extreme remoteness, and weakens with increasing market size.
\end{abstract}

\section{$2.1 \quad$ Introduction}

It is widely recognized that traders and middlemen of agricultural raw products are able to exercise a certain amount of market power, contradicting standard economic theory of perfect arbitrage and zero profits (Aker, 2010; Subramanian and Qaim, 2011; Piyapromdee et al., 2014). Osborne (2005) argues that the body of literature on intermediaries of agricultural markets is extensive when looking at the markets of industrialised economies. Southern markets, however, have rarely been studied in this respect although it is to be expected that monopsonistic pricing might be much more pronounced there: 'traders in a typical source market engage in imperfectly competitive behaviour in purchasing from farmers' Osborne, 2005, p. 1).

Some newer studies address this gap in the literature and pay attention to the role of traders. Most of these studies aim to find reasons behind the bad integration of agricultural markets in economically less developed countries, while only a few 
base their analysis on information stemming from traders. Fafchamps and GabreMadhin (2006) use data from a trader survey to quantify transaction costs, focusing on the cost of information. Fafchamps and Hill (2008) record prices paid at several stages of the value chain (including the farm gate) to collect evidence of market power, leading to imperfect price transmission. The abovementioned study by Aker (2010) analyses the effects of increased mobile telecommunication on the dispersion of prices. Even fewer studies estimate traders' production functions. Fafchamps and Minten (2002) estimate production functions to quantify the effect of social capital on the traders' levels of productivity.

No study was found to use traders' production functions for finding evidence of market power. This might be due to several reasons: firstly, it is difficult to measure the prices of the various outputs (i. e. services) offered by these individuals, such as changing the location of a good, or of providing credit. Besides that, in many cases the data on firms' individual output prices is not available at the level of detail required (Mairesse and Jaumandreu, 2005).

Our study investigates traders' market power by comparing the marginal value products (MVPs) of the agricultural raw input to their observed market price. A unique set of original survey data on Indonesian rubber traders - including detailed output prices on an individual level - enables us to estimate the traders' revenue functions and calculate the MVPs directly from them. The comparison to the observed market price is operationalised by calculating Lerner Indices (the normalised difference between market and observed prices) which are shown to be significantly different from zero. The traders exercise monopsonistic market power. In a subsequent step, we search for determinants that influence this market power. Our results suggest that market imperfections such as high transaction costs (typical for remote areas) increase the imbalance. Factors that reduce the traders' ability to exercise power are the size of the market, such as the agricultural area dedicated to cash crop production, and the number of traders operating in the area.

This paper is structured as follows: the data used in this study is introduced in section two. Section three provides background information on the Jambinese rubber market and the business practices of the subjects of this analysis - the traders and middlemen. The empirical methods are discussed in section four. Section five presents the results, before conclusions are drawn in section six. 


\subsection{Data}

The data that this study is based on were generated during a survey taking place from September to December 2012 in five districts of the Jambi Province on Sumatra, Indonesia in a joint project between the universities of Göttingen, Jambi, and Bogor 11 These five districts are the primary production areas of rubber in Jambi. In these five districts, 40 villages were selected randomly, stratified on a sub-district level (Faust et al., 2013). The total population of rubber traders in these 40 villages could be determined by a snowball-like search in the survey phase and totals to 313 individuals. Out of these, 221 were interviewed, which is equivalent to a response rate of $71 \%$. All prices, values, and quantities refer to September 2012. Since the figures mainly stem from accounting documents of the respondents, a high level of accuracy can be assumed (if no accounting was available, we relied on recall data). The traders were asked about details of the three most important suppliers and buyers whom they source from and deliver to, respectively. It is safe to assume that this covers all their buyers because $99 \%$ of the respondents sell to only one or two.

\subsection{Background: rubber in Jambi}

Why did we select rubber and the Jambi province? The fact that raw rubber has a high value per volume compared to other raw products and is not perishable makes it an extensively traded good that can be moved along complex value chains. Jambi is representative of a rubber producing province in Indonesia, the second largest producer in the world (see figure 2.1) ${ }^{2}$ Rubber is also important for the Jambi province in particular and is seen by policy makers as one key for reducing unemployment and poverty (Feintrenie et al., 2010). This all makes it an interesting case study for the application of the proposed method of estimating revenue functions in order to find evidence for market power.

Today, rubber is the main commodity produced by smallholders in Jambi. Jambi is a key producer of palm oil too, but a lot of this production takes place in the form of large scale plantation agriculture while rubber is predominantly produced by smallholders. Martini et al. (2010) argue that a mixed portfolio of rubber and palm oil would be the best strategy for smallholders to insure against price volatilities on both markets and provide an income which can keep up with wages

\footnotetext{
${ }^{1}$ Collaborative Research Centre 990: http://www.uni-goettingen.de/en/310995.html. We thank Jenny Aker (Tufts University), Todd Benson (IFPRI, Kampala), and Ruth Vargas Hill (IFPRI, Washington) who were so kind to provide the blank questionnaires they used for their respective trader surveys.

${ }^{2}$ Figure based on data from FaoStat (accessed on 08.10.2014).
} 
Figure 2.1: Global rubber production in 2012.

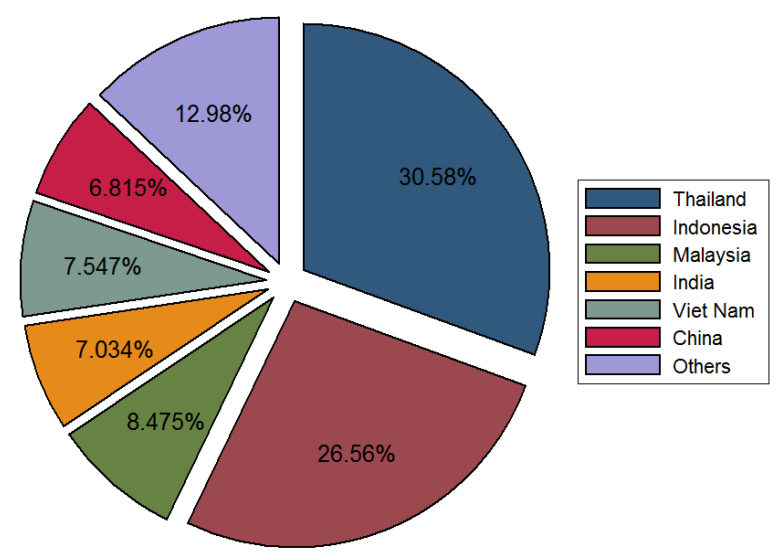

earned from providing labour in the cities. It can be observed, however, that the Jambinese population generally seems to prefer rubber. With 250000 rubber producing households, $31 \%$ of all Jambinese livelihoods rely on rubber (Statistics of Jambi Province, 2013). Policy makers also agree that rubber cultivation plays a key role for Jambi's future economic and social development. In contrast to palm oil, its primary production mode is smallholder agriculture because of the labour intensity. Rubber production's compatibility with food production increases food security as rubber can be intercropped with food crops such as rice, vegetables, and fruit (Feintrenie et al. 2010). This is especially true in the current time of land pressure. However, at present this is rarely exercised (Euler et al., 2012). Even larger scale rubber plantations have weaker negative environmental externalities than palm oil monocultures, for example on biodiversity (Fitzherbert et al., 2008) and the probability of flooding (Adnan and Atkinson, 2011).

In Jambi, the stakeholders in rubber trade (middlemen and agents of other traders) are heterogeneous along several dimensions and form complex networks (see Figure 2.2. Traders can either be independent entrepreneurs or agents working for a larger trader. The latter are referred to as Anak Ular ('children of the snake') which indicates their low popularity and perceived powerful position. The traders in our sample differ considerably in business size (trading between $300 \mathrm{~kg}$ and 200 tons per week, and buying regularly from 3 to 800 providers) and other characteristics, such as ethnicity, age, etc.

The buying procedure works as follows: the trader either lives in the village, or comes to the village at a fixed point in time (e. g. one day per week) to buy rubber. In either case, the rubber provided by the farmers comes in the form of a slab of coagulated rubber of 50-100 kg. The rubber is then typically weighed by the trader's employees before the trader assesses its quality by calculating the Dry 
Figure 2.2: Trade flows of rubber in the Jambi Province.

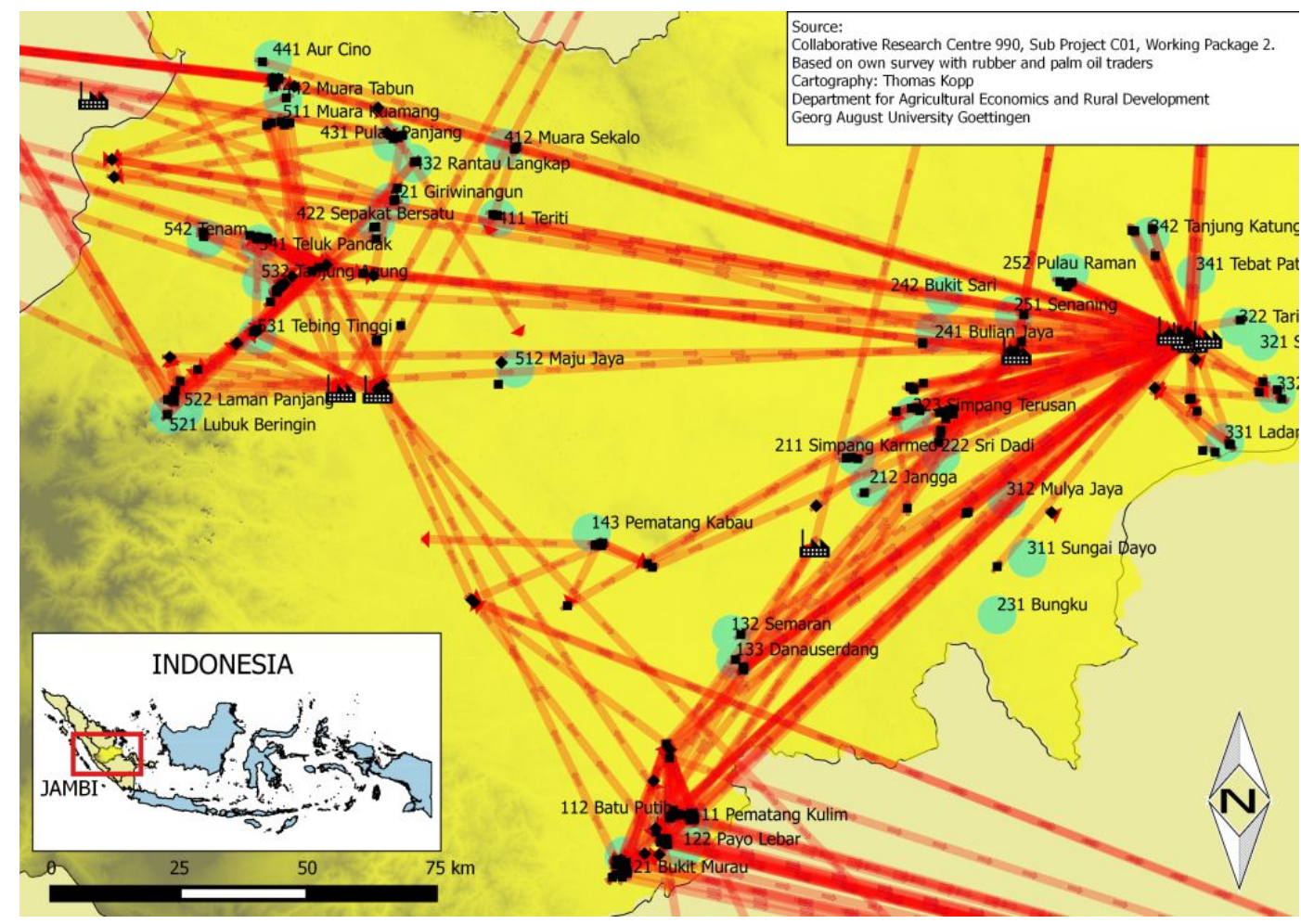

Source: Own production, based on original survey data. Borders of Jambi and Sumatra from Center for International Forestry Research, surface of Jambi from NASA/EOSDIS.

Rubber Content (DRC). The ideal DRC would be 100\%, but is most commonly graded down for several reasons. First is the basi content which refers to the contamination with water. Most farmers increase their rubber slabs' weight by storing them in water pools to make the slabs soak up water like a sponge. The second contamination is in the form of tatal ('rubbish') from the harvesting process, such as leaves, bark or dirt from coagulation boxes. Finally, the chemical that has been used for coagulation also affects the quality. While the highest quality is achieved with acetic acid, many farmers use cheap alternatives such as battery acid, triple super phosphate fertilizer, vinegar, or even floor cleaner Akiefnawati et al. 2010). It has to be noted that the terms basi and tatal are used interchangeably and some people may never have heard of one of them. However, all three kinds of quality determinants are known, and most commonly referred to in the way explained above. In this work, we use the term DRC to refer to all quality aspects combined. Traditionally the farmers produced sheets of unsmoked rubber, but had to switch to the production of thick slabs due to policy changes in the early 1970s, after which only the export of Technically Specified Rubber was allowed 
and lower grades were prohibited (Pitt, 1980). The disadvantage from the farmers' perspective is that the quality of unsmoked rubber sheets is less variable than the quality of slabs, which are therefore more prone to manipulation.

The downstream trading network (i. e. for selling the rubber) is very dense and complicated as one can observe in Figure 2.2 (above). When moving along the value chain from the village trader, the product passes on average 3.1 other traders before reaching the factory (dispersion: see Figure 2.3). While the prices that the middlemen receive for the product traded depend on their position in the chain, the prices that they pay do not (see Table 2.1). The fact that the prices received from selling rubber downstream are not transmitted to the providers shows that some traders are not operating at their marginal costs. This is already a first indicator of the traders acting as price setters.

Figure 2.3: Position of respondents in the value chain, starting from the factory.

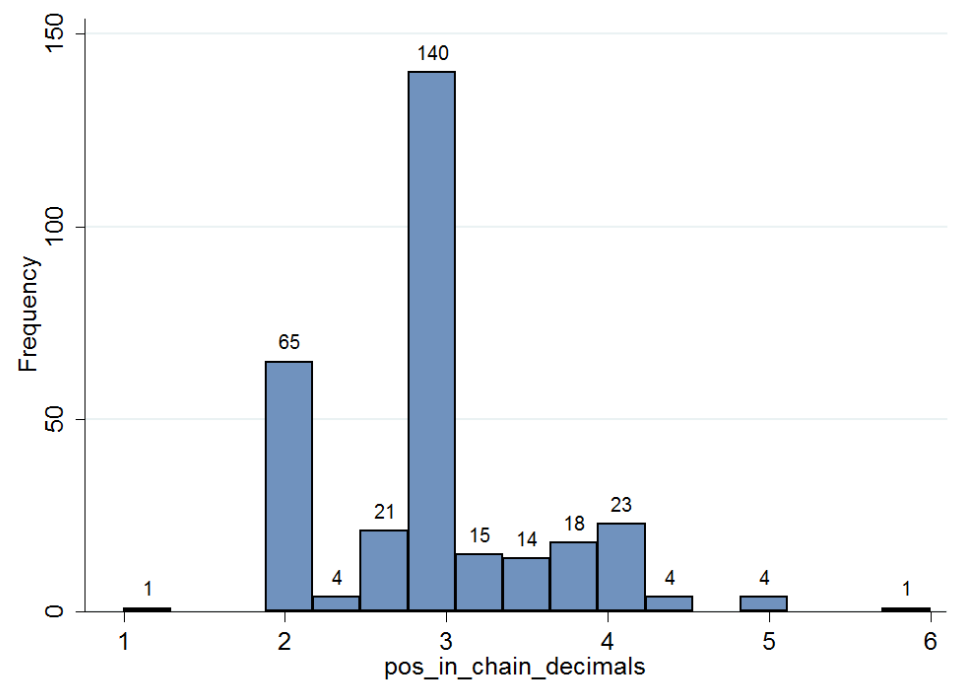

Source: Own production, based on original survey data. Number three indicates, for example, that the produce passes two other traders before reaching the factory. Decimal values are possible, because averages were taken for traders who sell along more than one downstream channel, if these differ in length.

Table 2.1: Spearman's rank correlation coefficients between buying and selling prices, and the traders' positions in the value chains.

\begin{tabular}{lcc} 
Variable A & Variable B & $\begin{array}{c}\text { p-value (H0: Variable A and } \\
\text { Variable B are independent) }\end{array}$ \\
\hline & & \\
selling_price & pos_in_chain & 0.0871 \\
buying_price & pos_in_chain & 0.3748
\end{tabular}


The market for processing rubber in Jambi is very concentrated. Nine crumb rubber factories are active in the province, of which five are located in the capital, Jambi City. $76.1 \%$ of all rubber that is produced in the province ends up in one of these, with the remaining share being sold to factories in neighboring provinces (calculations based on survey data). The factories process the slabs from the smallholders by cutting, washing and pressing it to Standard Indonesian Rubber 20 (SIR20) which is equivalent to the international standard Technically Specified Rubber. These factories sell the rubber on the international market, mainly to tyre producers in Japan, China, the U.S., and Europe. One exception is a local manufacturer of tyres, located in the Northern Sumatra Province (PT Bridgestone) which buys a share of their raw rubber supply directly from Jambinese traders.

While these factories are price takers on the international market, they do exercise market power towards their suppliers. Kopp et al. (2014) find that the prices received by traders and farmers in Jambi from the eventual buyers - the factories are transmitted from the international prices asymmetrically: in times of price hikes (i. e. when the factories' margins increase), the price changes are transmitted to the local market much slower than in times of price declines. The welfare effect stemming from the asymmetric price transmission alone was quantified at around three million U.S. dollars. It can be assumed that the total welfare loss is much larger, since the oligopsonistic behaviour is also likely to affect the absolute level of the prices.

The traders, on the other hand, are not only subject to market power exercised by their downstream buyers: they are also able to exercise market power themselves. There are a number of examples in the literature where indicators for market power could be found at the traders' level (McMillan et al., 2002, Pokhrel and Thapa, 2007). In the case of Jambi, up until now the evidence for these sorts of market imperfections is mostly anecdotal. Studies that focused on the middlemen in the Jambinese rubber market are Martini et al. (2010), and Arifin (2005).

One of the traders' strategies to implement and secure their superior bargaining position is by granting credits to smallholders. Subramanian and Qaim (2011) find that markets of agricultural output are interlocked with markets for other goods. This interlock explains why non-competitive (and therefore non-pareto efficient) market organizations can persist in an otherwise competitive market. These interlocks have the potential to offset imperfections on another markets. Applied to this case, the initial imperfection is the constrained access of smallholders to credit. The most prominent reasons for smallholders' limited access to formal credit in many developing countries are limited possibilities of contract enforcement and a lack of collateral due to non-formal property rights (Barnett et al., 2008). Rubber traders 
are traditionally providers of informal credit. Observations of our survey showed that no collateral is needed because the credit agreement is based on trust, stemming from ongoing personal interaction and close ties within the village community. This confirmed the observations made by Akiefnawati et al. (2010). However, this credit also increases the traders' bargaining power tremendously, since it is expected that an indebted farmer sells his or her produce exclusively to the provider of his or her credit. This strategy has also been reported in the cases of Benin and Malawi: the credit's '[...] main purpose is not to exploit farmers' need for cash in order to finance agricultural production, but rather a means for traders to secure future deliveries' (Fafchamps and Gabre-Madhin, 2006, p. 36). This behaviour could also be documented for the case of Jambi: $94.1 \%$ of the rubber traders who provide credit answered 'yes' to the question 'Does a farmer have to sell his/her rubber/palm oil to you if he/she wants to take a credit from you?'. $72.9 \%$ replied with 'no' when they were asked: 'If a farmer/other trader owes you money, can she sell her produce to another trader?' (All figures for this and the following paragraph are based on original survey data; for more information on the data see above).

The credit not only attaches the farmers to the traders, but these traders also manipulate the DRC level of the delivered rubber if the farmer is indebted. This would be an implicit interest since, for cultural reasons, the traders do not officially charge any interest on the credit. In interviews, $11.8 \%$ of the responding traders stated that they manipulate the basi estimation for suppliers who are indebted. This seems to be a small share, but given that this practice is understood as immoral, it can be expected that the figure given here is underestimating the true share because respondents might not 'admit' in interviews that they follow this practice. However, it is reasonable to understand this hidden interest as the traders' own capital costs which they pass on to the farmers.

It is the target of this analysis to empirically verify whether Jambinese rubber traders do indeed exercise market power towards their suppliers and - if so - what determines the extent of it. The key question is whether factor prices of the rubber input equal their marginal value products.

\subsection{Methodology}

The intuition of our empirical approach to test for market power at the traders' level is to estimate the revenue functions of the traders. We use these estimated functions to directly calculate the marginal value product (MVP) of raw rubber which would- in the situation of perfect competition - be equal to the observed 
market prices that the traders pay for this input. If the latter ones were smaller, this would be an indication of market imperfection. In a second stage, we find determinants for deviations from the MVP by calculating Lerner Indices for each trader, and regressing them on characteristics of the transactions (characteristics of the geographic location, of the traders, and of the trader-provider relationships).

\section{Model development}

Berndt (1996) argues that in situations of exogenous input quantities and endogenous input prices, the production (or revenue) functions need to be employed $3^{3}$ The advantage over estimating a cost function is that input prices do not enter the model which we wish to avoid, since these are the observed prices that are to be compared to the MVPs deducted from the estimated revenue functions. 'Production' is, in this case, understood as improving the value of the raw rubber that the traders buy, for example by changing its location, i. e. providing the service of transportation. Since the selling prices of rubber which the traders are confronted with vary substantially between the traders - depending on whom they sell to the standard approach of generating the output quantity by dividing the revenue by an industry-average of the prices would not account for these price differences and therefore lead to a serious bias (Mairesse and Jaumandreu, 2005). Instead we weight the output by the selling prices, resulting in the estimation of a revenue function. Mairesse and Jaumandreu (2005) find that it does not systematically change the estimated results if the LHS of a production function is deflated by the output prices or not (apart from the desired effect from the weighting).

A potential problem in the estimation of traders' production functions is one of endogeneity: traders who are generally more efficient might handle larger volumes, which would cause a correlation between the error term and this input quantity. However, in Jambi it is not the trader's choice how much rubber he or she trades, since they usually buy everything they can get. According to Zellner et al. (1966), the problem does not apply if the choice of how much input is used is not made by the trader. The same is true for the credit: the amount of the credit that the traders provide is determined by their providers' needs rather than their own choice. The credit is, as in other settings, too (e. g. Benin and Malawi, see Fafchamps and Gabre-Madhin, 2006), used as an instrument to attach providers to them. Thus the output/revenue per input is not correlated to the total quantity moved by the

\footnotetext{
${ }^{3}$ The reason why we do not estimate a value added function is that knowing which factors affect the value-added would not facilitate any conclusions on market power. It would be interesting to assess how the value added is distributed amongst all stakeholders of the value chain, but this is not feasible within the scope of this study since it would require detailed data on the cost structures of all stakeholders.
} 
trader.

\section{Application}

We base the specification of our model on the following transcendental revenue function in logarithmic form (Boisvert, 1982), 4

$$
\ln Y=\ln \alpha_{0}+\sum_{i=1}^{N}\left(\alpha_{i} \ln x_{i}\right)+\frac{1}{2} \sum_{i=1}^{N} \sum_{j=1}^{N}\left(\alpha_{i j} \ln x_{i} \ln x_{j}\right)+\varepsilon
$$

$Y$ on the LHS represents the value of the output while the $x_{i}$ on the RHS refer to the quantities of the inputs. $N$ denotes the total number of inputs and $\varepsilon$ the error term. For the reasons laid out above, the output enters in the form of gross revenue. The raw rubber that the traders buy is included as an intermediary input. Other variables that are included in the RHS are the bilateral distance between the trader and his or her buyer as a proxy for trade costs, the weekly hours that the traders work themselves, and their total transport capacity as a proxy for capital. Concerning the costs of hired labour, it cannot be deduced from theory if they are to be modelled in terms of working hours or total costs: the price of labour might account for unobserved quality differences which would argue for using the total costs. However, price differences might also be due to regional differences which would be a reason for using the amount of working hours. The latter two variables cannot enter the regression together due to double counting. We therefore estimate three models: one without hired labour (1), one with the total labour costs (2), and one with total hours worked (3). An F-Test is then employed to compare (2) and (3) with (1). If the reduced model is shown to represent the data best, its results are used further on. If the models that include the hired labour are better than the one without it, the Vuong's Closeness Test for non-nested models (Vuong, 1989) will be employed to determine whether to use (2) or (3).

The traders produce - from their suppliers' point of view - two services: changing the location of the product and providing credit. However, since from the traders' perspective their sole motivation of providing credit is to expand their market base and to attach providers to them, this is to be understood as a (quasi-fixed) input. Thus, the credit enters the regression on the RHS, together with the other inputs. The DRC does not enter the revenue function, since the input amount is equal to the output amount. This means that on the LHS the quantity is already deflated by the

\footnotetext{
${ }^{4}$ We also estimated a Cobb Douglas function. An F-test showed that it does not represent the data as good as the translog specification. Results are available on demand.
} 
output quality which is equal to the (weighted) average input quality. Accordingly, there is no need to control for this in the revenue function.

Before taking the logarithms of all variables, they are mean-scaled which enables the interpretation of the results as elasticities. One common challenge in the estimation of revenue functions is the occurrence of zeros in the input variables which results in missing values when the log is taken. This is the case - for example - if a very small trader does not make use of hired labour. These missing zeros are handled following Battese (1997): the observations with $\ln 0$ are replaced by 0 . An additional dummy variable, which represents the zero-inputs, is set to one in these cases, and to zero otherwise.

The variable indicating the credit that the respective trader provides is zero inflated and left censored (about $50 \%$ of the respondents did not give any credit in September 2012). So instead of normalising and taking the logs of this variable, the inverse sine hyperbolic transformation was employed, as suggested by Burbidge et al. (1988). Since the size of the credit given by traders is not exclusively determined by their choice, but also based on their providers' needs, it is also plausible to represent the credit as a dummy variable (one if credit was given). This specification was tested against the alternative of treating the credit given just like the other inputs via an LR test which gave a prob $>c h i^{2}$ of 0.0771 . It was therefore decided to employ the unrestricted model $5^{5}$

\section{Requirements and properties of the revenue function}

We test whether the estimated revenue function satisfies the required properties at each data point. These are the homogeneity condition (Boisvert, 1982), as well as the curvature properties for satisfying the conditions of positive and diminishing marginal products for every single observation (Morey, 1986). The condition of positive marginal products is checked by taking the partial derivatives with respect to each of the inputs. If they are $>0$ at every data point, the first condition is fulfilled. The decreasing marginal products are clarified by taking the second-order partial derivatives with respect to each of the inputs which is the diagonal of the bordered Hessian matrix (Morey, 1986). These need to be $<0$ at every observation in order to satisfy the condition. As it will turn out, the application of a standard OLS estimator produces estimates which violate the constraints 760 times. We thus impose the inequality constraints mentioned above, following the approach suggested by Henningsen and Henning (2009) using the R-packages micEcon and frontier ${ }^{6}$ For the first step, we estimate the unrestricted translog revenue function

\footnotetext{
${ }^{5}$ The results of the alternative model can be made available upon request.

${ }^{6} \mathrm{~A}$ list of the imposed constraints can be found in Appendix (1)
} 
before imposing the monotonicity constraint by minimum distance in the second step. In the third step, the non-restricted parameters are estimated conditionally on the restricted parameters. Imposing the constraints on every single point in the data is not desirable, because this would eradicate the flexibility of the transcendental logarithmic (translog) revenue function, and one would be left with a Cobb Douglas function. In order to keep the advantage of the translog specification, we impose the constraints for only one arbitrarily chosen point, as suggested by Ryan and Wales (2000) and applied by Chua et al. (2005). We select the sample mean to be this point. Imposing the monotonicity condition already significantly reduces the number of data points that violate the revenue function's curvature properties to twelve cases (quasi-concavity achieved in $94.3 \%$ of all observations).

\section{Calculation of Marginal Value Products}

In order to calculate the MVPs, Equation (2.1) is differentiated with respect to $\ln \left(x_{R}\right) \cdot 7$

$$
\frac{\partial \ln Y}{\partial \ln x_{R}}=\alpha_{R}+\alpha_{R R} \ln x_{R}+\left(\sum_{j=1}^{M}\left(\alpha_{R j} \ln x_{j}\right)\right)
$$

Substituting the assumption of perfect competition $\frac{\partial Y}{\partial x_{R}}=p_{R}^{c}$ and the equality 8 $\frac{\partial Y}{\partial x_{R}}=\frac{\partial \ln Y}{\partial \ln x_{R}} \frac{Y}{x_{R}}$ into 2.2 yields

$$
p_{R}^{c}=\left(\alpha_{R}+\alpha_{R R} \ln x_{R}+\left(\sum_{j=1}^{M}\left(\alpha_{R j} \ln x_{j}\right)\right)\right) \frac{Y}{x_{R}}
$$

with $p_{R}^{c}$ representing the price under perfect competition. In the subsequent step, the Lerner Index is calculated for each trader. The original formula normalises the positive difference between marginal costs and observed prices (i.e. prices minus marginal costs, since the former ones tend to be larger) by the observed prices (Lerner, 1934). Since we are comparing the marginal revenues and factor prices, we calculate the index as $L I=\frac{p_{R}^{c}-p^{*}}{p^{*}}$ with $p^{*}$ standing for the observed price.

\section{Determinants}

In the second stage regression, the calculated Lerner Indices from stage one are regressed on several characteristics of the traders' environment in order to find determinants of the market prices' deviations from the competitive prices. These

\footnotetext{
${ }^{7}$ note: $M=N \backslash R$

${ }^{8}$ Steps: with (a) $\partial \ln y / \partial y=1 / y$ and (b) $\partial \ln x / \partial x=1 / x$, the equality is given by (a) / (b).
} 
characteristics are differentiated between proximate causes (variable, such as market and trader characteristics), and ultimate causes (stable over time, such as characteristics of the geographic location). The former ones include the trader density in the survey village, the traders' 'size' (their wealth and trading quantity), their respective positions in the value chain, their access to information, their access to capital (credits), and their status (agent or independent trader). Unobserved trader heterogeneity is controlled for by adding a dummy for each trader. Ultimate causes include the general remoteness, size of village population, the quantity of rubber production, availability of lending institutions or an auction market, as well as the participation in the governmental 'transmigration' program. The heterogeneity of the providers, from whom the traders under consideration source the rubber, is controlled for with the following variables: the provider's status as farmer/other trader, the typical size and quality of delivery, their ethnicity, and the credit that has been taken. We test for heteroscedasticity with the Breusch-Pagan Test, which is confirmed. We thus use robust standard errors.

Since output quality is equal to the (weighted) average input quality, the hypothetical input price is for rubber of average quality. However, there is heterogeneity between farmers whom the traders buy from. As mentioned above, traders are accused of manipulating the estimation of the DRC for indebted suppliers. This accusation could be verified by a regression of the estimated DRC on the size of credits which were given out to farmers (Table 2.2). In case of zero-credits, log_credits takes the value 0 and the dummy of credits given is also set to 0 , following Battese (1997). As can be seen, the credit that is given does indeed influence the DRC. The low $R^{2}$ can be explained by the fact that the main determinant of the DRC estimation is still the quality. However, the variables representing the credits are significant. To account for this in the estimation of the possible determinants of market power, we generated the credit adjusted quality as the residuals from regression (4) in Table 2.2. The variables that enter the estimation of the revenue function are listed in Table 2.3 ,

In order to identify drivers of market power in the Jambinese rubber markets, each trader was asked for detailed information on three arbitrarily selected providers. These, together with characteristics of the trader him/herself, as well as characteristics of the market that they are operating within are used in the second stage regression (Table 2.4). The value of the respondent's house is an indicator of his/her wealth. The variable 'Informal_credit' refers to a money-lender or a rubber-trading warehouse that provides credit to suppliers. 'General_remoteness' represents the average distance between the respondent's location and the crumb rubber factories that can be accessed by the Jambinese traders. The number of households of each 
Table 2.2: Regression of estimated dry rubber contents on credits given.
(1)
(2)
(3)
(4)

VARIABLES

Credit Size Dummy

Dummy

Village

and Credit Dummies

\begin{tabular}{lcccc} 
& & & Size & Added \\
\hline \multirow{3}{*}{ log_credits } & & & & \\
& $0.0711^{*}$ & & -0.170 & $0.168^{* *}$ \\
dummy_credit_given & $(0.0407)$ & & $(0.153)$ & $(0.0757)$ \\
& & $1.211^{* *}$ & 3.516 & $-2.588^{* *}$ \\
Constant & & $(0.572)$ & $(2.154)$ & $(1.050)$ \\
& $5.388^{* * *}$ & $5.307^{* * *}$ & $5.307^{* * *}$ & $10.000^{* * *}$ \\
& $(0.324)$ & $(0.327)$ & $(0.327)$ & $(1.829)$
\end{tabular}

Observations

$\begin{array}{cc}666 & 666 \\ 0.005 & 0.007\end{array}$

$\begin{array}{cc}666 & 666 \\ 0.009 & 0.803\end{array}$

R-squared

Standard errors in parentheses

Coefficients of village dummies in (4) are not reported

*** $\mathrm{p}<0.01,{ }^{* *} \mathrm{p}<0.05,{ }^{*} \mathrm{p}<0.1$

Table 2.3: Variables entering the production function.

\begin{tabular}{clll} 
Variable & Label & Mean & Std. Dev. \\
\hline & & & \\
$Y_{R}$ & Value of rubber sold (IDR) & $1.29 \mathrm{E}+08$ & $2.74 \mathrm{E}+08$ \\
x1 & Quantity of rubber traded (kg) & 10324.5 & 19175.12 \\
x2 & Respondent's weekly working hours & 17.70894 & 19.08984 \\
x3 & Transport capacity (kg) & 2292.569 & 4293.935 \\
x4 & Distance to buyer (km) & 62.34715 & 97.34556 \\
x5 & Monthly costs of hired labour (IDR) & 1824851 & 3812094 \\
x6 & Weekly working hours of hired labour & 22.01606 & 43.53851 \\
x7 & Credit given to all providers (IDR) & $1.88 \mathrm{E}+08$ & $1.35 \mathrm{E}+09$
\end{tabular}

village, as well as the agricultural area that is not dedicated to rice production were drawn from the PODES2008 dataset.

\subsection{Results and discussion}

\section{First stage regression}

The results of the first stage regression are presented in Table $2.5^{9}$ It has to be kept in mind that this estimation was done at the trader level, i. e. each observation

\footnotetext{
${ }^{9} x_{-} R=$ rubber input, $x_{-} 1=$ respondent's working hours, $x_{-} 2$ =transport capacity, $x \_3=$ distance to buyer, $x_{\_} 4=$ hired labor, costs, $x_{-} 5=$ hired labor, hours, $x_{-} 6=$ all credit given.
} 
Table 2.4: Possible determinants of market power.

Variable

Lerner_Index

number_traders_karet

log_house_cost

providing_farms

providing_traders

pos_in_chain_traders

transmigrasi_village

general_remoteness

dist_to_closestfactory

households_in_village

no_podes2008_data

agric_area_non_rice

formal_credit_available

informal_credit_available

credit_mio

quality_credit_adjusted

little_information

discuss_prices

price_agreements

ethnic_resp_java
Label

Lerner Index

Number of rubber traders in village

Value of respondent's house

Number of farms that respondent buys from

Number of other traders that respondent buys from

Respondent's position in the value chain

Dummy for 'Transmigrasi' village

General remoteness of respondent

Distance to closest rubber factory

Number of households in village

no info on village characteristics

Agricultural area, non-rice

Availability of formal credit institutions

Availability of informal credit institutions

Debt of provider with respondent (in mio. Rupiah)

Credit-adjusted quality of delivered rubber

Respondent's access to information is restricted

Respondent discusses prices with other stakeholders

Respondent agrees on prices with other stakeholders

Respondent's ethnicity is Javanese
Mean Std. Dev.

$0.502913 \quad 0.338702$

$12.445 \quad 5.533$

$18.483 \quad 1.335$

$34.005 \quad 40.646$

$1.294 \quad 7.445$

$3.061 \quad 0.564$

$0.317 \quad 0.465$

$161.614 \quad 15.269$

$21.223 \quad 14.469$

$676.147 \quad 385.153$

$\begin{array}{ll}0.0367 & 0.188\end{array}$

$5626.314 \quad 5734.092$

$0.312 \quad 0.464$

$0.037 \quad 0.188$

$1.383 \quad 5.576$

$93.510 \quad 7.044$

$0.464 \quad 0.499$

$0.649 \quad 0.478$

$0.212 \quad 0.409$

$0.425 \quad 0.495$

is equivalent to one trader in the sample.

The DRC does not enter this estimation because the estimation is executed at the trader level. The quality of the output is equal to the average input of the input. The manipulation of the basi estimation is just one strategy of pushing down the input price towards the monopson price.

\section{Model choice}

The F-Tests indicate that the model which omits hired labour is superior to the models including hired labour in the form of working hours or total costs, respectively; both null hypotheses of the restricted model to represent the data better cannot be rejected (test results are $90.3 \%$ and $65.7 \%$, respectively). This observation is robust against changes in all model specifications which we have experimented with $\sqrt{10}$ We thus assume that model (1) of Table 2.5 represents the data best. Column (2) shows the results of the estimation based on the same choice of regressors as column (1), with the constraints on the curvature properties being imposed. Standard errors are not reported because their calculation would be biased since the regression is subject to constraints. For the second stage we use all

\footnotetext{
${ }^{10}$ Results for other specifications are available on demand.
} 
coefficients from column (2). The data used in the revenue function estimation have been cleaned for outliers ( 9 observations out of 218 were dropped). If the outliers are included, the estimated coefficients are not very different, but fewer are statistically significant. The F-Tests indicate that the model which omits hired labour is superior to the models including hired labour in the form of working hours or total costs, respectively; both null hypotheses of the restricted model to represent the data better cannot be rejected (test results are $90.3 \%$ and $65.7 \%$, respectively). This observation is robust against changes in all model specifications which we have experimented with 11 We thus assume that model (1) of Table 2.5 represents the data best. Column (2) shows the results of the estimation based on the same choice of regressors as column (1), with the constraints on the curvature properties being imposed. Standard errors are not reported because their calculation would be biased since the regression is subject to constraints. For the second stage we use all coefficients from column (2). The data used in the revenue function estimation have been cleaned for outliers (9 observations out of 218 were dropped). If the outliers are included, the estimated coefficients are not very different, but fewer are statistically significant.

It comes as a surprise that the production factor 'hired labour' does not play a role in the revenue generating process. The explanation for this lies with the fact that the hired labour input is relatively unimportant, compared with the other inputs, since many traders do not rely on paid labour at all.

\section{Calculation of price deviation}

Figure 2.4 shows the distribution of the calculated Lerner Indices. They indicate the percentage-deviation of the price that is paid from the MVP. If these values are equal, the Lerner Index takes the value 0. The average of the Lerner Indices is 0.29 (standard deviation: 0.27 ) which means that the average trader pays $29 \%$ below the MVP. The fact that the prices that most traders pay for their rubber input is far below this input's MVP is a clear indication for market power.

\section{Second stage regression}

Table 2.6 shows the results of the second stage regression that evaluates determinants of the level of market power exercised by the surveyed traders. The number of observations is larger than in Table 2.5 because, in this case, the regression was done on a further disaggregated level. This was accomplished by integrating up to three different providers who the traders source from as separate observations.

\footnotetext{
${ }^{11}$ Results for other specifications are available on demand.
} 
Table 2.5: Regression results of revenue function.

(1)

\begin{tabular}{|c|c|c|}
\hline $\begin{array}{l}\text { Elasticities } \\
\text { at sample mean }\end{array}$ & $\begin{array}{l}\text { Unconstrained } \\
\text { specification }\end{array}$ & $\begin{array}{l}\text { Constrained } \\
\text { specification }\end{array}$ \\
\hline$l n \_x 1 \_R u b b e r$ & $\begin{array}{c}1.0268^{* * *} \\
(0.0732)\end{array}$ & 1.0236 \\
\hline ln_x2_RespWork & $\begin{array}{c}0.0485^{* * *} \\
(0.0001)\end{array}$ & 0.0156 \\
\hline ln_x3_Transp Capacity & $\begin{array}{c}-0.0214 \\
(0.274)\end{array}$ & 0.0137 \\
\hline ln_x4_Distance & $\begin{array}{c}0.0105 \\
(0.4426)\end{array}$ & 0.0118 \\
\hline ln_xz_Credit & $\begin{array}{c}0.0019^{*} \\
0.0735\end{array}$ & 0.0003 \\
\hline Constant & $\begin{array}{c}-1.274^{* * *} \\
(0.0732)\end{array}$ & 0.0764 \\
\hline Observations & 209 & 209 \\
\hline R-squared & 0.987 & 0.986 \\
\hline
\end{tabular}

However, the number of observations is still smaller than in Table 2.2 as not all respondents bought rubber from each of the three providers under consideration in September 2012.

\section{Discussion}

The deviation from the hypothetical price under perfect competition is influenced by a number of factors. Generally, the results are robust to changes in model specification, differing mainly in the levels of significance and the magnitudes of the estimated coefficients. The rather large value of the $R^{2}$ value $(87 \%)$ shows that most of the variance of the dependent variable is explained. This is especially remarkable considering that one key determinant of the exact price is unobserved: the true quality of the delivered rubber is approximated by the credit-adjusted quality. As expected, with a greater market (more rubber traders, as well as a larger area of plantation agriculture) the Lerner Index decreases which is a sign of increasing competition. Surprisingly, villages that are bigger in terms of population are more prone to market power exercised by rubber traders. This does not contradict the previous result, since the agricultural (non-rice) area is a better predictor for market 
Figure 2.4: Lerner Indices of Jambinese rubber traders.

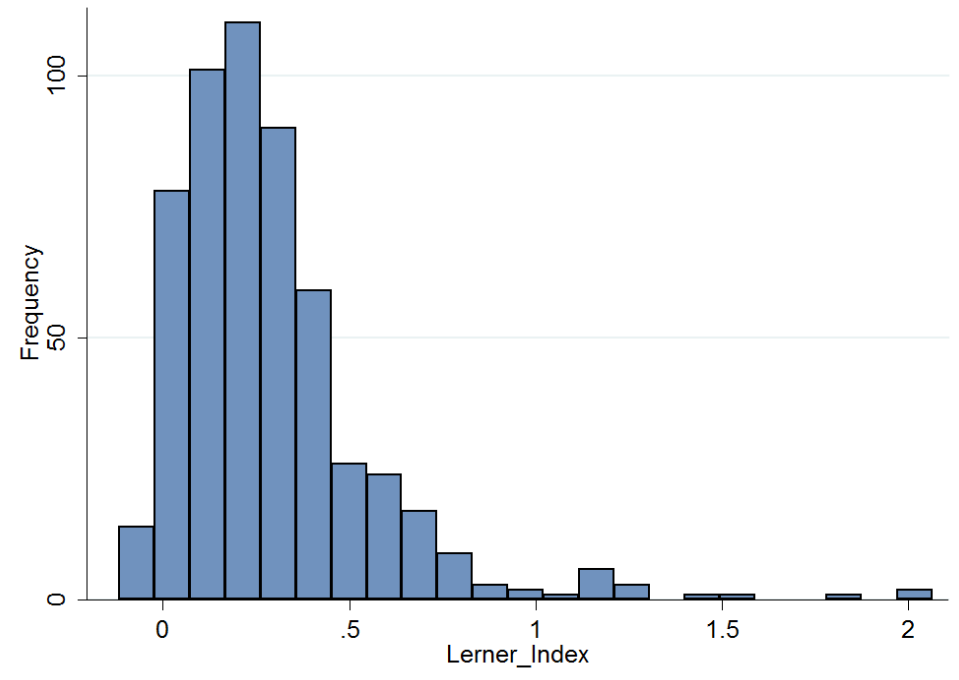

Source: Based on own calculations. 
Table 2.6: Determinants of market power that is exercised by traders.

Determinants

number_traders_karet

log_house_cost

providing_farms

providing_traders

pos_in_chain_decimals

transmigrasi_village

general_remoteness

dist_to_closest_auction_market

households_in_village

no_podes2008_data

agric_area_non_rice

formal_credit_available

informal_credit_available

credit_mio

quality_credit_adjusted

little_information

discusses_prices

price_agreements

ethnic_resp_java

Constant

Observations

R-squared

Standard errors in parentheses

Trader dummies not reported. Full results are available on demand.
Lerner_Index

$-0.0339 * * *$

$(0.0001)$

$-0.0086$

$(0.387)$

$-0.0013^{* *}$

$(0.0344)$

$0.0056^{* * *}$

$(0.0001)$

$0.1310 * * *$

$(0.0001)$

$-0.1190$

$(0.494)$

$0.0041^{* *}$

$(0.0313)$

$0.0048^{* * *}$

$(0.0001)$

$0.0004^{* * *}$

$(0.0001)$

$0.4060 * *$

$(0.0155)$

$-3.32 \mathrm{e}-06^{* *}$

(0.0466)

$-0.4400^{* * *}$

(0.0001)

$-0.0701$

(0.541)

$-0.0011^{*}$

(0.0639)

$-0.0062$

(0.144)

0.1570 ***

(0.0001)

0.1480 ***

(0.000110)

-0.2480 **

(0.0115)

$-0.0100$

(0.915)

$-0.0026$

(0.996)

466

0.869

\footnotetext{
$* * * \mathrm{p}<0.01,{ }^{*} * \mathrm{p}<0.05,{ }^{*} \mathrm{p}<0.1$
} 
size than population size. One explanation for the positive relationship between village size and market power could be that anonymity can be expected to be greater in larger settlements, which reduces the general level of mutual trust and fairness. Another factor that reduces the Lerner Index (i.e. increases competition) is the proximity to an auction market. Also, the more remote the location of a trader is, the more successful he or she is in exercising his or her market power. Traders who buy from many other traders (and relatively fewer farmers) can be considered to be in a relatively good bargaining position which is indicated by an increasing Lerner Index. According to the data, the availability of at least one formal credit institution reduces the market power of traders which supports the arguments laid out in the theoretical part. However, it seems that farmers who do get more credit from the traders are also the ones who receive better prices compared to the ones without credits. The reason behind this is that farmers taking relatively little credit receive a higher interest rate due to the fixed costs of providing credit. In the context of this study, these fixed costs consist of the time the trader invests to generate and continue personal ties with the debtor, as well as the time spent observing him or her. While traders' general access to information is negatively related to their ability to exercise market power, the ones who discuss the prices which they pay with other traders generate higher margins. This is another indicator pointing towards collusion.

\subsection{Conclusions}

The results of this study indicate that agricultural traders in Indonesia, more specifically the Jambinese rubber traders, possess monopsonistic market power. This could be shown via an innovative approach that was enabled by an exceptional set of data: we had access to detailed sales data on a single-transaction level. Such data are at a much more disaggregated level than in any other examples in the literature. These data enabled the estimation of a revenue function, which was used to directly calculate hypothetical rubber prices under the assumption of perfect competition. The hypothetical prices were compared to the observed prices that middlemen for rubber pay to their providers via calculating Lerner Indices. These proved to be significantly different from zero - a clear indication of market power.

In a second stage, the Lerner Indices were regressed on different characteristics of the market, of the traders and of the relationships between traders and their providers. If local markets are smaller (less agricultural output, fewer traders), the traders have more opportunities to exercise market power, as well as having a more remote location. Improving infrastructure could reduce the influence of 
'remoteness' on the functioning of the Jambinese rubber markets, as does the establishment of auction markets in a larger number. Since the availability of formal credit institutions is also negatively related to the exercise of market power, the support of farmers through micro credit might also help.

If our explanation of the influence of village size on market power is correct (and the verification of this certainly calls for further research), policy makers should focus on measures improving trust and comradeship between villagers. 


Chapter 3

Have Indonesian Rubber Processors Formed a Cartel?

Analysis of Intertemporal

Marketing Margin

Manipulation 


\title{
Have Indonesian Rubber Processors Formed a Cartel?
}

\section{Analysis of Intertemporal Marketing Margin \\ Manipulation}

\author{
Thomas Kopp ${ }^{1}$, Zulkifli Alamsyah ${ }^{2}$, Raja Sharah Fatricia ${ }^{2}$ and Bernhard \\ Brümmer ${ }^{1}$ \\ ${ }^{1}$ Georg August University, Göttingen, Germany ${ }^{2}$ Jambi University, Jambi, \\ Indonesia
}

\begin{abstract}
In Indonesia the agricultural sector plays a key role for inclusive economic development in rural areas. In the Jambi province, rubber is the most valuable export crop produced by small scale agriculture. The observed concentration in the crumb rubber processing industry raises concerns about the distribution of export earnings along the value chain. In this study we investigate the price transmission between international prices and the factories' purchasing prices. We make use of the non-parametric estimation technique of penalized splines in order to understand the error correction process without the need for restrictive a priori assumptions. We then estimate an Auto-Regressive Asymmetric Threshold Error Correction Model to find evidence for asymmetric price transmission, and to quantify the extent of the threshold effect. In a second step we calculate the rents that are redistributed. The analysis is based on daily price information over a period of four years (2009-2012). Our results suggest that factories transmit prices asymmetrically, which has substantial welfare implications: around three million U.S. Dollars are annually redistributed from Jambinese farmers to factories.
\end{abstract}

\subsection{Introduction}

For Indonesia the agricultural sector is of great importance. In 2011 it contributed $15 \%$ to the GDP and employed $36 \%$ of the workforce ${ }^{1}$ The most valuable export

${ }^{1}$ WorldBank World Development Indicators. Accessed March 2015, available at http: //databank.worldbank.org 
crop is natural rubber. With an annual output of three million metric tons, Indonesia is the second largest producer of natural rubber in the world, accounting for $27 \%$ of global production 2 More than 15 million people generate their main income from rubber cultivation (Fathoni, 2009).

In the future, it is likely that the importance of rubber for Indonesia will increase for two reasons. Firstly, the total demand for any kind of rubber will increase, due to economic growth in the emerging economies; and secondly the ever-rising price of crude oil will make synthetic rubber more expensive and thus increases the demand for its substitute natural rubber.

Rubber is predominately produced on the islands of Sumatra and West Kalimantan. They contribute $72 \%$ to the total production of the country (Arifin, 2005). The province of Jambi (Sumatra) is one example of a province that depends crucially on its agricultural sector. It also represents a typical rubber production area. $52 \%$ of the workforce is employed in the agricultural sector and 0.6 million ha (out of 1.4 million ha) are dedicated to rubber production, of which $99.6 \%$ are cultivated by smallholders (Regional Account and Statistical Analysis Division, 2012). Although Jambi is on average not an exceptionally poor province, the rural population is still disadvantaged compared to the populations in other parts of Indonesia. The average income is 17.5 million Indonesian Rupiah (1600 USD) ${ }^{3}$ per year Arifin, 2005, Regional Account and Statistical Analysis Division, 2012, which is far below the national average of 26.8 million Rupiah (2 450 USD) per year 4 Other development indicators show a similar picture, for example the life expectancy at birth is 71 years in Jambi, compared to 76 years in Jakarta (Regional Account and Statistical Analysis Division, 2012).

As rubber is predominantly cultivated by smallholders, rubber does have the potential to be one key to economic and social development in rural areas, improving the socio economic situation of millions. In total, 252000 Jambinese households (out of 619000) depend on rubber cultivation (Regional Account and Statistical Analysis Division, 2012). This means that roughly one million people in Jambi are affected.

It follows that malfunctions in this market can have a tremendous effect on the livelihoods of small scale farmers and their families if imperfections in the rubber market are disadvantageous for this group. It should therefore be a primary policy target to ensure that these markets function properly.

\footnotetext{
${ }^{2}$ FAO FAOSTAT. Accessed March 2015, available at http://faostat3.fao.org/home/E

${ }^{3}$ Exchange rate (December 2013) from Oanda Corporation.

${ }^{4}$ WorldBank: WorldBank World Development Indicators. Accessed March 2015, available at http://databank.worldbank.org
} 
However, this does not seem to be the case. The Jambinese rubber sector is characterized by strong oligopsonistic market power. On the processing side we can observe a strong concentration of the demand for the product of the farmers, as there are only nine crumb rubber factories in Jambi, vis-à-vis 252000 farmers. These factories do not appear to be in tight competition, but are rather collaborating closely. All of them are organized in the association of the rubber processing sector, Gapkindo. A report prepared for the development agency USAID by Peramune and Budiman (2007) found that Gapkindo is a very efficiently organized and politically powerful lobbying-institution that represents the interests of rubber processors and brokers. Its main target is 'the development of rubber processing industries' and to 'network among members' (Peramune and Budiman, 2007, p. 32). There are strong indications that some individual firms exploit their network to behave in a way that resembles a classical cartel or oligopsony (ibid.). Within the scope of this analysis it cannot clearly be distinguished between a cartel and an oligopoly since the data required for a game theoretical approach or the determination of the cartel price (cost structures of the factories, demand structure) are not available. The establishment of the link between the evidence for asymmetric price transmission and the occurrence of market power is based on Meyer and von Cramon-Taubadel (2004).

In order to shed light on the price formation process in the rubber value chain, we are employing a price transmission approach. In particular we study the vertical transmission between the output- and input prices of the five crumb rubber factories in Jambi City from 01 January 2009 until 31 December 2012 via an Asymmetric Threshold Error Correction Model (ATECM), as introduced by von Cramon-Taubadel (1998). To specify the error correction model correctly and without having to rely on a priori assumptions, we employ the non-parametric technique of penalized splines before estimating a set of candidate parametric models and test which one represents the data best, as suggested by Serra et al. (2006). In addition to demonstrating the existence and extent of market power, we also quantify a part of the resulting redistribution of welfare from the suppliers to the factories. These welfare implications are shown to be substantial.

To the best of our knowledge, this is the first paper combining the approaches of non-parametric and parametric estimation techniques of estimating asymmetric price transmission processes with a welfare perspective to quantify the distributional consequences of this intertemporal marketing margin manipulation. The dataset of daily prices on such a disaggregated and local level is unique.

The paper is organized as follows: section two provides the background of the rubber market in the Jambi province and introduces the typical marketing chain 
for natural rubber originating from smallholder production in this area. In section three the intuition behind asymmetric price transmission is discussed. Section four is dedicated to the model development, and section five presents the statistical results. The subsequent section six derives the resulting welfare implications before section seven concludes.

\subsection{Background}

\section{Rubber marketing in the Jambi Province}

The Jambinese rubber sector is displayed in Figure $\left.3.1\right|^{5}$ Most farmers sell to a village trader who then has the choice between three different kinds of stakeholders to sell to: a factory, a warehouse or another trader, for example on the district level. This choice is influenced by various factors, including the remoteness of the trader, her capital, access to credit and information, etc. (Sujarwo et al., 2014).

Figure 3.1: Marketing channels for rubber.

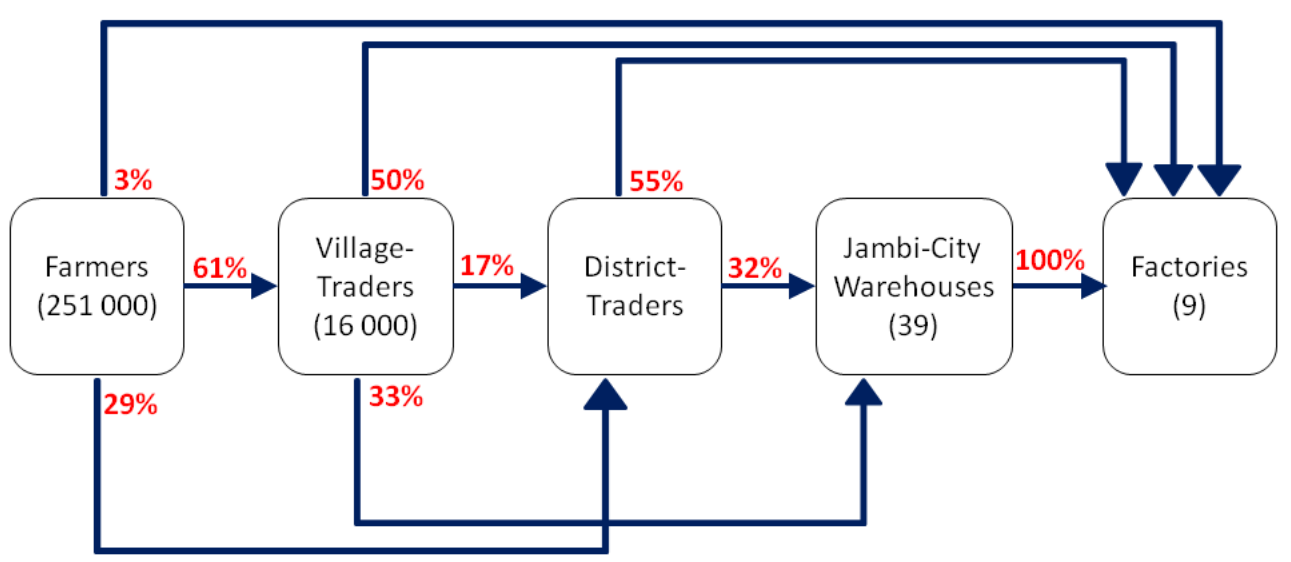

Source: author's calculations, based on own survey data (2012) and Euler et al. (2012). The percentages indicate which marketing channel is employed and for how often.

There are approximately 16000 traders in the Jambi province and nine factories of which five are located in the capital Jambi City (citealpRegionalAccountandStatisticalAnalysisDivision2012 and own survey data, 2012).

\footnotetext{
${ }^{5}$ Farmers' marketing channels do not add up to 100, because they sell a minor share on auction markets $(6 \%)$ where the buyer is unknown, as well as to farmers' associations (1\%). The missing $13 \%$ of the district traders stem from the fact that they can also sell to another trader, which was omitted from this graph.
} 


\section{Market concentration at the processing stage}

It appears that oligopsonistic market power occurs at several stages of this value chain. On the village-level the traders' market power seems to be based on the farmers' credit constraint as well as asymmetric information vis-à-vis the farmers (Kopp and Brümmer, 2015).

In this paper, however, we are focusing on the market power at the next stage: the gates of the factories. The incriminating indicators are strong. During our traders survey in 2012 some respondents claimed that they were victims of market power of downstream stakeholders (other traders, warehouses, and factories). It seems possible that the critique they are expressing is justified to at least some extent. Each of the five factories that are located in Jambi City reports the price that it is paying each day for their main input - slabs of raw rubber - to one central agent (their association) and also has the option to get the information on its competitors' prices from this agent. This enables each factory management to control its competitors' pricing.

Another piece of evidence for the power of the factories is the standard procedure that follows if an external investor wants to construct a new crumb rubber factory. Before getting the required permission by the government, the officials responsible will first consult with the rubber processors' association on whether to give the permission or not (Jambi Provincial Government Office for Trade and Industry, personal communication, 2012).

Anwar (2004, cited in Arifin, 2005) argues that the margin of Jambinese rubber factories is much higher than those in other provinces. While Anwar argues this to be the result of the close geographic proximity of Jambi to one of the most important export market ports (Singapore), it is much more likely that this observed increased margin comes from the oligopsony power of the rubber factories Arifin, 2005).

This market power has a tremendous effect on the distribution of welfare, both for the rubber farmers and the Jambinese society in general. The welfare loss experienced by the farmers consists of a) the income that is redistributed from them to the factories due to the lower price and b) due to lower production. In the long run it is reasonable to argue that the farmers do have the possibility to increase their rubber output, for example by shifting their production from palm oil to rubber. After 20-25 years an oilpalm plantation has to be replanted and the investments required for replanting oilpalm or establishing rubber are similar.

However, as the supply function of the rubber farmers is unknown, it is not possible 
to derive how much the supplied quantity and thus the total welfare loss would be in the case of a general improvement of the price level. Therefore we will concentrate on the farmers' welfare loss due to the redistribution based on a below competitive market price in times of price hikes. We are going to show that this oligopsonistic market power is exercised and how large the welfare loss to the farmers is, that results from intertemporal marketing margin manipulation.

\subsection{Methodology}

One way of finding empirical evidence for the existence of market power is by testing for a non-constant transmission of price changes (Kinnucan and Forker, 1987; McCorriston et al., 2001; Meyer and von Cramon-Taubadel, 2004). We are aware that the literature of New Empirical Industrial Organization provides with structural models a more direct approach to indications of market power (Bresnahan, 1982). However, these approaches require detailed information on the firms' demand and supply structures, which is data on a level of detail that we do not have access to. The asymmetry that we are discussing here implies that positive changes of an agent's selling price are passed on to her provider at a lower speed than negative price changes. This means that when the agent's margin increases - that is in times of international price hikes - the buying price is corrected less rapidly than when the margin decreases ${ }^{6}$

The assumption behind the asymmetric price transmission between the international rubber price and the Jambinese price for raw rubber is that the factories are price takers at the international market. While Indonesia as a whole can be assumed to have an influence on international rubber prices, this is unlikely to be true for the five Jambinese factories under consideration. At the domestic market, however, it can be assumed that they are price setters. Both these assumptions are going to be tested. One can therefore understand the shocks that arise in the first one as exogenous and the ones in the latter as reactions to that shock. In Figure 3.2, the two lines represent the input- and output-prices. The margin of the factory is the squared area. Negative shocks are transmitted faster than positive ones, which means that in the case of a negative shock the margin of the processor stays constant, while after a positive shock the margin increases (striped area). The assumption behind the asymmetric price transmission between the international rubber price and the Jambinese price for raw rubber is that the factories

\footnotetext{
${ }^{6}$ If asymmetries in the short-run dynamics occur (not only in the adjustment parameter) it would also be interesting to analyse these dynamics via impulse response functions. As we will see however, there are no asymmetries in the short-run dynamics, so the generation of impulse response functions would not increase the quality of information.
} 
are price takers at the international market. While Indonesia as a whole can be assumed to have an influence on international rubber prices, this is unlikely to be true for the five Jambinese factories under consideration. At the domestic market, however, it can be assumed that they are price setters. Both these assumptions are going to be tested. One can therefore understand the shocks that arise in the first one as exogenous and the ones in the latter as reactions to that shock. In Figure 3.2, the two lines represent the input- and output-prices. The margin of the factory is the squared area. Negative shocks are transmitted faster than positive ones, which means that in the case of a negative shock the margin of the processor stays constant, while after a positive shock the margin increases (striped area).

Figure 3.2: Intuition of asymmetric price transmission.

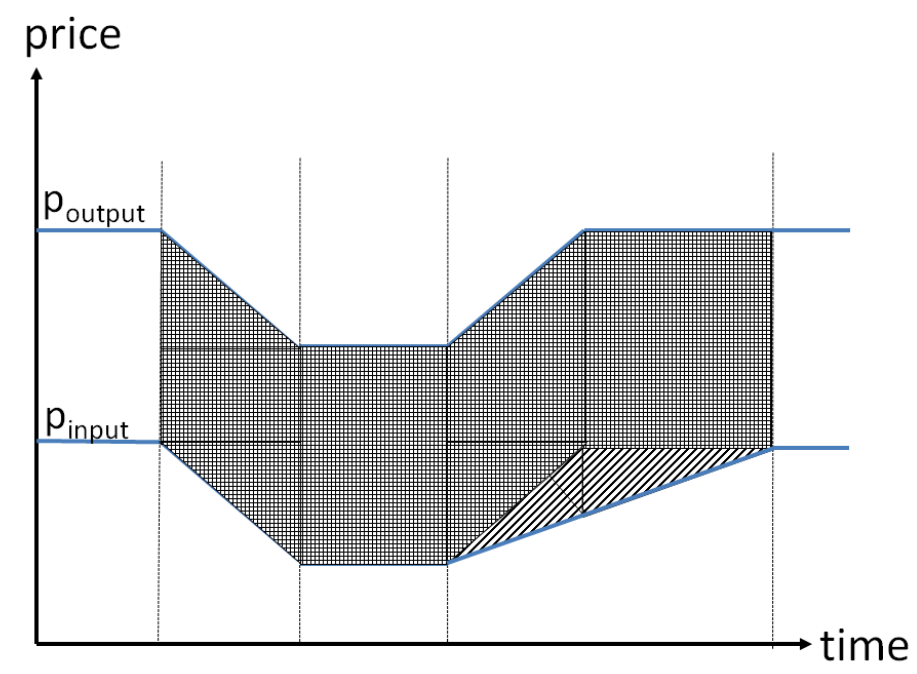

Source: author's draft.

\section{Non-stationarity and co-integration}

Given that we are working with prices, a non-stationarity nature of the data is expected which will be tested via the Augmented Dickey-Fuller (ADF) test with both variables of interest $\left(l_{-} p^{S e l l}\right.$ and $\left.l n_{-} p^{B u y}\right)$. As will be shown, they are indeed non-stationary, which we address by taking the first differences. We will then test whether the two series are co-integrated which is done by employing both the Johansen test (Johansen, 1998) and the Engle-Granger Two-Step method (Engle and Granger, 1987). For both tests we need to find the optimal lag-length. As we are using daily data, it is likely that the price of one day depends also on past shocks. To select the optimal number of lags we consider the Akaike's Information 
Criterion (AIC), Schwarz's Bayesian information criterion (SBIC), and Hannan and Quinn information criterion (HQIC).

\section{Error correction model}

We assume a multiplicative mark-up model. The intuition behind using a multiplicative instead of an additive model is that the margin is assumed to be a percentage markup. This has been concluded from qualitative interviews with representatives of the rubber factories. We have tested both approaches, and the results confirmed that taking the logarithm represents the data better. $p_{t}^{B u y}$ refers to the buying price at time $t$ and $p_{t}^{\text {Sell }}$ to the selling price. The long-run ('cointegrating') relationship in its logarithmic form is given by

$$
\ln p_{t}^{\text {Buy }}=\beta_{0}+\beta_{1} \ln p_{t}^{\text {Sell }}+\varepsilon
$$

which we estimate with the Johansen method. The reason for doing so (despite our general approach of the Engle-Granger two-step method) is that the Johansen approach delivers better results when estimating the co-integrating relationship Gonzalo, 1994). From the residuals of this relation we can generate the error correction term (ect) which is defined as follows:

$$
e c t_{t}:=\ln p_{t}^{B u y}-\hat{\beta}_{0}-\hat{\beta}_{1} \ln p_{t}^{\text {Sell }}
$$

In the case of a positive price shock on the international level (i.e. a positive deviation from the long-run equilibrium in which the factories' margin increases) the ect will be $<0$ and if the price is shocked negatively, the ect is $>0$. The error correcting process (symmetric case) is expressed as

$$
\Delta \ln p_{t}^{B u y}=\xi_{0}+\alpha e c t_{t-1}+\sum_{\omega=1}^{M}\left(\gamma_{\omega} \Delta \ln p_{t-\omega}^{B u y}+\lambda_{\omega} \Delta \ln p_{t-\omega}^{S e l l}\right)+\varepsilon
$$

$M$ is the number of lags, $\xi_{0}$ a constant, and $\gamma_{\omega}$ and $\lambda_{\omega}$ the coefficients of short-run dynamics. $\varepsilon$ represents an error term. Figure 3.3 (continuous line) illustrates the error correcting process by graphing the ect from the previous period against the change of the buying price in the current period. In the 2nd quadrant the correction of positive price shocks is represented while the correction of negative shocks can be seen in the 4 th quadrant.

For the thoughts laid out in the theoretical section above, the model is extended to a threshold error correction process, which is the generalization of a simple 
asymmetric adjustment. The existence of any threshold is tested for with a SupLM test as suggested by Hansen and Seo (2002). Based on model (3) the ect is split up into $N$ regimes by $N-1$ thresholds, which are located at $\Psi_{\lambda}$ for $\lambda \in[1, \ldots, N-1]$ and $e c t_{t}^{\varsigma}:=e c t_{t}$ if $\Psi_{\varsigma-1}<e c t_{t} \leq \Psi_{\varsigma}$ for $\varsigma \in[1, \ldots, N]$ :

$$
\Delta \ln p_{t}^{\text {Buy }}=\xi_{0}+\sum_{\varsigma=1}^{N} \alpha_{\varsigma} e c t_{t-1}^{\varsigma}+\sum_{\omega=1}^{M}\left(\gamma_{\omega} \Delta \ln p_{t-\omega}^{\text {Buy }}+\lambda_{\omega} \Delta \ln p_{t-\omega}^{\text {Sell }}\right)+\varepsilon
$$

For an 'asymmetric' process, which is the simplest form of a threshold error correction $\left(\mathrm{N}=2\right.$ and $\left.\Psi_{1}=0\right)$, the error correction is displayed in Figure 3.3 (dotted line).

Figure 3.3: Symmetric error correction (continuous line) and asymmetric error correction (dotted line).

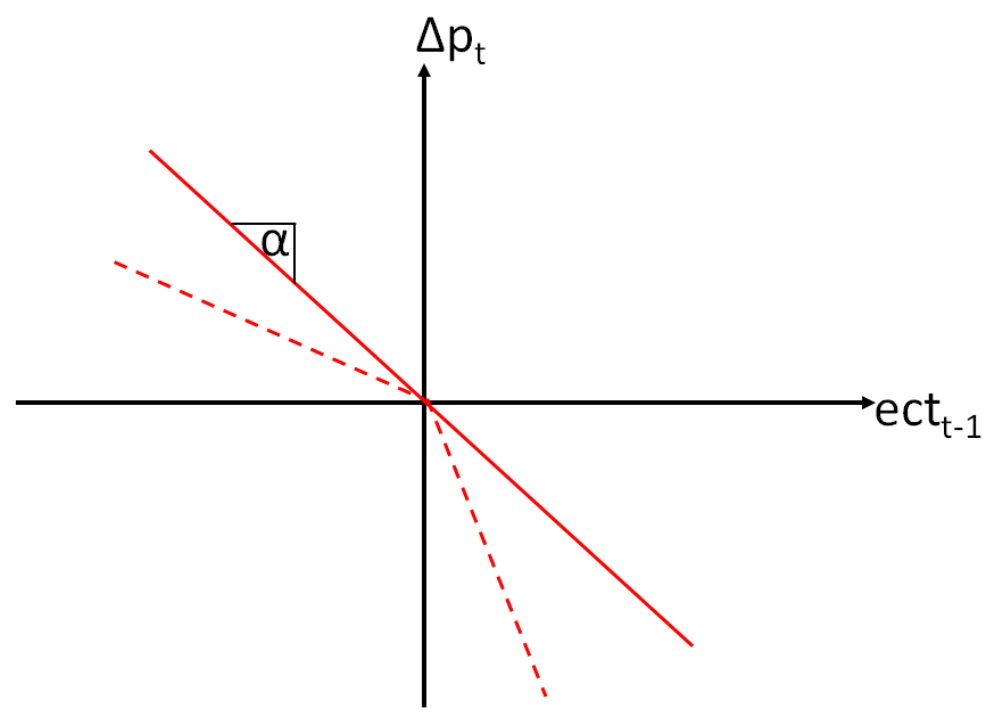

Source: author's draft.

\section{Non-parametric estimation}

Most authors in the literature on threshold error correction models use a parametric estimation technique (Hansen and Seo, 2002, Lloyd et al., 2006, and Ihle et al. 2012). The drawback of this procedure is that one has to make certain a priori assumptions for specifying the model, such as the number of thresholds. In order to overcome this limitation, we employ a non-parametric approximation. While using non-parametric estimation techniques to detect unknown relationships is a widely used technique in the statistical and financial literature (Krivobokova et al. 2010, Escribano, 2004), in the agricultural economics literature this has not been 
employed a lot. An exception is the work by Serra et al. (2006) who use a local polynomial fitting approach in order to understand the error correction process without the need for restrictive a priori assumptions. Contrary to that, we are working with penalized splines (Eilers and Marx, 1996). Regression splines consist of the sum of a number of polynomial functions. The spline is fitted to match the data by giving each of these functions an individual shape. Penalizing the splines refers to the method of including a penalty-term, which smoothes the spline by penalizing excessive zigzagging (i.e. big differences between neighboring values) of the spline (Wood, 2003).

\section{Candidate models for parametric estimation}

In order to get to know the exact slope-coefficients which are necessary for calculating the distributional effects, we will continue with a parametric regression approach, based on the insights from the non-paramethric methods. Several approaches are employed to model the error correction process before the model that represents the data best will be chosen via a testing procedure described below.

To start with, we estimate a simple linear error correction model (M1) which corresponds to the model described in equation 3.3. The second model (M2) is an asymmetric error correction model which corresponds to equation 3.4 with the specifications $\mathrm{N}=2$ and $\Psi_{1}=0$. For the third model (M3) we assume a one-threshold model with no restriction on the location of the threshold. The intuition of model three (M3) is that the price gets corrected quickly during price drops (regime 3) and moderate hikes (regime 2) when the factories generate a normal margin. In times of large price increases (regime 1) however, the prices get corrected much slower: the factories generate a greater margin. M3 corresponds to equation 3.4 with $\mathrm{N}=2$ and an unknown value of $\Psi_{1} .7$

The exact location of this threshold can be found via a grid search approach. We test each possible value of the ect as the threshold value $\Psi_{1}$, estimate the model and save the log-likelihood value. We then select the model with the highest loglikelihood.

\section{Threshold determination and model choice}

We find the threshold of model M3 via the grid search following the method laid out above. At the same time, no assumptions have been made about the location of the threshold.

\footnotetext{
${ }^{7}$ It was also experimented with a smooth-transition type of model as employed by Hassouneh et al. (2012). The results did not show statistical significance, but can be made available on demand.
} 
After estimating the different models described (M1-M3), we will test which of them represents the data best. As we compare models with different specifications concerning the number of regimes (one and two), we rely on an information criterion again. We employ the AIC which is in this case superior to other information criteria as laid out by Burnham and Anderson (2002).

\section{Distributional effects}

The quantification of the distributional effects stemming from asymmetric price transmission is based on the forgone profit for smallholders due to slower price transmission in times of tremendous price hikes, compared to a baseline scenario of the fastest adjustment possible which is assumed to be the adjustment that occurs in times of price decreases (see Figure 3.4). As discussed above, we do not focus on the total welfare effect because the price elasticities of the supply and demand are unknown. The part of the welfare effect which stems from the intertemporal marketing margin manipulation is calculated as the difference between the price that is theoretically possible in times of price hikes and the price that is actually paid, multiplied by the quantity. The generation of impulse response functions would not increase the quality of information, since the short-run dynamics were not proven to be asymmetric.

Figure 3.4: Welfare effect during adjustment process after shock at $\mathrm{t}=0$

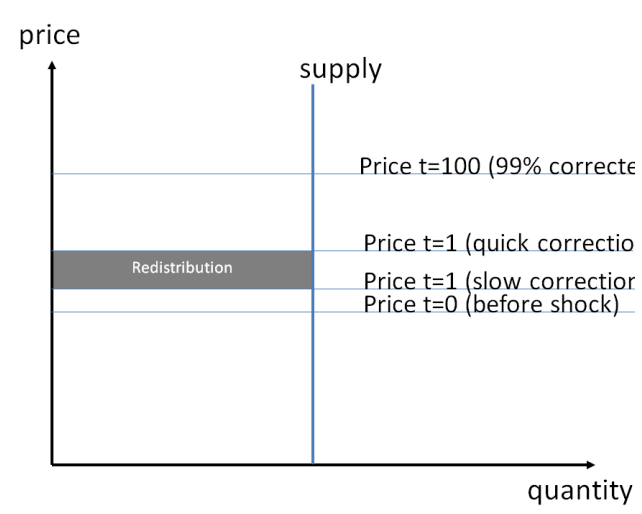

(a) time $=\mathrm{t}+1$

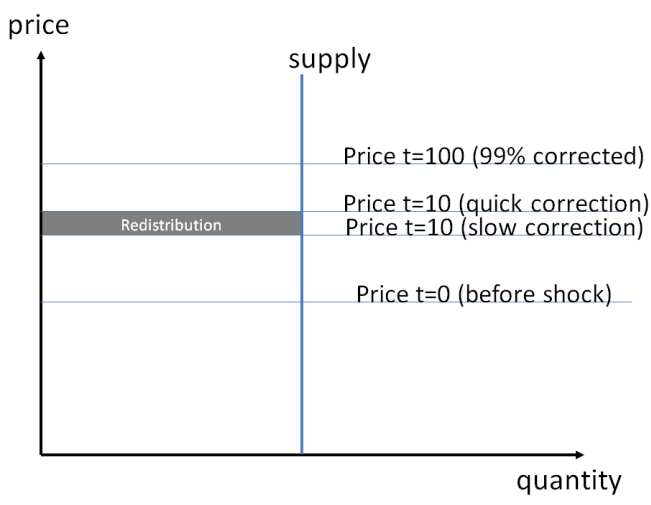

(b) time $=\mathrm{t}+10$

Source: author's draft.

In order to quantify the effect that the intertemporal marketing margin manipulation had on all Jambinese farmers, we calculate the differences between two hypothetical scenarios of the local price development after 14 periods (the time after which a farmer sells his/her produce is around two weeks) following each shock to the global price during 2009-2012. The two scenarios differ in the assumed 
adjustment parameter, following the results from the asymmetric error correction model.

We start with the following equation

$$
\ln p_{t}^{\text {Buy }}=\ln p_{t-1}^{\text {Buy }}+\Delta \ln p_{t}^{\text {Buy }}+\varepsilon
$$

in which we substitute $\Delta \ln p_{t}^{B u y}$ from a simplified version (without lagged prices) 8 of equation 3.3 and then ect from equation 3.2 in order to calculate the adjusted price after one period:9

$$
\ln p_{t}^{\text {Buy }}=\ln p_{t-1}^{\text {Buy }}+\hat{\alpha}\left(\ln p_{t-1}^{B u y}-\hat{\beta}_{0}-\hat{\beta}_{1} \ln p_{t-1}^{\text {Sell }}\right)+\varepsilon
$$

Iterating this procedure 14 times generates the price after 14 periods after the shock in period 1. In the computation we omit the error term, assuming it to be zero. The difference $p^{\text {diff }}$ between the two scenarios is given as

$$
p^{d i f f}=\exp \left(\ln p_{t+14}^{B u y\left(\alpha^{+}\right)}\right)-\exp \left(\ln p_{t+14}^{B u y\left(\alpha^{-}\right)}\right)
$$

The total redistribution $(R E D)$ based on intertemporal marketing margin manipulation is then the sum of all price differences, multiplied by the quantity sold at time $t+14$ :

$$
R E D=\sum_{t=1}^{T}\left(p_{t}^{\text {diff }} q_{t+14}\right)
$$

\subsection{Data}

The daily buying prices from the five factories in Jambi City were provided by Gapkindo. There is one price for each factory available for each day from 1 January 2009 until 31 December 2012, except for Sundays and public holidays. Out of these five series, an unweighted average for the Jambi-buying price was generated. The selling prices were drawn from PT. Kharisma (2013), a marketing company located in Jakarta. These prices represent the average results of the auctioning of Standard Indonesian Rubber (SIR20) on each day when rubber was sold (four or five days per week, except for two weeks of Christmas holidays and two weeks during Ramadan).

\footnotetext{
${ }^{8}$ We can make this simplification of equation 3.3 since the short-run dynamics are not asymmetric.

${ }^{9}$ The adjustment of $p^{\text {Sell }}$ to $p^{\text {Buy }}$ is close to zero, since $p^{\text {Sell }}$ was shown above to be clearly the leading price, and not reacting to $p^{\text {Buy }}$ )
} 
In combination, this gives us 706 days for which we have both selling and buying prices. The price series are graphed in Figure 3.5 .

Figure 3.5: Time series of buying and selling prices.

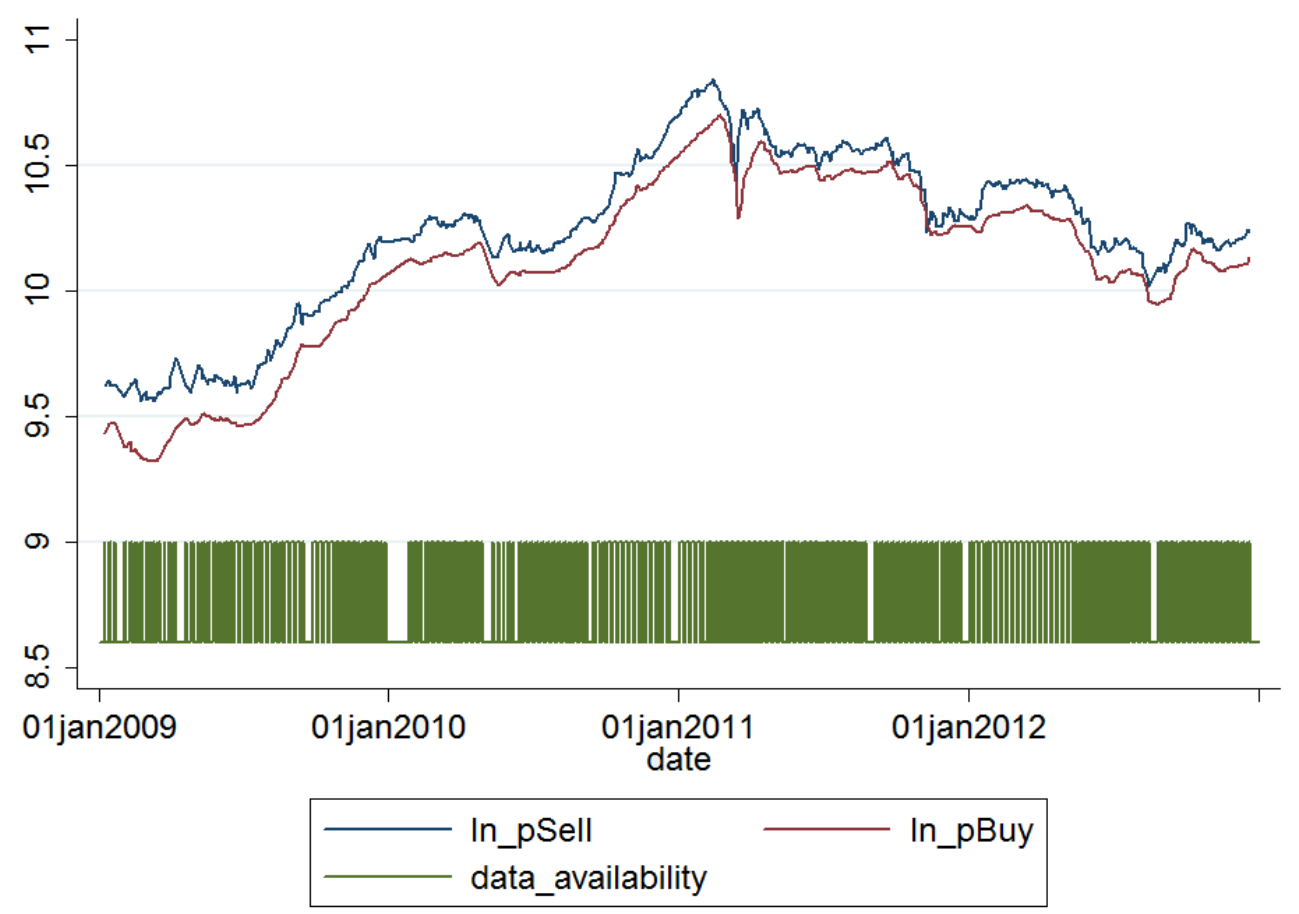

Source: author's production. Values are the logarithm of the prices in Indonesian Rupiah. 1.00 USD = 10.93 Indonesian Rupiah (December, 2013). The green bar indicates the existence of data, so the holes in the green bar represent days without data. In the graph, the last point before a gap was connected with the first one after it.

\subsection{Results}

\section{Non-stationarity and co-integrating relationship}

The initial suspicion could be confirmed. The series are indeed both non-stationary (the $\mathrm{H} 0$ of non-stationarity cannot be rejected at a confidence level of $10 \%$ ). To avoid the problem of spurious regressions, we take the first differences. As the results of the ADF test show (H0 can be rejected at a $1 \%$ confidence level), this solves the problem. The SBIC suggests a lag-length of the order two, the HQIC three lags, and the AIC opts for four lags. Following Ivanov and Kilian (2005), who suggest to trust the AIC in situations of large sample sizes $(>250)$ and data of relatively high frequency (>weekly), we use four lags. The second reason for choosing the lag order suggested by the AIC is the danger of biasing the results by 
under-parametrizing the model, while over-parametrizing does not cause too much damage (Gonzalo, 1994). So the lag length was specified as four periods in each case, including a constant and without trend. Test results are available on request.

From the test for a simple (i. e. non-threshold) ARVECM (results: see appendix (2) with the Johansen method we can confirm our assumption that the factories are clearly price-takers on the international market and price setters on the domestic market. The selling price does not react significantly to the buying price $(\alpha=-0.0153$, p-value $=0.511$, appendix $(2)$, column 1$)$, while the reaction of the buying price is strong and highly significant $(\alpha=-0.0593$, pvalue $=0.001$, appendix (2), column 2). Using the Engle-Granger two-step approach results in a very similar adjustment parameter of -0.0582 for the buying price and is also highly significant ( $\mathrm{p}$-value $=0.001$ : appendix (2), column 3 ). Hence, the use of the Engle-Granger two-step approach seems appropriate. The co-integrating relationship is presented in Table 3.1. We continue the analysis using the residuals of the co-integrating relationship generated with the Johansen method $\left(p^{\text {Buy }}=0.45\left(p^{\text {Sell }}\right)^{1.07}\right)$, following the results of Gonzalo (1994) who finds that the Johansen method delivers the best results when estimating long-run relationships. An F-Test confirms that the constant is significantly (1\% level) different from the value zero. Testing the residuals with the ADF test yields a test statistic of -6.980 , with which we can reject the $\mathrm{H} 0$ of non-stationarity at the $1 \%$ level. Figure 3.6 shows the dispersion of the ect. The results of Hansen and Seo's (2002) SupLM test indicate the presence of a threshold, as the $\mathrm{H} 0$ of an error correction process without a threshold can be rejected at a $10 \%$ level (robust SupLM), and respectively a $1 \%$ level (standard SupLM) of significance (results: see appendix (2)).

\section{Penalized splines}

Figure 3.7 shows the penalized spline (blue line). The dotted lines represent the $5 \%$ confidence intervals 10 In order to deal with the small numbers of observations at both ends of the population, we add a thin plate penalized spline for comparison (bronze line) (Wood, 2003). The thin plate regression splines penalize by compiling the spline of the group of functions which are the most relevant. These are chosen via an Eigenvalue decomposition.

The splines exhibit narrow confidence intervals in the area of many observations and indicate one threshold in the region [-0.05; 0], thus indicating at least two regimes. The two regimes can be characterized as follows: the slope is steeper for positive values of $e c t_{t-1}$, which means that the shock gets corrected more rapidly in cases

\footnotetext{
${ }^{10}$ These calculations were carried out with the software $R$ 3.0.1 and version 1.7-22 of $R$ package MGCV.
} 
Figure 3.6: Distribution of ect values.

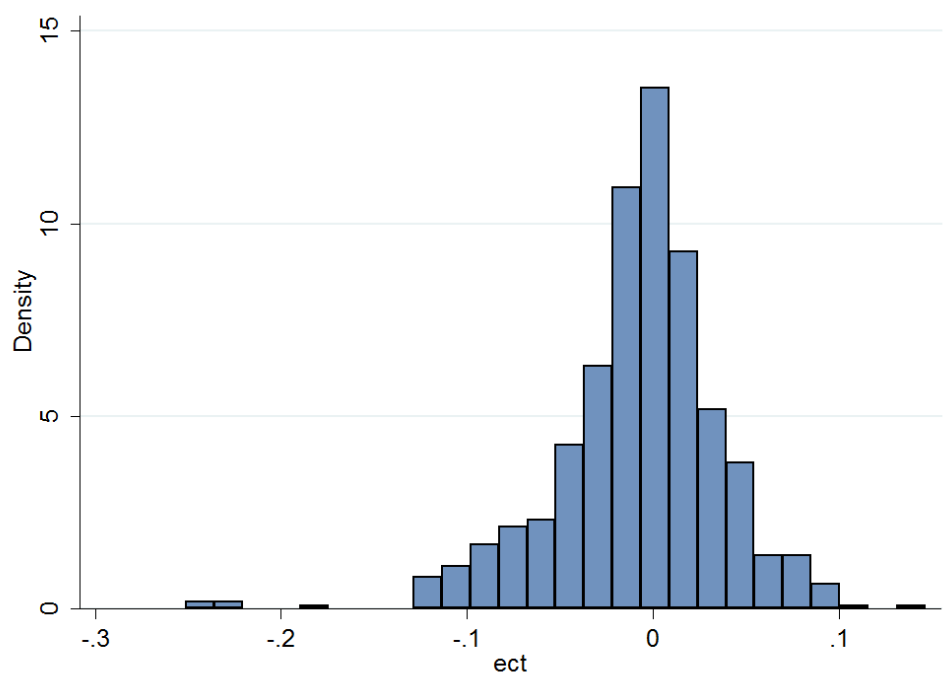

Source: author's production. The extreme values at the left end of the distribution are not outliers, but plausible values for the ect. They all occurred during one tremendous price hike from 17.-24. March 2011.

Table 3.1: Estimates of long-run relation.

\begin{tabular}{lcc}
$l n_{-}$pBuy & OLS & Johansen \\
\hline ln_pSell & $\begin{array}{c}1.067^{* * *} \\
(0.0071)\end{array}$ & $\begin{array}{c}1.067^{* * *} \\
(0.0186)\end{array}$ \\
Constant & $\begin{array}{c}-0.811^{* * *} \\
(0.0723)\end{array}$ & -0.800 \\
& & \\
& & \\
Observations & 706 & 702 \\
R-squared & 0.982 & \\
\hline \multicolumn{2}{c}{ Standard errors in parentheses } \\
$* * *$ p $<0.01,{ }^{* *} \mathrm{p}<0.05,{ }^{*} \mathrm{p}<0.1$
\end{tabular}

Since the VEC is not linear, it does not report t-statistics. The Johansen results have four observations less, because they include lags, while the first step of the Engle-Granger method does not require the inclusion of lags.

of negative price-shocks than in the case of positive price-shocks. While in the area $[-0.1 ; 0]$ the splines are robust to changes in their specification ${ }^{11}$ the confidence intervals widen substantially at the rather extreme values in $]-\infty ;-0.1[\cup] 0.1 ; \infty[$, which is caused by the small number of observations in these areas.

\footnotetext{
${ }^{11}$ Available on request.
} 
Figure 3.7: Penalized splines.

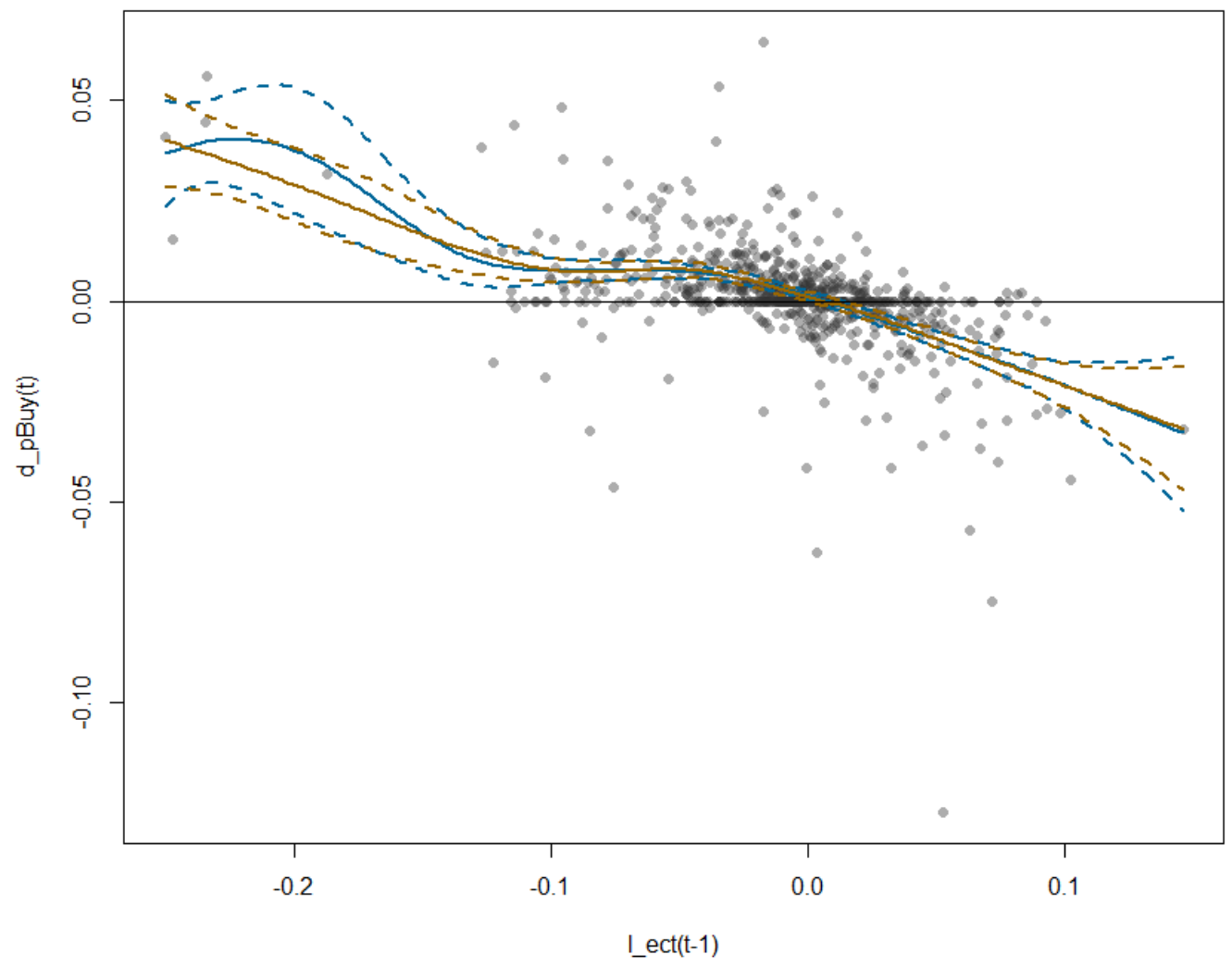

Source: author's production.

\section{Model choice}

Table 3.2 presents the AIC values of the models M1-M3. Following this criterion, M3 represents the data best. Executing an F-Test indicates that the two slope-coefficients of Model 3 are different from each other with a significance of $6.58 \%$. The following discussion is therefore based on the two-regime model with one threshold at -0.0383844 (M3).

Table 3.2: Results of Akaike Information Critereon.

\begin{tabular}{ccccc} 
Model & $\ln (\mathrm{L})$ & $\mathrm{k}$ & AIC & Rank \\
\hline M1 & 2223.7814 & 10 & -4427.5628 & 3 \\
M2 & 2224.8331 & 11 & -4427.6662 & 2 \\
M3 & 2226.7141 & 11 & -4431.4282 & 1
\end{tabular}




\section{Parametric regressions}

The estimation results are presented in Table 3.3. The specification of M3 stems from a one-dimensional grid search. Its results are shown in Figure 3.8. The display of the likelihood values shows two peaks which indicate possible locations for the threshold, one at the ect value of -0.0383844 (splitting up the ect into one regime of 135 observations and one of 571 observations) and one at the value of 0.052372 (662 and 44 observations per regime). Considering that the likelihood values are nearly identical (2226.714 with the threshold at the 135th observation vs. 2226.863 at the 662nd observation) but the latter value produces one regime of only 44 observations, we chose the first possibility ${ }^{12}$

Figure 3.8: Results of one-dimensional grid search.

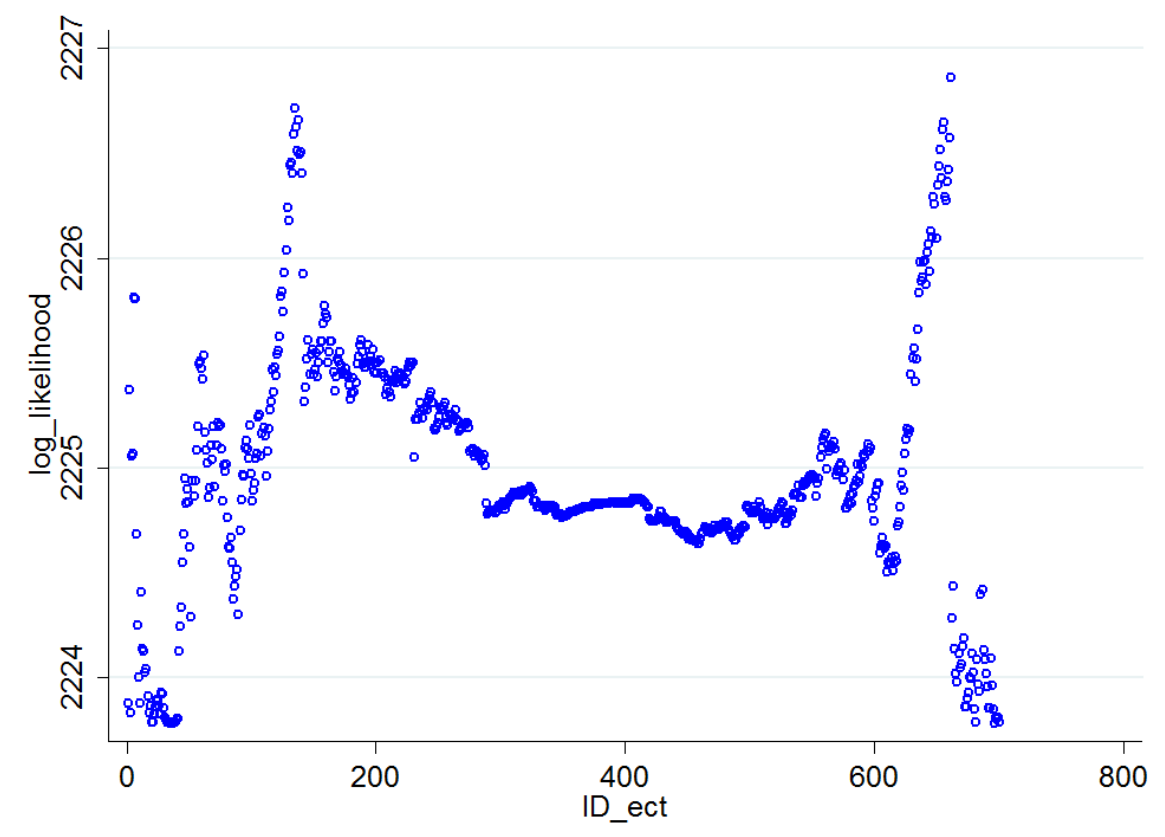

Source: author's production.

\subsection{Discussion}

\section{Interpretation of coefficients}

Table 3.3 displays the results of the three models of the parametric estimation. On average (column M1), $5.83 \%$ of a price shock is corrected per day. If the buying price deviates from the long-run equilibrium price by $100 \%$ for example (i.e. it

\footnotetext{
${ }^{12}$ For model tests see below. The results of the estimation that assumes the other threshold can be made available on demand. We also executed a two-dimensional grid search and estimated a three-threshold model, whose results can also be made available on demand.
} 
Table 3.3: Results of all models discussed.

\begin{tabular}{|c|c|c|c|}
\hline$d_{-} l n_{-} p B u y$ & $\begin{array}{c}(\mathrm{M} 1) \\
\text { Regular OLS }\end{array}$ & $\begin{array}{c}\text { (M2) } \\
\text { One Threshold } \\
\text { (at zero) }\end{array}$ & $\begin{array}{c}\text { (M3) } \\
\text { One Threshold } \\
\text { (at }-0.0383844)\end{array}$ \\
\hline L.ect & $\begin{array}{c}-0.0583^{* * *} \\
(-4.234)\end{array}$ & & \\
\hline L.ect_pos & & $\begin{array}{c}-0.0875 * * * \\
(-2.954)\end{array}$ & $\begin{array}{c}-0.0935^{* * *} \\
(-4.284)\end{array}$ \\
\hline L.ect_neg & & $\begin{array}{c}-0.0473^{* * *} \\
(-2.601)\end{array}$ & $\begin{array}{c}-0.0438^{* *} \\
(-2.561)\end{array}$ \\
\hline LD.ln_pSell & $\begin{array}{c}0.156^{* * *} \\
(5.676)\end{array}$ & $\begin{array}{c}0.149^{* * *} \\
(5.055)\end{array}$ & $\begin{array}{c}0.145^{* * *} \\
(4.882)\end{array}$ \\
\hline L2D.ln_pSell & $\begin{array}{c}0.139^{* * *} \\
(4.535)\end{array}$ & $\begin{array}{c}0.136^{* * *} \\
(4.385)\end{array}$ & $\begin{array}{c}0.134^{* * *} \\
(4.289)\end{array}$ \\
\hline L3D.ln_pSell & $\begin{array}{c}0.109^{* * *} \\
(4.078)\end{array}$ & $\begin{array}{c}0.110^{* * *} \\
(4.115)\end{array}$ & $\begin{array}{c}0.110^{* * *} \\
(4.124)\end{array}$ \\
\hline L4D.ln_pSell & $\begin{array}{l}0.0364 \\
(1.136)\end{array}$ & $\begin{array}{l}0.0360 \\
(1.121)\end{array}$ & $\begin{array}{l}0.0357 \\
(1.113)\end{array}$ \\
\hline LD.ln_pBuy & $\begin{array}{l}0.0544 \\
(1.081)\end{array}$ & $\begin{array}{l}0.0541 \\
(1.070)\end{array}$ & $\begin{array}{l}0.0543 \\
(1.069)\end{array}$ \\
\hline L2D.ln_pBuy & $\begin{array}{l}-0.0192 \\
(-0.371)\end{array}$ & $\begin{array}{l}-0.0211 \\
(-0.411)\end{array}$ & $\begin{array}{l}-0.0222 \\
(-0.433)\end{array}$ \\
\hline L3D.ln_pBuy & $\begin{array}{l}0.0365 \\
(0.893)\end{array}$ & $\begin{array}{l}0.0330 \\
(0.817)\end{array}$ & $\begin{array}{l}0.0308 \\
(0.772)\end{array}$ \\
\hline L4D.ln_pBuy & $\begin{array}{c}0.130^{* *} \\
(2.057)\end{array}$ & $\begin{array}{c}0.125^{* *} \\
(1.971)\end{array}$ & $\begin{array}{c}0.124^{* *} \\
(1.969)\end{array}$ \\
\hline Constant & $\begin{array}{c}4.98 \mathrm{e}-05 \\
(0.125)\end{array}$ & $\begin{array}{c}0.000646 \\
(1.112)\end{array}$ & $\begin{array}{c}0.000529 \\
(1.260)\end{array}$ \\
\hline Observations & 701 & 701 & 701 \\
\hline R-squared & 0.387 & 0.389 & 0.392 \\
\hline
\end{tabular}

is half of what it should actually be in the long-run), $5.83 \%$ of that shock is, on average, corrected on the following day. This is equivalent to an average half-life of a price shock of 11.4 days. Reasons for these deviations include a shock to the international price, or past shocks which have not been fully corrected.

When accounting for the asymmetric price adjustment, the picture looks different. During the last four years, after 135 out of 390 price hikes (positive shocks to the price, i. e. ect $<0$ ), which is roughly $1 / 3$ of these cases, the price was corrected significantly slower than during price declines. More specifically, these 135 cases 
were at times of extreme price hikes, i.e. ect $<-0.0383844$. It takes 16.5 days to correct half of a strong positive price change and only 7.5 days in the case of a negative or small positive shock (see Figure 3.9. The simulations are based on equations 3.6 and 3.7 , see below). The sign of the threshold value is counterintuitive (negative ects refer to positive price changes) because the ect in the analysis was defined as the long-run equilibrium price minus the actual price in that period. This means, more plainly, that when the international price sinks, the factories' buying prices adjust twice as fast as when the international price rises strongly. The time needed to correct $99 \%$ of a shock is 49 days in the case of a negative shock and 107 days in the case of a strong positive shock. The lagged values of $p_{t}^{\text {Sell }}$ are positive and significant while the lags of $p_{t}^{\text {Buy }}$ are insignificant which supports the results from the Johansen test above that $p_{t}^{\text {Sell }}$ is the leading price.

Figure 3.9: Correction of shocks over time.

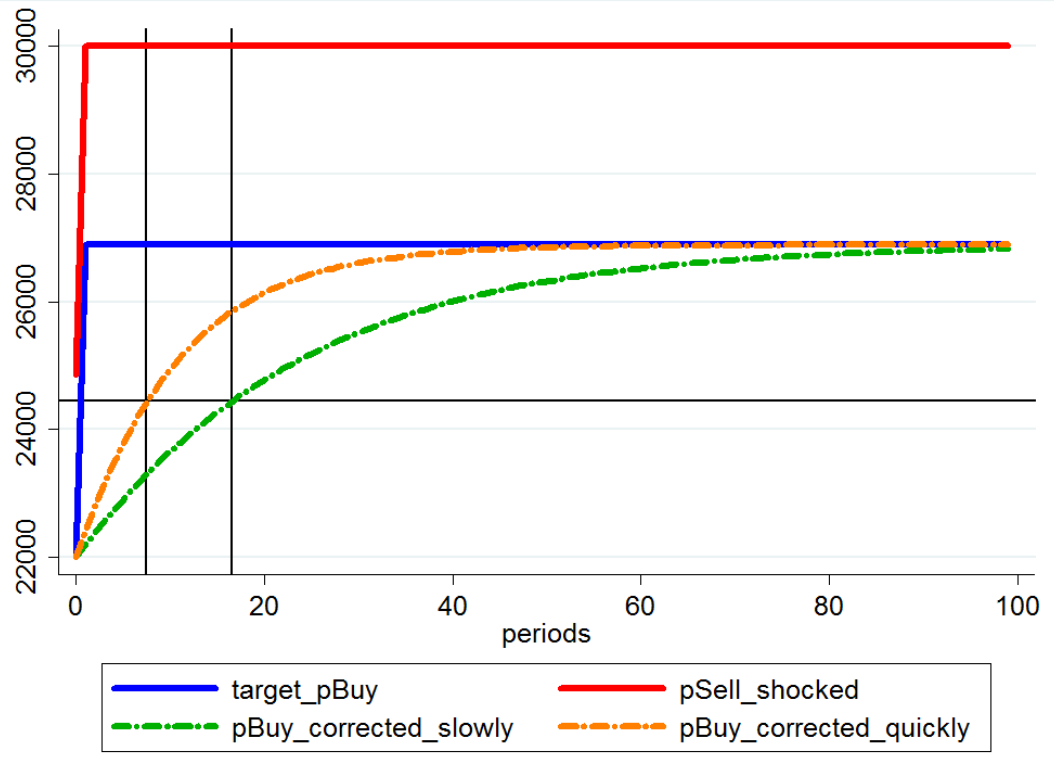

Source: author's calculations. In Indonesian Rupiah; 1.00 USD = 10.93 Indonesian Rupiah.

There are two reasons explaining why the price shocks are not transmitted in an instant (9.4\% per period is a very quick error correction, considering that we are working with daily data). Firstly, technical reasons in the factories are an issue, such as the communication between the selling and buying departments. The second reason is more of a methodological issue. For the analysis, the average of the prices of five crumb rubber factories was generated. Since changing their prices identically would be too much of an obvious indication of collusion, there are always small differences between the five prices. These small differences impact 
the average in a way that leads to an apparent short delay in the transmission time that is the average between the firms.

\section{Market power or not?}

As asymmetries in price adjustments can be the result of different kinds of processes, other than market power (von Cramon-Taubadel, 1998), this kind of analysis cannot provide a definite 'proof' of market power. Meyer and von CramonTaubadel (2004) show that asymmetric price transmission (APT) is not necessarily caused by market power. In their literature review, they present an overview of reasons for asymmetric price transmission other than market power, arguing that the proof of asymmetric price transmission is not necessarily equivalent to a proof of market power. For the case of our study however, all these alternative explanations that can lead to APT can be ruled out, leading us to the conclusion that the APT observed in the rubber processing sector in Jambi is indeed caused by market power, based on cartelistic or oligopsonistic behavior.

a) 'Menu costs' or the costs associated with changing the price: the prices that the factories are paying to their suppliers are changing every single day. There is no reason to believe that the costs of changing the price depend on the direction of the price change.

b) Fixed costs forcing a firm to operate close to its production capacity: as the agricultural input (the slabs of coagulated rubber) is extremely durable; the factories always have a stock available that is big enough to keep the factory running for more than a week.

c) Perishability generates an incentive to sell the product quickly: processed crumb rubber is not perishable.

d) A strong inflation in times of rising prices leads to data that exhibit asymmetry: while the inflation of the Indonesian Rupiah is greater than that of the U.S. Dollar, it is not great enough to have any impact on a daily basis which is the horizon of our data.

e) Policy interventions, price support, etc. can also lead to asymmetric price transmission, but has not occurred in Jambi (or on a national level in Indonesia) during the timeframe under consideration. Neither were new factories built or a new national/provincial government elected. The other input prices have also stayed constant (energy has been subsidized at a constant level, and the minimum wage did not change during the time of analysis). Hassouneh et al. (2010) suggest searching for a regime-switch which we do not find. 
f) Processing time: though a delayed reaction (caused by processing time) in combination with high inflation can show misleading signs of APT, this does not apply here because of two reasons: 1.) While it is true that inflation is high in Indonesia (4.3\% in 2012) ${ }^{13}$ we are working with daily data. During the typical reaction times the price hike due to inflation is close to zero. 2.) Besides that, we are observing a potentially monopsonistic setting, implying that the shock that hits the leading (selling) price occurs after the processing. If factories who set their buying price (and take their selling price) would want to set the buying price according to what they receive for that specific load of rubber after processing, they would have to anticipate the price after the processing already at the time of purchasing. This would be impossible.

g) Non-cooperative game: there are cases where it looks like price-fixing has happened, while in fact there is no outspoken agreement. It occurs in situations in which firms possess a credible threat of punishing another firm which deviates from the cartel-solution (Perloff et al., 2007). However, only rarely could it be argued that these companies would have an agreement that is not the subject of debate, especially given the fact that in all other respects they are such close companions. Besides, even if there is indeed no explicit agreement on pricing, the oligopsony-hypothesis would still hold.

An explanation why cartels adjust (increase) their buying prices at all - i. e. why they do not always pay a low price to the farmers - is that even cartels face restrictions concerning their price setting. There is always one margin that cannot be exceeded without risking government interference. This is the margin that is realized in times of constant or falling prices but secretly increased when the prices rise.

\section{Distributional consequences}

The 252000 Jambinese rubber producing smallholders produce 281000 tons of rubber per year on average (Regional Account and Statistical Analysis Division, 2012 ) and we assume them to sell, on average, the same amount every day at which they sell. Entering all numbers into Equations 3.6 to 3.8 yields a forgone revenue of 31.7 billion IDR (2.9 million USD) for the Jambinese rubber farmers in times of rising prices in every year. This is only the amount that is redistributed from farmers all over Jambi to the factories, due to the asymmetric price transmission of the factories. The total welfare loss due to the below free-market prices can be

\footnotetext{
${ }^{13}$ Inflation in 2009: 4.8\%, 2010: 5.1\%, 2011: 5.4\%. All from World Bank Database, 2015, dataset 'Inflation, consumer prices (annual \%).
} 
assumed to be substantial, too. For a single farmer, this amount represents $2.25 \%$ of his or her annual revenue. Considering that around $32 \%$ of the revenue turns into profit (calculation based on Euler et al., 2012), the calculation of the forgone profit is based on the following: profit $\pi$ is equal to $r s$ with $r$ being the revenue, and $s$ the profit share of the revenue (32\%). $\pi=r-c$ with $c$ representing the costs. The possible increased revenue (if the price transmission was symmetrical) $r^{\prime}$ is equal to $r(1+x)$ with $x$ being the percentage share of the possible increase of the revenue $(2.25 \%)$. Then $\pi^{\prime}=r^{\prime}-c$. The potential increase of profit can be calculated as

$$
\left(\pi^{\prime}-\pi\right) / \pi=(r(1+x)-c-(r+c)) /(r s)
$$

Increasing the revenue by $2.25 \%$ would have lead to an increased profit of $7.03 \%$. So effectively each farmer could have generated $6.97 \%$ more profit when the prices were increasing by more than the threshold value.

\subsection{Conclusions}

The indications that the five rubber processing businesses in Jambi City, Sumatra possess over proportional market power and use it to rig the prices which they are paying to their suppliers are strong. In this paper we found evidence for an asymmetric transmission of prices, which has led to a great redistribution of revenue from the farmers to the processors during the four years of observation. Compared to a non-monopsonistic market situation, the farmers have missed out on an income from rubber production of $7 \%$. The net welfare loss that has been generated in the process could not be quantified in this analysis (due to missing information on the price elasticities on the supply and demand sides), but can be assumed to be substantial. It is likely that these kinds of processes occur all over Indonesia.

The group has achieved its advantage by correcting price changes on the international market (where its members act as price takers) asymmetrically. If the international price drops, the buying price decreases much quicker than it adjusts in times of great price hikes. All alternative explanations for asymmetric price transmission - other than market power - could be ruled out for the rubber processing sector in Jambi. Risk managing strategies would lead to a generally lower price level, but not to a different reaction depending on the direction of price changes.

One policy recommendation that could be drawn from our results is to involve all stakeholders (including representatives of farmers) in the consultations before the 
decision on granting permits for the construction of a new crumb rubber factory. If more factories were competing for the input of raw rubber, the general price level would be expected to increase.

Another issue that has been touched upon only briefly is the behavior between the Jambinese rubber processors. It would be interesting to know if there is a rather random selection of the stakeholder who applies price changes first, or one clear Stackelberg leader determining the price with others who are following. With this sort of game-theoretical approach one would be able to get an even more detailed picture of the roles of the different stakeholders within the cartel, and the functioning of it as a whole. This calls for research at a more disaggregated level. 


Chapter 4

Preference Erosion - the Case of Everything But Arms and Sugar 


\title{
Preference Erosion - the Case of Everything But Arms and Sugar
}

\author{
Thomas Kopp ${ }^{1}$, Sören Prehn ${ }^{2}$ and Bernhard Brümmer ${ }^{1}$ \\ ${ }^{1}$ Georg August University, Göttingen, Germany, ${ }^{2}$ Leibniz Institute of \\ Agricultural Development in Transition Economies, Halle (Saale), Germany
}

\begin{abstract}
While the European Union's Everything But Arms (EBA) agreement has granted unlimited preferential access to the European market for the Least Developed Countries (LDCs) since 2001, the sugar sector has been exempted for the first years. Only from 2009 on, the LDCs were entitled to export an unlimited amount of sugar to the EU, receiving the intervention price. The expected increase in sugar imports led the EU to substantially reduce the intervention price, besides other measures. This caused a disadvantage for countries which had been granted preferential access to the European market already: the African, Caribbean, and Pacific (ACP) countries. Our paper quantifies this erosion of preferences, employing a gravity framework. In terms of methodology we are addressing two fundamental problems well known in the gravity literature. The occurrence of excess zeros in the dependent variable of such disaggregated data is tackled with the employment of the scale-independent Negative Binomial Quasi Generalised Pseudo Maximum Likelihood estimator. The problem of identification is addressed by modeling the policy change with the continuous Preference Margin instead of using dummy variables. We find that preference erosion did occur. The ACP countries were indeed negatively affected by the consequences following the introduction of the EBA.
\end{abstract}

Acknowledgments: We thank Maria Cipollina, Valentina Raimondi, and Luca Salvatici for generously sharing working paper versions of upcoming papers. 


\subsection{Introduction}

The European Union's Everything But Arms (EBA) agreement was designed to make the poorest countries better off by granting them preferential access to the common European market. But this noble goal might be overshadowed by some unwanted by-effects for other countries. In this work we are taking a close look at a potentially important phenomenon: preference erosion (PE), exemplified with the case of sugar.

The European Union (EU) sugar market used to be regulated and strongly protected. It accounted for around two thirds of all protection that concerns trade between the EU and less developed countries (Conforti et al., 2007). African, Caribbean, and Pacific (ACP) countries have had preferential access to this protected market. But due to commitments following the negotiations of the World Trade Organization's Uruguay Round, as well as a lost panel against three big sugar producing countries, there was a lot of pressure on the European Common Market Organization (CMO) for sugar in the midst of the last decade to reduce its subsidized sugar exports. In 2004 the WTO found that the EU were guilty of subsidizing more sugar exports than it had committed itself to for two reasons: first because the sugar that is supposedly exported without subsidies in fact enjoys an indirect cross-subsidization 11 via the sugar which is directly subsidized and secondly it was found that the EU's interpretation of one footnote of the agreement (concerning exports equivalent to the size of the ACP-imports) was wrong (Hoekman and Howse, 2008). Besides, the preferential agreements with the ACP countries do not conform to WTO law in general. On one hand granting preferential access to Least Developed Countries ${ }^{2}$ (LDCs) is explicitly allowed but it is forbidden to discriminate within the group of all developing countries. Within the group of $\mathrm{ACP}$ countries however, there is a growing number of countries which are not 'least developed'. In order to comply, the ACP agreements had to be transformed into Regional Trade Agreements (RTAs), which - again due to WTO law - must be reciprocal.

In order to keep giving trade advantages to the poorest countries on earth and conforming to WTO regulations, the Everything But Arms (EBA) agreement has been introduced in 2001 which gives preferential access to the group of the Least Developed Countries via unlimited zero tariff imports. The introduction of the EBA and the associated great increase of inflows of sugar, i. e. oversupply, augmented the pressure on the CMO already in the time in which the ACP program was still

\footnotetext{
${ }^{1}$ As defined in Tangermann (1997).

${ }^{2}$ The term refers to a group of 48 countries, which are defined by the United Nations Organisation as particularly less developed.
} 
running $3^{3}$ There was no other way for the EU but to lower the intervention price for sugar. The following decrease of the price was tremendous and heavily affected the ACP countries which had profited from the high price before. Preference erosion did occur (Calì et al. 2013).

Sugar is a powerful example to show the negative impacts of the EBA for two reasons: firstly, it is a very intensively traded good: one third of the world production ${ }^{4}$ is sold to the world market. Secondly, the EU sugar market was strongly protected. During the last decade, the domestic price constituted on various times three times the world market price (Conforti et al., 2007). According to studies analyzing the overall impact of preferential trade systems, their impact is - general speaking narrow. This does not mean, however, there are no countries that would not benefit a lot from them (for sugar typical examples include Fiji and Mauritius); hence an approach is called for that focuses on individual countries. The fact that sugar exporters in other countries can profit from the artificially high EU price makes it a very special case. The study of Cipollina and Salvatici (2010) for example explicitly leaves sugar out because it does not fit into their model.

During our analysis we are solving two basic problems, one of theoretical nature and an empirical one: the first is an bias due to omitted variables: in order to account for multilateral resistance (MR) between countries as suggested by Anderson and van Wincoop (2003), we incorporate bilateral fixed effects (Feenstra, 2002). The problem of identification states that if, as in many examples throughout the literature, one or a set of dummies accounts for the policy change under investigation, this might capture other characteristics of the combination of the two countries who signed the Preferential Trade Agreement (PTA; EU and ACP/LDC), too. Another issue of using this kind of dummies is one of collinearity. We are solving the problem of identification by using the 'Preference Margin', a continuous variable to account for the changed policy instead of dummy variables (Cipollina and Salvatici, 2010), as well as by including trade flows of countries which are not affected by the policy changes into the analysis. To take into account the fact that the preferences for sugar are given in the form of tariff rate quotas, an innovative approach for calculating the preference margin is applied (Raimondi et al., 2012).

The abovementioned empirical problem stems from the fact that we are using data on highly disaggregated level (HS6). As we are analyzing the effect of trade preferences, this is to be preferred over aggregated data because the trade preferences are

\footnotetext{
${ }^{3}$ As it turned out however, the sugar inflow did not increase as much as anticipated for two reasons: first was the limited capability of the LDCs to increase their production and secondly the record high sugar price on the world market.

${ }^{4}$ Global production in 2005: 150 million metric tons.
} 
also applied on product level (Anderson and Yotov, 2010). However, these highly disaggregated data also constitute a problem well known in the literature of gravity analysis: the regular occurrence of zero values for the trade flows (Chen and Li, 2014). This is expected to produce biased estimates because the zeros cannot be assumed to be distributed randomly. The problem of 'excess zeros' has been acknowledged by a number of authors, including Cipollina and Salvatici (2007), and especially for the agricultural sector which is a 'micro sector' according to Prehn et al. (2012). During the last years, a lot of progress has been made to tackle this problem (Santos Silva and Tenreyro, 2006, Prehn et al., 2012). However, only few of them (Prehn et al. 2012) address the issue of scale-dependence, i.e. if used for estimating a continuous dependent variable the results depend on the unit chosen. So far, no paper accounts for it in an empirical application. This paper is the first one to make use of the newly developed scale-independent Negative Binomial Quasi Generalised Pseudo Maximum Likelihood Estimator (NB-QGPML, Bosquet and Boulhol, 2014).

In summary, this study builds on most recent data and employs the approach of calculating a Preference Margin (PM) in a way that has been introduced only recently which addresses the issue of identification. It is also the first paper to use the new version of the Negative Binomial QGPML Estimator to solve the problem of scale-dependence.

To the best of our knowledge, this is the first paper empirically assessing the erosion of preferences granted to ACP countries after the introduction of another preferential trade agreement for the example of sugar. As we will show, PE occurred after the adoption of the EBA agreement because of the associated change in the Common Market Organization for sugar, namely the tremendous decrease of the intervention price.

The paper is structured as follows: section two provides the political background and the explanation of $\mathrm{PE}$ while section three is devoted to methodological issues. In section four we describe the data, before presenting results in section five. Section six concludes.

\subsection{Political background}

\section{The EU Sugar Policy in the Global Context}

The sugar market has been amongst the markets in the EU which are subject to greatest regulation. The policy instruments of the Common Market Organization (CMO) concerning sugar had primarily been by a quota system, a high inner Eu- 
ropean intervention price, and a correspondingly strong emphasis on protection against the international market via prohibitive import tariffs (Cardwell, 2004).

The EU enjoys the right to protect its sugar sector so fiercely because it has declared sugar a 'sensitive product' for which the WTO grants exceptions from many rules 5 The exact target value for the intervention price used to be calculated with the aim that the costs of sugar production in the least efficient sugar producing regions of the EU could be covered $\sqrt[6]{6}$ These intervention prices could assume a multiple of the world price (e.g. the triple in 2006).

When the sugar-CMO was introduced in 1968, the initial target was for the EU to become a self-supporter and to sustain the (at that time) key sector of agriculture. In the following decades, the sugar market structure changed fundamentally, featuring most prominently a great increase in mechanization and productivity, accompanied by the centralization into a small number of big companies (Gotor, 2009). At the turn of the century, the EU graduated from a net-importer to a net-exporter, exporting around 4.5 million metric tons 7 This was partly driven by the fact that the intervention prices were up to three times the world market prices, which enabled the EU to become the second greatest exporter of white sugar. To be able to export all that white sugar, subsidies were used 8 The money that the EU spent on protecting the sugar sector (namely paying the export subsidies) amounts to $40 \%$ of total value of all sugar produced by non-OECD countries 9 The domestic supply is controlled via production quotas that are categorised as A-, B-, and Cquotas. While the A-quota limits the production for use in the $\mathrm{EU}$ and is subject to the intervention price minus $2 \%$ and the B-quota sugar is entitled to an export subsidy (the international market price plus the subsidy gives the intervention price minus 37.5\%) 10 The C-' quota' is technically not a quota: it refers to the sugar that is produced additionally to each farm's quota and is getting exported without subsidies. A prohibitive tariff shields the EU from cheaper imports to prevent an oversupply.

During the same time, the EU has also been the fourth greatest importer of raw sugar because of the preferential access which was granted to other countries by a number of PTAs that had been developed parallel to the CMO. WTO legislation

\footnotetext{
${ }^{5}$ Countries have the right to declare a small number of agricultural goods of their choice to be 'sensitive products' for political or historical reasons.

${ }^{6}$ In 2009 the price that factories received was 631.90 Euro/ton for white sugar and 523.70 Euro/ton for raw sugar while the price for sugar beet was 47.00 Euro/ton for A-quota sugar and 32.00 Euro/ton for B-quota sugar (Gotor, 2009).

${ }^{7}$ Since 2011 , the EU is a net importer again.

${ }^{8}$ See below for a detailed description of the quota system.

${ }^{9}$ All numbers of this paragraph were taken from Hoekman and Howse (2008).

${ }^{10}$ The $2 \%$ and $37.5 \%$ that are subtracted are used to finance the export-subsidies.
} 
allows PTAs to be established between countries of different stages of economic development and grant agents in poor countries cheaper or tariff-free access to the markets of relative rich countries. These preferences are only of value if markets are protected strongly: if they are liberalized or the global price equals the domestic one, the advantages from preferences are limited (Conforti et al., 2007).

Thus, preferential market access is essential for a great number of sugar producing countries. The most important PTAs were a series of agreements with the African, Caribbean, and Pacific (ACP) countries. When the European Union was funded, many of its initial members had these kinds of agreements in place with their former colonies, accounting for traditional trade relations. With the founding of the EU these preferences were bundled within the Generalized System of Preferences (GSP). One annex, called Sugar Protocol (SP), granted tariff-free access within a certain quota to 19 ACP countries and India and are of enormous value to them (Conforti et al., 2007).

One critical issue of the preferences to ACP countries is the fact that they were not in line with the agreements made in the WTO's Uruguay negotiation round: while it is allowed to grant preferences to LDCs, the selection of the 19 ACP countries rather represent former colonial ties between the EU member states and these countries. As most of these countries are not least, and some not even 'less developed', this agreement could not be continued. Instead it was planned to transform it into several RTAs, the so-called Economic Partnership Agreements (EPAs) of the EU. They are, also following WTO rules, reciprocal.

It was also within the PTA framework that the Everything But Arms (EBA) agreement was initiated in 2001. The target was to be further able to give preferential access to poor countries without violating WTO law 11 It guaranteed for the group of the Least Developed Countries unlimited, tariff-free access to the European market for all goods except arms and ammunition.

With the EBA, a big further supply of sugar on the EU market was expected, as a few of these countries possess a great comparative advantage in sugar production. This tightened a conflict with other sugar producing member states of the WTO: as a result of the Uruguay negotiation round (1995) the EU agreed to a maximum of subsidised sugar exports of 1.2735 millions of tons of sugar within the B-quota per year. In 2004 however, the WTO court found that the EU subsidised the export of much more sugar than it had committed itself to (Hoekman and Howse, 2008). The successful arguments of the suing countries Australia, Brazil, and Thailand claimed

\footnotetext{
${ }^{11}$ On the sixth WTO ministerial conference in 2005, non-reciprocal schemes of preferential access were formally agreed to be tolerated.
} 
that this exaggerated subsidization of exports arose for two reasons: the C-sugar that was not supposed to receive subsidies had been 'cross-subsidized' via the Aand B-subsidies. This resulted in 2.8 millions of tons which 'should be treated as subsidized exports and be subject to reduction commitments' (Gotor, 2009). Secondly, the EU's interpretation of a footnote in the Uruguay Round's results was found to be incorrect: the EU claimed that the sugar entering the EU under the PTAs with ACP countries (and is then re-exported) should not be included in the sum of exports which were subsidized. Both the WTO Panel and the Appellate Body rejected this understanding. The two factors combined lead to an export of 4.1 millions of tons of subsidized sugar in 2001, which constitutes 2.8 millions more than the EU had committed itself to (Chaplin and Matthews, 2006) 12

Thus, as the EU exported already more than that amount, the expected increase of the sugar supply due to the implementation of the EBA had to be compensated. This is why sugar was classified as one of the rare exceptions to the EBA: imports were not fully liberalized right away, but was delayed by four years to come into effect. Then duty-free quotas were introduced which gradually increased until 2009 since when there are no more quantitative restrictions.

But on a longer perspective, only one solution was possible: a tremendous reduction of the intervention price. From 631.9 Euro/ton in 2004 and before, it was gradually reduced to 404.4 Euro/ton in 2009 (see Figure 4.1). An overview of the evolution of EU sugar policies is provided in Table 4.1 .

\section{The Erosion of Preferences}

This affected not only the European farmers, but also another group that had profited from the protected European sugar market before: the countries from the ACP region. These countries were signatories of a series of PTAs with the EU, starting in the 1960's. Two sub-agreements which ruled their imports of sugar need consideration here, namely the SP and Special Preferential Sugar (SPS). Both gave a tariff-free quota to the ACP countries (plus India), which potentially improved the welfare of a few of them. A prominent example is Mauritius which used to highly depend on the preferential sugar export for decades: $90 \%$ of its sugar exports went to the EU.

This process of the reduction in the advantages from preferences is called preference erosion. When predicting the outcomes on the affected countries, a differentiation within this heterogeneous group is essential: an ACP country faced a cut in prices which would definitely result in a welfare loss (see Figure $4.2 \mathrm{a}$, the red shaded area

\footnotetext{
${ }^{12}$ Figures from 2001; taken from Hoekman and Howse (2008).
} 
Figure 4.1: Price development.

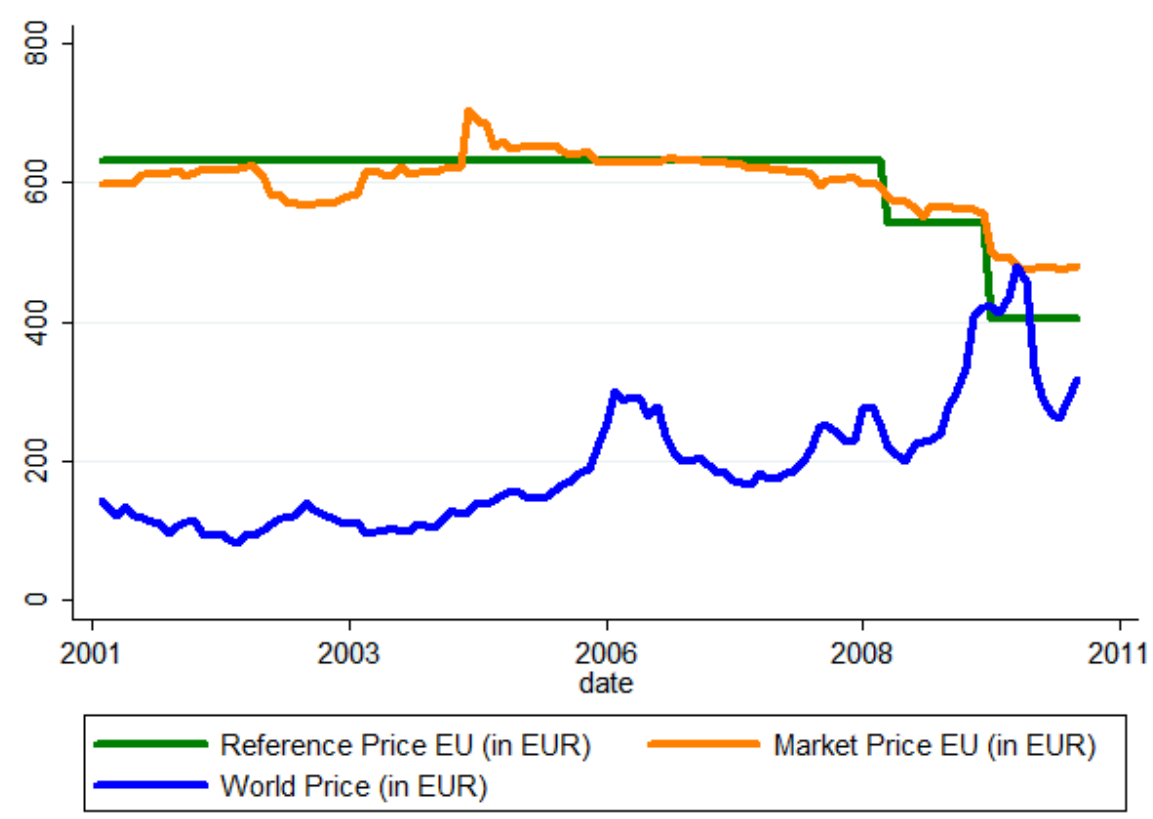

Source: own calculations.

Figure 4.2: Welfare effects of policy changes.

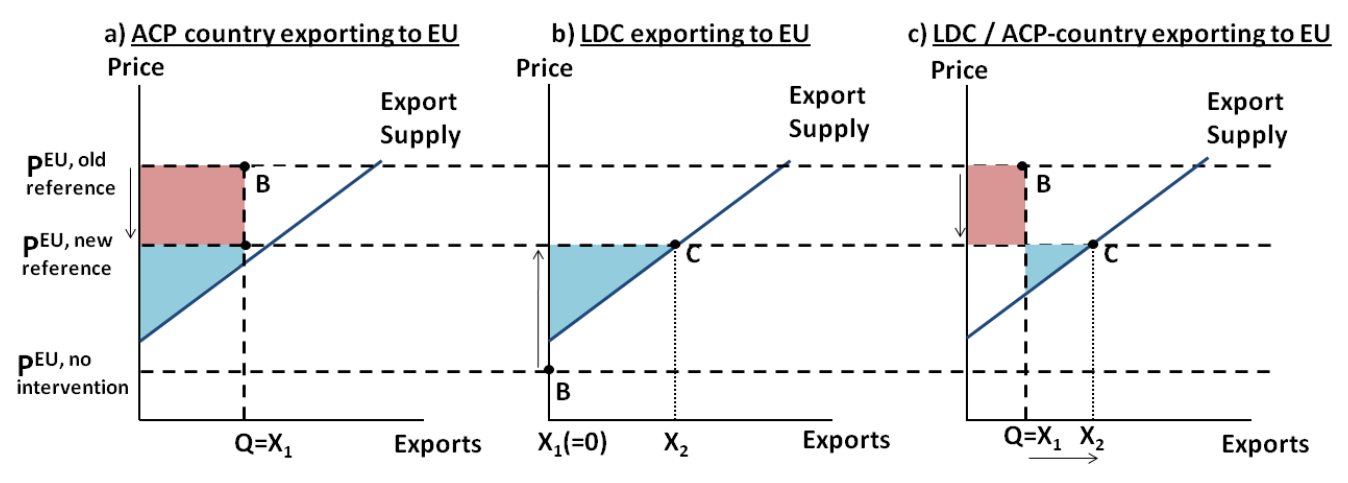

Source: own draft.

indicates the welfare loss). An LDC on the other hand is predicted to unambiguously profit from the EBA, because it has now access to a market with a price which is considerably higher than the one obtained on the world market (see Figure $4.2 \mathrm{~b}$, the blue area represents the welfare gain). For countries that are both signatory of the EBA and the SP/SPS the expected impacts are ambiguous: as they had already been able to sell at the European price before, the decrease in the price means a loss in profit for every ton of sugar sold. Meanwhile they face no more quantitative restrictions and can thus export more sugar to the Union which might 
overcompensate the losses from the lower price (see Figure 4.2 , the red shaded area is the welfare loss, the blue one the gain) 13

Table 4.1: Development of EU sugar policies.

Time Event

1968 Introduction of CMO for sugar (intervention price, import tariffs, quota system)

1968 GSP, incl. SP

2001 EBA introduction (sugar, rice, bananas exempted)

2004 WTO ruling against EU

2005 EBA starts to include tariff free quotas for sugar (gradually increases during the subsequent four years)

2008 Reduction of intervention price

2009 EBA valid for all products
Parties affected

EU producers and consumers, world price

ACP producers

LDC producers

EU governments

LDC producers

$\mathrm{EU}, \mathrm{ACP}$, and

LDC producers

EU consumers

LDC producers

Source: own production.

\subsection{Methodological issues}

\section{Estimation strategy}

The erosion of preferences can be caused by three factors: a shrinking of the quota which a country is allocated a preferential tariff for, an increase of the preferential tariff rate, or a decrease of the price that is paid. Concerning the preferential admission to the sugar market for ACP countries, the quota allocations stayed rather constant, and the preferential tariff was always zero. It is the fixed price within the Union that has decreased.

Since at the time of the introduction of the EBA the EU's CMO was altered in parallel (see Table 4.1 and Figure 4.1), disentangling the effects of all policy changes poses a challenge for the empirical analysis. In order to find empirical evidence

\footnotetext{
${ }^{13}$ It is possible that traders speculate in anticipation of the increased export opportunities of Least Development Countries due to the EBA and the associated end of export restrictions. However, the data do not indicate this. During the timeframe under consideration, the stocks of sugar in the LDCs did constantly decrease. This can be explained by the high costs of sugar storage due to the risk of agglutination in relation to its price per volume. (For this reason, most agricultural commodities are not suited for speculative storage.) In the countries under consideration, storage facilities are generally not great, which makes speculative storage of varying quantities difficult. Speculation would also require speculative capital, which is difficult to find in LDCs, due to imperfect capital markets (not that the sugar would have to be kept in the respective country in order to fulfill the rules of origin at the time of selling). What countries do is 'strategic storage' of constant quantities in order to ensure security of supply. This is, however, independent of the price.
} 
for the theoretically expected impacts, we firstly calculate the Preference Margin $(P M)$. The $P M$ is then included in a gravity model that is specified to predict the trade flows of sugar to the EU from all its trading partners. The participation of LDCs in the EBA scheme is indicated by the dummy $D_{-} e b a$ that takes the value one for the participating countries and zero for non-participants 14 The participation in the SP scheme is also captured by dummies. In this case, however, two dummies are employed in order to account for the reduced value of the preferences after 2007: D_sp_until_2007 is one if a country has signed the SP (or the SPS) and if the observation is made in the years until 2007. D_sp_after_2007 becomes one for SP (and SPS) signatories for observations from 2008 onwards. The interaction terms PM_eba, PM_sp_until_2007, and PM_sp_after_2007 were added to distinguish between the effect of the $P M$ on the different groups 15

\section{Preference Margin}

Most studies that analyse the impact of certain policies on trade values via gravity models based on panel data use dummies to capture the effect of the policy (e.g. Baldwin and Taglioni, 2007). It makes sense, however, to capture the effect of our interest, the changing policies manifested in the CMO, not only by the means of dummy variables that indicate whether a country did or did not sign a certain agreement. This would not account for the differences in how extensively a country makes use of their quotas, and might also capture other effects, resulting in endogeneity problems. The reason is that in many cases the fixed effect dummies (see below) are collinear with the policy dummies (Cipollina et al., 2013), i.e. it captures other effects that are caused by the relationship of the two countries that are connected by the PTA. In order to control for this, we add a continuous policy variable, called Preference Margin, an approach initially suggested by Carrère et al. (2010). Various methods were developed by different authors for calculating the $P M$ and been applied to various scenarios. One possible approach for calculating the $P M$ has been suggested by Nicita (2011) who develops one relative and one potential PM. Other methods have been employed by Cipollina et al. (2014), Fugazza and McLaren (2014), and Nicita and Rollo (2013). However, since their approaches require data that are difficult to achieve (such as on countries' import demand elasticities), and for the disadvantage of not accounting for non-fulfillment of quotas, we employ the measure introduced by Raimondi et al. (2012). These

\footnotetext{
${ }^{14} \mathrm{~A}$ discussion on why policy dummies are required despite the use of the $P M$ is provided in the next section.

${ }^{15}$ This specification was chosen in order to account for all possible interdependencies between the policy variables (the PM and dummies indicating membership in the LDC- and ACP-groups). In order to demonstrate the robustness of the other estimates against changes in the interaction terms, Appendix 2 shows the results of all other possible interactions.
} 
authors develop the $P M$ as suggested by Carrère et al. (2010) further to account for preferences that are given in the form of tariff rate quotas, and explicitly include the possibility of out-of-quota imports, i.e. for situations in which countries export more sugar than they get allocated within their quota. The $P M$ is therefore calculated following Raimondi et al. (2012) who also assume economies of scale in the exporting countries:

$$
P M_{j}^{k}=\gamma \frac{\left(T_{M F N}^{k}-T_{j \text { in }}^{k}\right)}{1+T_{j \text { in }}^{k}}+\lambda \frac{T_{M F N}^{k}-\frac{\left(T_{j \text { out }}^{k}\left(Q_{k j}-\bar{Q}_{k j}\right)+T_{j i n}^{k} \bar{Q}_{k j}\right)}{Q_{k j}}}{1+\frac{\left(T_{j o u t}^{k}\left(Q_{k j}-\bar{Q}_{k j}\right)+T_{j i n}^{k} \bar{Q}_{k j}\right)}{Q_{k j}}}
$$

$Q_{k j}$ indicates the export quantity of country $j$ in year $k$ and $\bar{Q}_{k j}$ the quota. For the time at which all LDCs got unlimited tariff free access to the European market, the quotas were set to their actual exports into the EU. $T_{M F N}^{k}$ refers to the MFN tariff the EU is applying in year $k$. As the MFN tariff has always been prohibitive, we calculated the applied tariff as the percentage difference between $p^{\text {World }}$ and $p^{E U}$. This procedure has been suggested by Cipollina and Salvatici 2010 in order to not over-estimate the $P M . T_{M F N}^{k}$ therefore accounts for the reduced value of preferences caused by the lower intervention price. $T_{j \text { in }}^{k}$ stands for the in-quota tariff while $T_{j \text { out }}^{k}$ represents the out-of-quota tariff. $\gamma=1$ if $Q_{k j} \leq \bar{Q}_{k j}$ and $\lambda=1$ if $Q_{k j}>\bar{Q}_{k j}$. Both take the value zero otherwise. Since $T_{j \text { in }}^{k}$ is always zero in our analysis and $T_{j \text { out }}^{k}$ is equal to $T_{M F N}^{k}$, the equation can be simplified to

$$
P M_{j}^{k}=\gamma T_{M F N}^{k}+\lambda \frac{T_{M F N}^{k}-\frac{\left(T_{M F N}^{k}\left(Q_{k j}-\bar{Q}_{k j}\right)\right)}{Q_{k j}}}{1+\frac{\left(T_{M F N}^{k}\left(Q_{k j}-\bar{Q}_{k j}\right)\right)}{Q_{k j}}}
$$

The Preference Margin has been calculated according to equation (4.2). The developments of the $P M$ in each ACP country are displayed in Figure $4.3^{16}$ As the EU price deteriorated from 2008 onwards due to the EBA, the existing preferences of the non-EBA countries decreased in value. However, since the world price has steadily increased during the time of our analysis (exception: 2006) (see Figure 4.1), the $P M$ has already declined before 2008. The decline in $P M$ values after 2008 is therefore caused both by the reduced EU intervention price, and the increased international price ${ }^{17}$ In order to disentangle the effect, the dummies indicating

\footnotetext{
${ }^{16}$ For the purpose of illustrating the development of the preferences for ACP countries, we added $100 \%$ since the $P M$ is only the percentage difference 'between the tariff faced by an MFN exporter and the tariff faced by the preferred country' (Raimondi et al., 2012). This is the form in which it enters the regression, also following Raimondi et al. (2012).

${ }^{17}$ The fluctuation in the years before are owed to the fact that the SPS quotas were not constant over time, which meant that some countries every now and then over-exhausted their allocated quota (e.g. Kenya in 2001, 2003, and 2005 or India from 2001 to 2003).
} 
the EBA and SP membership are included in the regression.

Figure 4.3: Development of $P M$ in ACP countries.

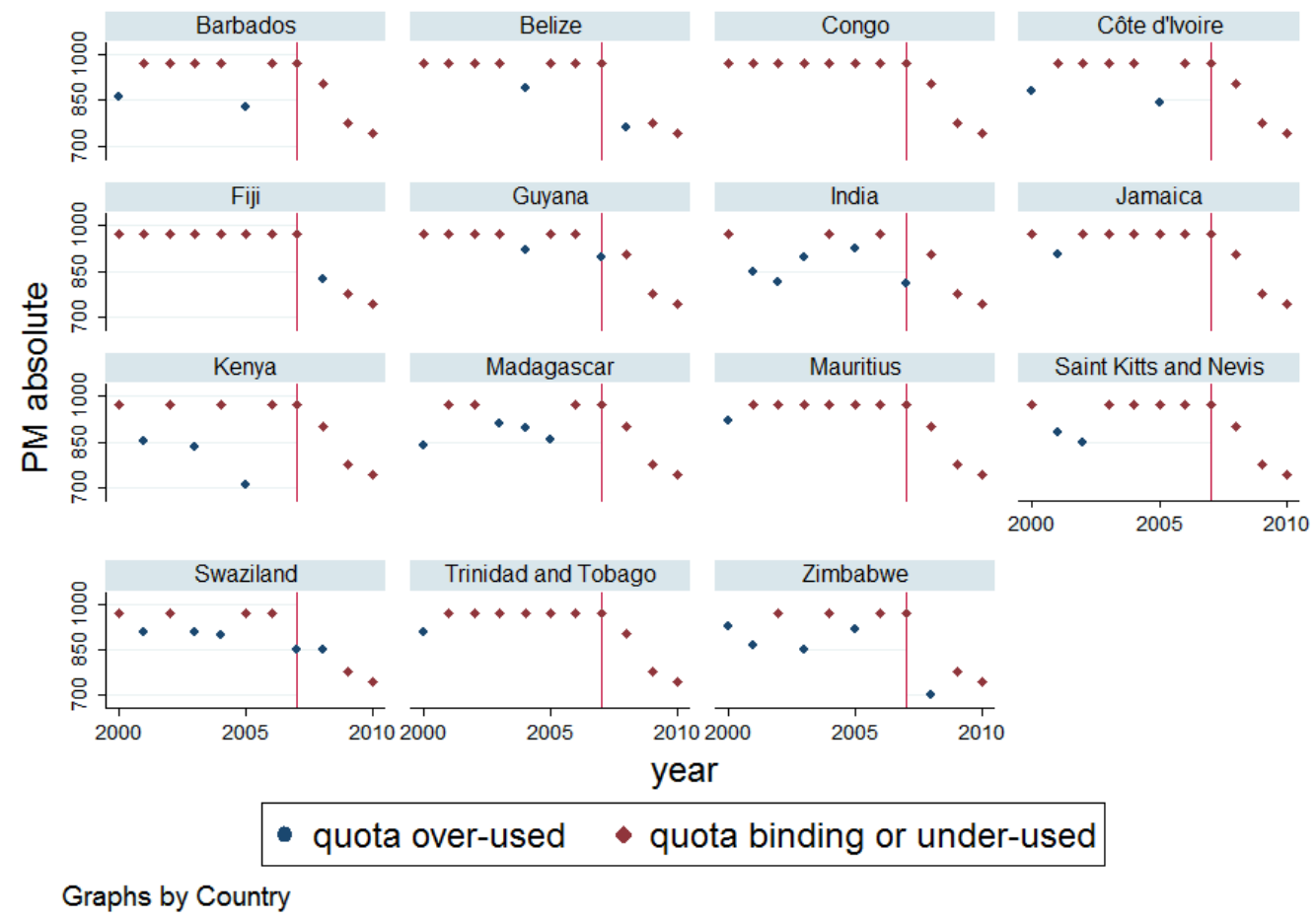

Source: own calculations.

\section{Gravity Model}

For showing the importance of preferences for countries exporting sugar to the EU, and that the value exported by ACP countries declined tremendously after the 2007 policy changes, a gravity model is employed. The gravity model had firstly been introduced by Jan Tinbergen (1962). It is based on the Newtonian gravity equation in physics, which expresses the gravitational force between two bodies as the product of their masses over the squared distance between them. In economical applications the physical mass of bodies is translated into a country's GDP and the physical distance proxies the trade costs of moving a product from country $i$ to $j$. The basic form commonly employed in the literature is given in its logarithmic form by

$$
\ln V_{i j}^{k}=\beta_{0}+\alpha_{1} \ln G D P_{i}^{k}+\alpha_{2} \ln G D P_{j}^{k}+\alpha_{3} \ln d i s t_{i j}+\varepsilon_{i j}^{k}
$$

with $V_{i j}^{k}$ representing the bilaterally traded value from country $i$ to $j$ in year $k$, 
$G D P_{i}^{k}$ and $G D P_{j}^{k}$ referring to their respective economic 'weight', and $d i s t_{i j}$ the distance between them.

The variables of our interest include the Preference Margin (assuming economies of scale) $P M_{i}^{k}$ and the dummies representing the policy changes in the sugar market. They refer to the introduction of EBA for the LDCs, and the associated erosion of preferences for sugar protocol signatories from 2008 onwards. The following set of dummies is constructed: $d_{-} e b a_{i}^{k}$ is set to unity if the country receives preferences within the EBA agreement. d_sp_until_2007 ${ }_{i}^{k}$ assumes the value one if the country belongs to the ACP group if the observation stems from 2000 to 2007, and $d \_s p \_a f t e r \_2008_{i}^{k}$, if later. Finally, we add cross-terms by multiplying $P M_{i}^{k}$ with the abovementioned dummies (yielding d_PM_eba ${ }_{i}^{k}, d_{-} P M_{-} s p_{-} u n t i l_{-} 2007_{i}^{k}$ and $d \_P M \_s p \_a f t e r \_2008_{i}^{k} 18$

Since we focus on one subsector in agriculture (sugar), proxying the exporter's economic size via the GDP would lead to biased estimates. Instead we use the annually produced sugar quantity $\left(\operatorname{sugarprod}_{i}^{k}\right)$.

Multilateral Resistance Terms (MRTs) gained their first credit after being introduced by James E. Anderson (1979). In the last decade they played a crucial role when the 'Border Puzzle' was solved. The puzzle is that intra-country could be observed to be larger than inter-country trade in many instances which could initially not be explained. Anderson and van Wincoop (2003) propose to include the MRTs in an explicit form. The MRTs refer to the level to which every single country is reluctant to trading. Bilateral trade flows are accordingly not only influenced by barriers that exist between the two, but also on the economic integration of each of them with the rest of the world. The exporter-specific effects thus capture the general trading regime of countries towards all their trade partners. Since the MRTs cannot be observed, they are captured via Fixed Effects (FEs), as suggested by Feenstra (2002). The dummies exporter ${ }_{j}$ (respectively importer ${ }_{i}$ ) are set to one if the exporter is $j$ (respectively importer is $i$ ). Since we are focussing exclusively on mono-directional trade flows (namely into the EU), the dummy importer $_{i}$ would always assume the value zero which is why it is left out of the equation.

This also means that the multilateral resistance terms and the country FEs are equivalent to each other and can be condensed therefore into one single variable. In effect, country Fixed Effects are employed to capture the bilateral Fixed Effects.

\footnotetext{
${ }^{18}$ It was also experimented with including the cross-terms for countries that were signatories of both the SP and EBA agreement (also differentiated by _until_2007 and _after_2007), but as there are only four countries in this category the results became rather irrelevant. They can be made accessible on demand. The use of cross-terms of indicator and continuous variables which divide continuous variables into 'blocks' to differentiate between treatment and non-treatment groups is explained by Bates and Watts, 1988
} 
This procedure has also been exercised, for example, by Agostino et al. (2010). Since the the exporter dummies capture all time invariant country characteristics, including the geographical distance to the EU, ln dist ${ }_{i j}$ does not enter the estimation.

Year dummies are capturing global macroeconomic shocks which affect all concerned trading partners similarly. As only mono-directional trade-flows into the $\mathrm{EU}$ are entering this analysis, these time dummies capture the economic size (i. e. sugar production in this case) of the EU which can thus be dropped.

The model is augmented as follows in order to control for other determinants of trade flows whose omission could lead to biased estimates: the polity variable refers to the political system existing in the exporting country. This variable's inclusion has been suggested by Agostino et al. (2010) and ranges from -10 ('autocracy') to +10 ('democracy'). Adding the exchange rate between the trading partners is also common practice in the gravity literature, because currency depreciation gives the exports of a given economy a more competitive position in the rest of the world since they become cheaper Anderson and Van Wincoop, 2003) 19 The gravity model to be estimated is specified as follows:

$$
\begin{aligned}
\ln V_{i j}^{k}= & \beta_{0}+\alpha_{1} D \_e b a_{i}^{k}+\alpha_{2} D \_s p \_u n t i l_{\_} 2007_{i}^{k}+\alpha_{3} D \_s p \_a f t e r \_2007_{i}^{k} \\
& +\alpha_{4} \ln P M_{i}^{k}+\alpha_{5} \ln P M_{-} e b a_{i}^{k}+\alpha_{6} \ln P M_{-} s p \_u n t i l_{-} 2007_{i}^{k} \\
& +\alpha_{7} \ln P M_{s} s p \_a f t e r \_2007_{i}^{k}+\alpha_{8} \ln \text { exrate }_{i}^{k}+\alpha_{9} \ln \text { sugprod }_{i}^{k} \\
& +\alpha_{10} \text { polity } y_{i}^{k}+\sum_{i=1}^{I}\left(\gamma_{i} \text { exporter } i\right)+\sum_{k=1}^{K}\left(\delta_{k} \text { year }_{k}\right)+\varepsilon_{i}^{k}
\end{aligned}
$$

$V_{i j}^{k}$ represents the mono-directional trade flows of sugar from country $i$ into the EU; the most important exogenous variables are the variables that capture the policy, as described above. Sugprod ${ }_{i}^{k}$ stands for the size of the sugar sector of the exporter; polity $_{i}^{k}$ is an index for the political system and exrate ${ }_{i}^{k}$ controls for the exchange rate. exporter ${ }_{i}$ is the fixed effect dummy that captures the constant characteristics of every country; year $_{k}$ captures general macroeconomic shocks and $\varepsilon_{i}^{k}$ is the error term.

The equation does not include some terms that are commonly used throughout the gravity literature, such as 'colonial ties', 'common language', 'common boarder', 'common language' and the like. The challenge that this application faces is that the EU is considered as a single trading partner, but comprises a great diversity

\footnotetext{
${ }^{19}$ It was experimented with various other natural or manmade time-variant barriers that could influence the TCs, such as the KOF index of globalization, the population share of secondary students enrolled, the length of telephone lines per 100 people, indices on the rule of law, government effectiveness, economic freedom, and corruption, but there was too little variation in the series as to produce significant estimates.
} 
in languages. Besides that, the great majority of colonising activities have been exercised by current EU members on the terrain of current LDCs. Including these variables would result in perfect collinearity.

\section{Estimation Techniques}

Santos Silva and Tenreyro (2006) have shown that the until-then commonly used OLS estimator is unsuitable for estimating trade flows in gravity estimations. The problem is that gravity models are usually specified in a logarithmic form 20 Besides that, trade data on a highly disaggregated level (as it is the case in our data) includes excess zero-values. Out of the 850 observations in our sample, 192 $(23 \%)$ take the value zero. Some authors just drop the observations which are zero, others use $\ln \left(V_{i j}+1\right)$ as the dependent variable. But as a zero-value is likely to be the true result of an economic decision, both approaches will consequently produce biased estimates (Cipollina and Salvatici, 2007). Prehn et al. (2012) emphasize the effect especially for the agricultural sector because of the highly disaggregated data commonly used in these types of analyses. Alternatively, Santos Silva and Tenreyro (2006) suggest using the Pseudo Maximum Likelihood estimator instead (PML), developed by Gourieux et al. (1984). They suggest assuming either a Poisson distribution (PPML) or a Gamma distribution (GPML). In recent years the Negative Binomial Quasi Generalised PML (NB-QGPML), which converges towards the Poisson- and Gamma-Distributions, has been increasingly used, for example by Head et al. (2009) and Westerlund and Willhelmsson (2011). This procedure estimates the gravity model in two steps, with firstly estimating a dispersion parameter. However, this estimator has shown to be scale-dependent: Bosquet and Boulhoul (2014) show that if the NB-QGPML is applied to data with a continuous dependent variable, the size of the dispersion parameter depends on the unit chosen for the dependent variable, i.e. whether the dependent variable is measured for example in dollars or thousands of dollars. If the chosen unit is large (like thousands or millions), the NB-QGPML converges towards the GPML, while it converges towards PPML if the unit is small (e.g. dollars). As Bosquet and Boulhoul (2014) prove, the problem in the traditional NB-QGPML estimation is that the first-step equation is constrained by implicitly relying on the nominal variance assumption. They solve this problem by relying on the GLM variance assumption when constructing their version of the NB-QGPML estimator (henceforth NB-QGPML ${ }^{G L M}$ ). This means that the conditional variance is assumed to be a linear combination of the conditional mean and the square of the conditional

\footnotetext{
${ }^{20}$ The problem stems from Jensen's inequality, which states that the log of the expected value is unequal to the expected value of the log.
} 
mean ${ }^{21}$ Hence we estimate the model as depicted in equation (4.4), without taking the logarithm of the dependent variable. The qualities of the three estimation procedures are compared to each other via the McFadden Pseudo $R^{2}$. The final model to be estimated is given in equation (4.5).

$$
\begin{aligned}
V_{i j}^{k}= & \exp \left(\beta_{0}+\alpha_{1} D \_e b a_{i}^{k}+\alpha_{2} D \_s p \_u n t i l \_2007_{i}^{k}+\alpha_{3} D \_s p \_a f t e r \_2007_{i}^{k}\right. \\
& +\alpha_{4} \ln P M_{i}^{k}+\alpha_{5} \ln P M_{-} e b a_{i}^{k}+\alpha_{6} \ln P M_{-} s p \_u n t i l_{-} 2007_{i}^{k} \\
& +\alpha_{7} \ln P M_{-} s p \_a f t e r \_2007_{i}^{k}+\alpha_{8} \ln \text { exrate } e_{i}^{k}+\alpha_{9} \ln \text { sugprod } \\
& \left.+\alpha_{10} \text { polity }_{i}^{k}+\sum_{i=1}^{I}\left(\gamma_{i} \text { exporter }{ }_{i}\right)+\sum_{k=1}^{K}\left(\delta_{k} y e a r_{k}\right)+\right) * \varepsilon_{i}^{k}
\end{aligned}
$$

\subsection{Data}

The sizes of the allocated quota per country for calculating the $P M$ were provided by the EU commission. The quotas are defined on a yearly basis from July to June due to the European sugar season. We denoted for example '2001' to the time span from July 1st 2001 to June 31st 2002. The MFN tariff comes from the WTO database. The dependent variable of the regression analysis, sugar imports to the EU (HS code 1701-11: 'raw sugar not containing added flavouring or colouring matter') were drawn from the Eurostat database ${ }^{22}$ These monthly data were aggregated in a way to represent the sugar year in which the quotas are allocated (July until June of the following year). As suggested by the theory above, it looks like the total sugar exports from ACP countries to the EU decreased, while the impact on countries that signed the EBA is not obvious (see Figure 4.4). The data required for constructing the policy dummies were gathered from the EUR-Lex database which provides all EU legislation, commission reports, and so on. Data on sugar production ('sugar, centrifugal', scale: 1 ton) were taken from FAOstat. The exchange rate enters the estimation as 'PPP conversion factor (GDP) to market exchange rate ratio' which is the ratio between the PPP conversion factor and the exchange rate. It accounts for the differences of prices for a representative bundle of goods and services between the country under consideration and the US. These data were extracted from the World Bank database 'World Development Indicators'. In order to create a benchmark against which the policy changes are to be measured, our panel database does not only include the countries that signed any PTA with

\footnotetext{
${ }^{21}$ On the website of Clément Bosquet, the STATA code for the estimator is provided: https: //sites.google.com/site/clementbosquet/supplemental-material.

${ }^{22}$ The EU is treated as one single country in the model because of the legislative framework which governs the sugar sector (the Common Agricultural Policy). It constitutes one single integrated market where stakeholders in each member state operate within the identical institutional framework. For the empirical analysis this should not introduce a bias, since it is the effect on third countries that are under consideration.
} 
the EU but also every country that has exported sugar in the respective years, as suggested by Hornok (2011) ${ }^{23}$ Our analysis considers the time beginning in the sugar year 2000/2001 and ending when the intervention price did not play a great role anymore because the international prices outperformed the EU reference price: 2010/2011 (see Figure 4.1).

Figure 4.4: Aggregate exports in millions of Euros.

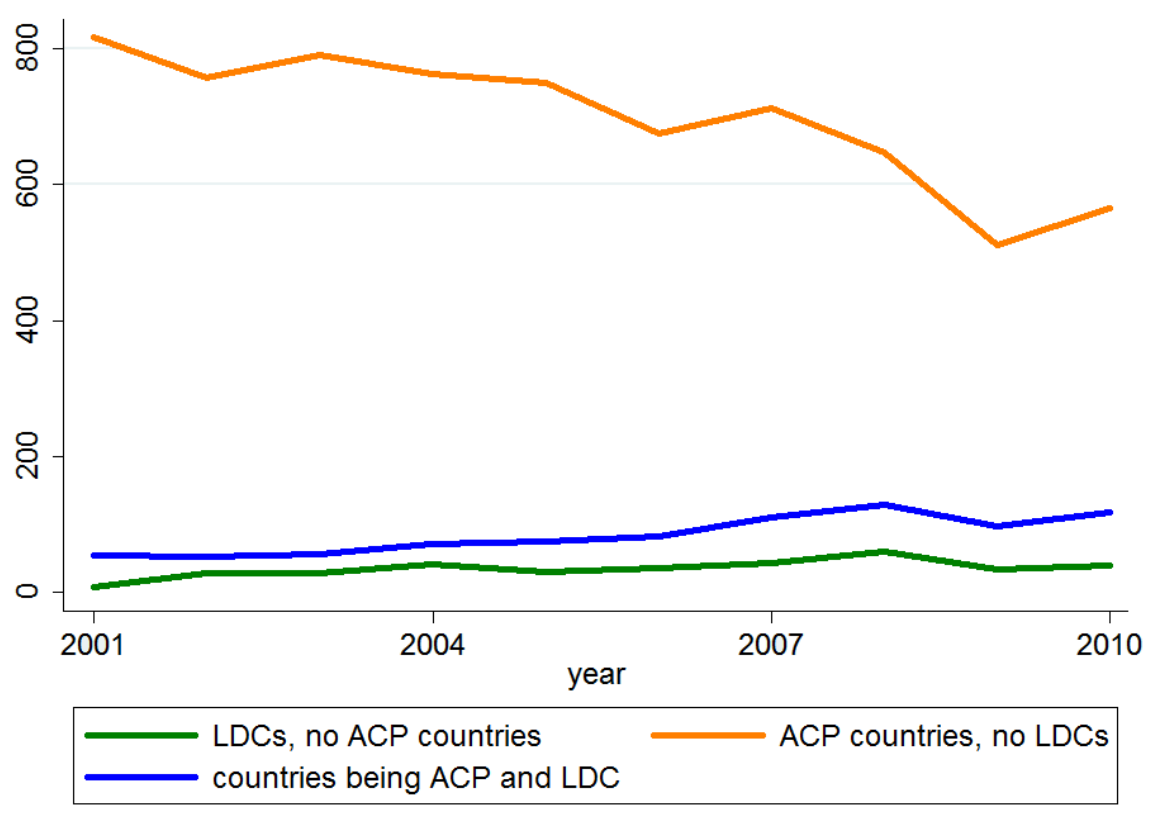

Source: own calculations.

\subsection{Results and interpretation}

Column 1 of Table 4.2 shows the coefficients of a PML estimation assuming a Gamma distribution and the estimation of column 2 assumes a Poisson distribution. Results of the NB-QGPML ${ }^{G L M}$ are reported in column 3. The results generated with the NB-QGPML ${ }^{G L M}$ lie closer to the results of the estimator assuming a Gamma distribution (column 2) than to the ones generated assuming the Poisson

\footnotetext{
${ }^{23}$ The countries that exported less than ten tons during the timeframe under consideration were excluded from the analysis in order to eliminate a potential source of errors in the data, as well as outliers which export for example very small quantities of a highly differentiated product, since the target of the analysis is to find general evidence for the homogenous product sugar. The decision for ten tons as the minimum for being considered as a commercial producer is arbitrary, of course. However, the results of the estimation are robust to changes of this value (if 100 (1000) tons are taken as a minimum, the number of observations decreases from 850 to 783 (634), and if no minimum is set it increases to 940). A list of all countries entering the regression, including their status as EBA and/or SP signatory are provided in the Appendix.
} 
Table 4.2: Estimation results.

(1)

(2)

(3)

\begin{tabular}{lccc} 
Exogenous Variables & PML-Gamma & PML-Poisson & NB-QGPML \\
\hline & & & \\
D_eba & $4.856^{* * *}$ & $1.732^{* * *}$ & $1.756^{* * *}$ \\
& $(0.001)$ & $(0.001)$ & $(0.001)$ \\
D_sp_until_2007 & $-3.674^{* *}$ & $-2.549^{* * *}$ & $-2.563^{* * *}$ \\
& $(0.035)$ & $(0.001)$ & $(0.001)$ \\
D_sp_after_2007 & $-5.959^{* * *}$ & $-3.217^{* * *}$ & $-3.210^{* * *}$ \\
& $(0.001)$ & $(0.001)$ & $(0.001)$ \\
log_PM & $2.429^{* * *}$ & $0.691^{* * *}$ & $0.723^{* * *}$ \\
& $(0.003)$ & $(0.007)$ & $(0.004)$ \\
log_PM_EBA & -1.454 & $-0.512^{* *}$ & $-0.524^{* *}$ \\
& $(0.316)$ & $(0.018)$ & $(0.019)$ \\
log_PM_SP_until_2007 & $-2.303^{* * *}$ & $-0.660^{* * *}$ & $-0.692^{* * *}$ \\
& $(0.007)$ & $(0.005)$ & $(0.007)$ \\
log_PM_SP_after_2007 & -1.383 & -0.161 & -0.539 \\
& $(0.172)$ & $(0.686)$ & $(0.203)$ \\
log_exrate & 0.0223 & $-0.264^{* * *}$ & $-0.229^{* * *}$ \\
& $(0.984)$ & $(0.001)$ & $(0.001)$ \\
log_sugprod & 3.637 & $0.853^{* * *}$ & $0.780^{* * *}$ \\
& $(0.638)$ & $(0.001)$ & $(0.001)$ \\
polity & -0.0103 & $-0.0257^{* * *}$ & $-0.0180^{*}$ \\
& $(0.909)$ & $(0.002)$ & $(0.056)$ \\
Constant & -34.9 & $6.219^{* *}$ & $7.196^{* * *}$ \\
& $(0.756)$ & $(0.016)$ & $(0.008)$ \\
Observations & & & \\
McFadden Pseudo $R^{2}$ & 850 & 850 & 850 \\
\hline & 0.22 & 0.96 & 0.97 \\
\hline
\end{tabular}

Robust pval in parentheses

Standard errors adjusted for 84 clusters in countryNR $* * * \mathrm{p}<0.01,{ }^{*} * \mathrm{p}<0.05,{ }^{*} \mathrm{p}<0.1$

Coefficients of year- and country-dummies are not reported but can be made available upon request.

distribution (column 1), which indicates that over-dispersion is not strong 24 . The following interpretation is based on the estimates from the supposedly most efficient estimator, the NB_QGPML ${ }^{G L M}$ in column 3, which has the highest Pseudo $\mathrm{R}^{2}$ value.

The dummies that indicate the signature of the EBA and the SP need to be interpreted in combination with the constant. They are always above zero and significant at a level of $1 \%$. The SP members however performed worse in term of sugar

\footnotetext{
${ }^{24}$ Dispersion parameter $=3.352 \mathrm{e}-08$.
} 
exports to the EU than the average during the timeframe under consideration. This can be explained by the relatively good starting position at the beginning of the decade. From then on, they faced no increase in their quotas, but decreasing EU prices and an increasing world price. The LDCs' position, on the other hand, has improved during this time.

In order to assess the hypothesis that preference erosion has occurred, the effect of the preferences which were granted during the period until 2007 has to be compared to the following period. In order to do so, we calculate the difference between the average, ceteris paribus effects of the preferences for $\mathrm{ACP}$ countries in both periods $\operatorname{diff}_{c p}{ }^{25}$. The calculation of the actual effect of the dummy variables is based on Santos Silva and Tenreyro (2006).

$$
\operatorname{diff}_{c p}=\left(\exp \left(\alpha_{2}-\alpha_{3}\right)-1\right) * 100 \%
$$

The result of equation 4.6 is $91.0 \% \sqrt{26}$ The advantage obtained from the preferences granted to ACP countries has been larger for the time until 2007 than after. Before the regime switched in $2007 / 2008$, the effect from being a signatory of the SP was 91.0 percentage points higher than afterwards, which means that preference erosion has occurred. One important factor contributing to this high value is the reduction of the intervention price. After the introduction of the EBA, the ACP countries were indeed negatively affected.

The overall effect of the $P M$ has to be interpreted together with the interaction terms, too. Summing the coefficients up indicate a positive overall effect of preferences, as expected (Equations 4.7 and 4.8) ${ }^{27}$ However, the role the PM played for the LDCs and ACP countries was below-average, as $\alpha_{5}$ and $\alpha_{6}$ are below zero. LDCs and ACP countries react less elastic to changes in the preferences they receive, compared to non-members who have preferences for other reasons. One possible explanation is that in ACP countries and LDCs the sugar is produced from sugar cane, a perennial crop which means that changes in the institutional framework translate slower into production decisions than in areas where sugar is produced from beet, which is an annual crop.

$$
\text { Effect }_{L D C}^{P M}=\left(\alpha_{4}+\alpha_{5}\right)=0.20
$$

\footnotetext{
${ }^{25}$ The value of $\mathrm{ACP}$-preferences in the first period minus the value of $\mathrm{ACP}$-preferences in the second period.

${ }^{26}(\exp ((-2.563)-(-3.210))-1) * 100 \%$.

${ }^{27} 0.723-0.524$ and $0.723-0.692$, respectively. Since these are logarithms of continuous variables, they can be interpreted as elasticities without having to be transformed such as the coefficients of the dummy variables in Equation 4.6 .
} 


$$
\text { Effect }_{A C P}^{P M}=\left(\alpha_{4}+\alpha_{6}\right)=0.03
$$

Considering the control variables, a significantly positive value can be found for sugar production, as predicted by theory. The sign of the variable indicating the exchange rate is negative, as expected. The political systems of exporting countries seems to have a negative influence on the countries' sugar export: the more autocratic a regime is, the more sugar it exports into the EU. However, it needs to be mentioned that the coefficient is significant only at a level of $10 \%$, and of a small magnitude.

\subsection{Conclusion}

This article evaluated the effects of the EBA agreement which has been established between the European Union and the group of the Least Developed Countries in 2001. The agreement was designed to increase the potential for the LDCs' economic development by granting them tariff free access to the European market. In particular we focused on the sugar market, which is subject to a great amount of interventions, embraced in the Common Market Order for sugar. It included an intervention price high above the world market price, high domestic protection, as well as production quotas.

Other trade preferences had been in place since the creation of the CMO. The beneficiaries were countries that the EU's member states have colonial ties with, referred to as the African, Caribbean, and Pacific countries. In the beginning of the 21st century, different political and economic developments (including the EBA agreement and a lost WTO trial) put great pressure on the CMO in its former form which required a great reduction of the intervention price. This reduction did not only hurt the European farmers, but also the producers in countries that were also profiting from the high European intervention price: the beneficiaries of preferential trade agreements, namely the ACP countries. This process is called preference erosion and has been quantified in this article.

The empirical analysis was executed with a fixed effects gravity estimation to represent the mono-directional trade flows of sugar into the EU. The empirical challenges that typically arise with the application of a gravity model to a micro-sector were addressed as follows. The problem of identification was tackled by adding a continuous variable to capture the policy changes. The occurrence of excess zeros in the dependent variable was addressed by applying the newly developed NB_QGPML ${ }^{G L M}$ estimator, which provides results that are superior to the usu- 
ally employed approaches of PML regressions that assume either a Gamma or a Poisson distribution. All three procedures were applied and compared. The study builds on panel data from 76 sugar exporting countries in eleven years.

As prognosticated in the qualitative part, the discrimination to the advantage of countries that had signed any preferential trade agreement had a positive effect for these countries' exports of sugar to the EU market. At the same time, preference erosion did occur: countries that had already been enjoying preferences before 2007 were clearly worse off in the following years. This was caused by a dramatic drop of the high EU intervention price, which had been up to three times of the world market price until then. Before the regime switched in 2007/2008, the effect from being a signatory of the SP was 91.0 percentage points higher than afterwards.

The cause for this reduction is partly the creation of the EBA, since this agreement was expected to lead to a tremendous increase of the sugar supply in Europe. Consequently, more sugar would have had to be sold on the world market with subsidies than compatible with the WTO regulations. 


Chapter 5

\section{Discussion of Results and Open Questions}




\subsection{Overview}

This dissertation discussed market distortions on several scales. According to the overarching theoretical framework, distortions arise either from market malfunctions, or are introduced by policy makers. The final chapter first summarises the results of the previous chapters. Afterwards, some limitations are highlighted, and an outlook on future research opportunities to overcome these limitations is presented. The thesis concludes with the relevance and wider implications of the work presented.

The malfunctions include non-competitive markets and failure of otherwise perfectly competitive markets. The former ones can be caused by a strong concentration of the market (due to the small size of a market, for example), by entrance or exit barriers, heterogenous goods, and information asymmetries. Reasons for market failure include the existence of externalities, failures on other markets that are interlinked with the market under consideration (e.g. credit constraints incurred by smallholders), high transaction costs, public goods, and government failure. Depending on different authors' definitions, highly dispersed distributions of income or wealth can also be understood as a failure of the market mechanism. In the part of this work that delved into market malfunctions, the focus was set on the demand side, where concentration is associated with the existence of monopsons, oligopsons, or monopsonistic competition.

The second class of market distortions which are considered here are caused by political interference. They can have different motivations: the correction of market malfunctions as described above, or redistribution 11 The instrument that is employed to correct for market failures depends on the observed failure. If, for example, externalities are present, a tax (subsidy) can be used to internalise the external costs (benefits). Redistribution can also be achieved in various ways. The instrument that is currently under use to support European farmers is a direct payment system at the individual farm level.

The scale dimension was introduced into the theoretical framework in order to systematically combine the results from a micro- and macro-perspective. This is important because the implications of micro processes for a greater scale - as well as the trickling down of macro processes to the micro-scale - are not always obvious. Distortions on a micro-scale, such as market failure on the market of one product, or a policy applied at only one region can be expected to have immediate effects at the local scale, but less tractable impacts at a more aggregated scale. Likewise, the effects of distortions on a greater scale may trickle down to the individual

\footnotetext{
${ }^{1}$ Or the correction of previous interventions.
} 
stakeholder at a quick rate or, as the other extreme, hardly be recorded.

This theoretical framework was applied to a) the local rubber market in Jambi, Indonesia, which is characterised by strong monopsonistic market power on all levels, and b) the European common market order for sugar which is regulated heavily.

More specifically, chapters two and three provide an analysis of malfunctions within the Indonesian rubber market, of which chapter two looks at a micro-scale and chapter three at a meso-scale. The micro-scale analysis shows that village traders of rubber in Jambi do exercise market power. The price that they pay to their providers lies significantly below the input's marginal value product. This market power is amplified in situations of extreme remoteness, and weakens with increasing market size. For the larger scale of the processing industry, market power does exist as well, and is substantial. The factories engage in asymmetric price transmission, which means that price changes on the world market are transmitted to the input providers faster if the international price decreases than it does in times of price hikes. The asymmetric transmission of prices alone leads to an annual redistribution of around three million U.S. Dollars in Jambi (the total redistribution due to market power can be assumed to be much larger, but could not be assessed with the available data).

Chapter four analyses the effects of policy intervention on a meso-scale. The analysis focuses on the results of a market intervention on third countries, namely the reduction of the intervention price of the European sugar market. The price reduction was motivated by the effects of previous policies, as well as changes in the institutional framework in which the common market organisation for sugar is embedded. Relevant previous policies are the various preferential trade agreements and the sugar CMO itself, and institutional changes refer to obligations resulting from multilateral trade negotiations within the World Trade Organisation. Results indicate that ACP countries were indeed negatively affected, i.e., that preference erosion did occur. The loss they incurred due to the reduction of the intervention price was larger than the gain they received due to the possibility to increase exports to the EU.

The results of this dissertation are relevant for future decisions on whether or not politically intervening on agricultural markets is necessary, and how that intervention can take place. The key questions are when to intervene, and by what measure. 


\subsection{Welfare- and policy implications across scales}

\section{The Indonesian rubber market}

The findings of chapters two and three of this study are based on price transmission analysis and structure-conduct-performance approaches, respectively. They show how imperfections exist all along the value chain for rubber in Jambi on a microand meso-scale. The processors exercise market power towards their suppliers, and traders towards small scale farmers. The results of chapter three show that on the processor level, the redistribution due to asymmetric price transmission alone is worth around three million U.S. Dollars per year. From this perspective, it can be concluded that over a greater time frame, rubber production is far below the optimal level $2^{2}$ Our findings suggest that the fundamental reasons for market malfunctions in the rubber market in Jambi are information asymmetries, nonhomogeneity in demand, market concentration, and restrictions in entry and exit.

For an optimal, Jambi-wide combination of price and total quantity demanded, free entry and exit on the processing stage need to be possible. Due to the high sunk cost of investment into the construction of a rubber factory, it is not guaranteed that the permit to build more factories would guarantee a welfare maximising number, i. e. there might be a natural oligopsony. There is another option, which could be easier to implement and have a higher chance of success. The Jambinese government could announce the subsidisation of transport of rubber slabs to other markets (to other provinces on Sumatra, or even neighbouring Java Island). This would work as a threat to the processors and prices were likely to increase. If the information is well spread, the prices would probably adjust so quick that the costs incurred by the Jambinese government were very limited. This is, of course, the perspective from the researcher's desk, which does not take into account the economy of political decision making. There is a practical problem in the implementation of such a policy. If many producers were accepting the offer, it would quickly become very expensive and the government might withdraw from the plan. If the stakeholders currently exercising market power anticipate this scenario, the government's threat would become less credible, leading to no change in prices and high costs for the government.

\footnotetext{
${ }^{2}$ This does not consider potential negative externalities generated by rubber monoculture plantations which is the predominate mode of production in Jambi (for a brief discussion of this issue, see below).
} 


\section{The European sugar market}

In chapter four the focus was set on the welfare effects associated with the changes of the European sugar regime on non-EU stakeholders. The groups affected include ACP and LDC producers, EU producers and consumers, the EU Budget, and nonEU consumers. Out of these, the welfare effects for the ACP and LDC producers were assessed. The results indicate that LDCs profited from the establishment of the preferntial trade agreement, as expected. ACP countries, on the other hand, unambiguously lost due the erosion of their preferences due to lower prices. The most recent developments which are not discussed in chapter four are sketched out below.

When assessing the organisation of the sugar regime and the implementation of the recent changes from an ex-post perspective, one finds several aspects which could have done better: if it had been anticipated that the former common market order for sugar could not be sustained forever (as it was eventually proven), and if decisions were made under the anticipation of all future developments, it would have been more efficient to realise the desired level of support by paying transfers that are decoupled from production quantity to the farmers both in the EU and the South. Francois (2006) suggests that this should (and still could) be implemented through increased financing of development cooperation, or direct payments to producers in ACP countries. This support would have had to be paid from the EU budget, instead of using a combination of consumers rent and tax money as has been the case. Such an approach would not manipulate the quantity supplied, and therefore be a measure of redistribution without efficiency losses.

In the recent years, some small progress towards that target has been made. Following the reform of the CMO for sugar, 40 million Euros were transferred to ACP producers. This can only be considered a small step, since a total of 1.5 billion Euros were allocated to EU sugar producers as compensation after the reform (Francois et al., 2006). With possible further liberalisation of the sugar market on the horizon, which would result in further reductions of the intervention price in the future, there is great scope for further losses to the producers both in the South and in the EU.

Predictions based on the current status forecast great changes within the sector. According to the commission of the European Union (EU Commission, 2013) it is likely that the quota system will expire by 2017. Nolte et al. (2012) expect the market to restructure fundamentally after this $3^{3}$ Sugar production in the EU

\footnotetext{
${ }^{3}$ Their analysis is based on the assumption of an abolition of the quota system in 2015 but is equally valid if the quota system is abolished by 2017 .
} 
is predicted to concentrate in the comparatively most advantaged regions, and $\mathrm{ACP} / \mathrm{LCD}$ imports to decline slightly. While the price would still be higher than the international price due to ongoing protection via tariffs, it is expected to be below current levels 4 Whether anybody will be compensated, and - if yes - who, remains an open question.

For the sugar growers in LDCs and ACP countries the abolishment of the quota system (even if achieved at the cost of a lower price) is not necessarily a negative development. Due to the nature of the policy from the Southern producers' perspective (export quota), it cannot be guaranteed that the advantages of the current policy really reach the producers, since a quota-policy is often associated with the unproductive activity of rent-seeking (Krueger, 1974). This is also the case for trade preferences, where limited groups of stakeholders are able to 'extract [...] a significant share of the rents from preferential access' Francois et al. 2006, p. 213). Abbott (2002) finds that tariff-rate quotas such as the ones provided within the European sugar regime are a failed market access instrument, due to the challenges associated with the allocation of quotas. However, the same picture cannot be expected across all countries in the ACP and LDC groups. In order to get an understanding of the different dynamics in each of them, a micro-analysis would be needed in the form of country specific case studies.

\subsection{Limitations}

\section{Paper one}

In chapter two, the exclusive focus is set on distortions and problems caused by the agricultural traders in Jambi. What is not mentioned is their possible crucial importance for the sector, since they are the ones facilitating the access of small scale farmers in the periphery to the centralised processing industry. Their presence is therefore essential for the marketing of rubber, and their absence could well result in a collapse of the market. However, more differentiation is needed here as there might be traders that are more important to the functioning of the market than others. Since the market can be understood as a 'network-structured interaction between many agents' (Easley and Kleinberg, 2010, p. 249), the traders' relative importance can be assessed using network analysis. In this context, each trader is represented by a node and the trade routes between them by links. Thus, the market is simplified to a collection of nodes and links which can be analyzed independently from the spatial location of the traders. The original geographical

\footnotetext{
${ }^{4}$ Unless the international price stays constantly at very high levels - which is unlikely. That would have the potential to let the EU re-emerge as a significant exporter.
} 
reference is abstracted from. This abstract network represents the mutual access between the stakeholders. The observed connections between traders can be analysed along several dimensions, such as the network structure (analysis of possible paths), the centrality (relative importance), or clustering of individual nodes (Easley and Kleinberg, 2010).

A structural analysis enables the understanding of the functioning of the whole network. It may be that there is a limited number of traders who are crucial for the overall performance of the value chains. These could, for example, be traders who collect rubber in remote areas via a sub-network of other, smaller traders and cover the large distances to the factories themselves. Such a configuration is referred to as a 'scale free' network, which is characterised by small average shortest paths and large clustering (see Figure 5.13). An alternative possibility is a network of a regular lattice configuration which describes a rather homogenous structure of traders (see Figure 5.1p, Manitz, 2014). In this case, greater distances are covered by an increasing number of in-between-traders who all transport the good for similar (physical) distances along the value chain. 'Small-world' networks (see Figure 5.1.) combine elements from both sets of characteristics: they are similar to homogenous networks, but include shortcuts between otherwise distant nodes (Manitz, 2014). Wilhite (2001) shows with a series of computer simulations that small-world-like networks are the most efficient form of organisation for the flow of goods within the global economy, or - better put - produce an acceptable trade-off between efficiency of markets and search time of stakeholders. This observation is possibly also true for the Jambinese rubber market.

Figure 5.1: Network structures.

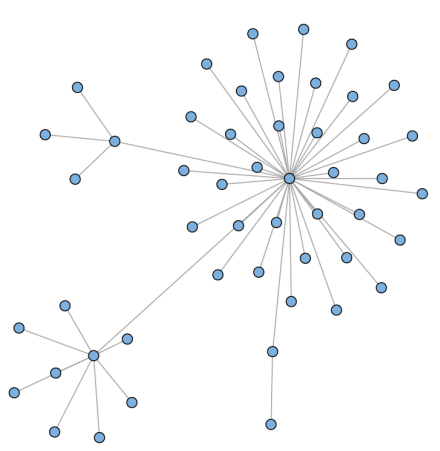

(a) Scale-free

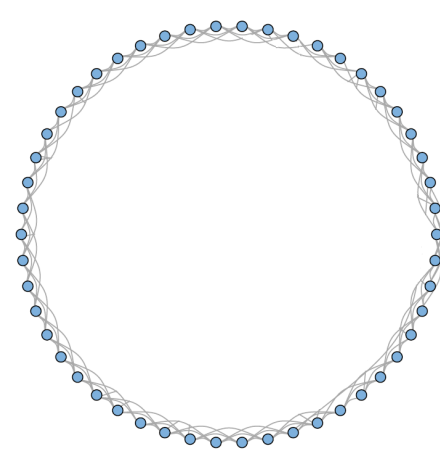

(b) Lattice

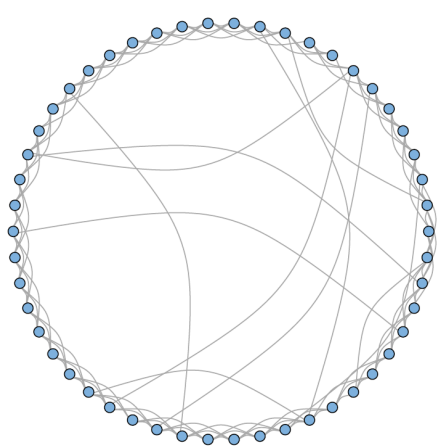

(c) Small-world

Source: Manitz, 2014

It should, however, not be forgotten that the individual traders do exercise market power. In the framework of network analysis, the relative importance of a single 
trader in the network can be understood as an indicator of his or her bargaining power (additional to other techniques such as the ones presented in this dissertation). It can be assessed by a descriptive analysis of the fundamental structure of the network, i. e. the position of individual nodes (traders) and their links. The centrality, for example, captures the relative importance of nodes and comprises the 'degree of centrality' (representing the number of connections from different nodes) or - more sophisticated - the 'betweenness' and 'closeness': the betweenness of one node indicates between how many nodes (on one path) it is positioned, and the closeness the average distance to all other nodes in the network (Easley and Kleinberg, 2010; Manitz, 2014). Most power arises from network-nodes that lie a) on many paths along which the good can be traded and b) between many nodes on each path (Easley and Kleinberg, 2010). In this application, the goal would be to identify these most important traders, and see in what relation the margin they receive stands to their function.

An analysis of the clustering within the network could provide insights on the occurrence of groups of traders working together, which would indicate cooperation, possibly collusion of the stakeholders that form these clusters. It is implemented in the form of community detection algorithms that search for groups of nodes that are disproportional highly interconnected, located in networks that exhibit an otherwise relatively low number of links between the groups.

\section{Paper two}

The most important limitation of the paper presented in chapter three is that it does not generate insights about the dynamics between the Jambinese rubber processors. This is due to the fact that the analysis is carried out on an aggregate level: the buying prices of the five factories enter as an average. Selling prices are not differentiated between the factories either.

It is therefore not possible to draw conclusions regarding the relationship between the five rubber processing factories. Their interactions could be of the nature of an oligopsony or of monopsonistic competition. If it is an oligopsony, the individual agents (factories) can either behave in a cooperative way (cartel case) or exhibit non-cooperative behaviour. Each of the three cases would lead to a different equilibrium, depending on the strategy each agent chooses to follow.

However, the observed equilibrium does not unambiguously indicate one underlying structure of the market. Under the assumption of a punishment model for example, in which agents can pose a credible threat, even the non-cooperative behaviour within an oligopsony would lead to the cartel result. On the other hand, 
a cooperative behaviour does not necessarily result in the cartel solution (Perloff et al., 2007).

In the case of the Jambinese rubber processors, a Bertrand framework concerning the rubber input can be assumed: the processors set the prices for slabs of raw rubber and the suppliers react by deciding upon the quantities that they sell to each factory. If prices differ, the factory offering the highest price would be able to purchase virtually all rubber that is offered at a particular point in time. A cooperative behaviour is associated with a multilateral reduction of the price for the raw rubber input, while non-cooperative behaviour is indicated by one stakeholders' raise of his/her input price.

The focus of this work would be on strategic decisions and not so much on the fundamentals (as laid out in the introduction to this work), since the fundamentals are difficult to observe in contrast to input prices, which do not affect fundamentals. Since the decisions in this competition concern prices, it is appropriate to allow for continuous strategies, which means that the agents do not only have the choice on whether to cooperate or not, but also on the extent of the (non-)cooperation, as the decision variable - the input price - is continuous.

The target of the econometric analysis would be to determine the structure and the strategies that produced the actual economic outcome. One approach is suggested by Perloff et al. (2007) who present a method to estimate strategies directly. They first theoretically reconstruct the different kinds of games that are played by two stakeholders based on different assumptions on the nature of their relation. These are solved to find the respective equilibria. Based on these theoretical findings as well as empirical data, a model is estimated that enables the generation of conclusions on which strategies are followed by the firms. The advantage of this approach is that it enables the researcher 'to estimate firms' strategies subject to restrictions implied by game theory and test hypotheses based on these estimated strategies' (Perloff et al., 2007, p. 213). The data required for the Bertrand game are time series data of input and output prices.

In their approach, Perloff et al. (2007) assume a sequence of static games, which means that the agents only maximise current profits. This is in contrast to a dynamic setting where agents also maximise future profits. The validity of this assumption will need to be checked carefully. Another open question towards the approach of Perloff et al. (2007), who consider two-player scenarios only, is whether both theory and empirical estimation can be extended to an application with five agents, as is the case in Jambi.

Alternatively it would also be possible to search for systematic differences and pat- 
terns in the different agents' reactions to international price changes with price transmission analysis. These approaches include the analysis of spatial price transmission between the five factories by estimating a spatial vector error correction model, or to estimate a vertical price transmission model, consisting of the long run equilibrium between each of the five factories' prices and the world market price, and then the vector error correction model.

\section{Paper three}

One possibly problematic assumption of this paper is that the EU is taken to be one country. It is implicitly assumed to be a single point in which no trade occurs. However, changing that would be a difficult thing to achieve, due to data limitations. It is not very clear which EU member exactly imports the sugar stemming from third countries. For the sake of the analysis which focuses on the effects on third countries, this problem should be of limited relevance, however. In the assessment part of the paper, the concept of welfare applied is not very differentiated. It considers neither questions of inter- nor of intra-generational justice, due to long-term externalities of agricultural production (see below).

This analysis is based on secondary data and therefore subject to the limitations associated commonly with this kind of data. However, the most central variables trade flows and preferences (quotas) - were provided by Eurostat and the EU commission which are assumed to be very reliable since the Eurostat data concerning imports are generated from the European customs authorities. Other explanatory variables such as the exchange rate and total sugar production are drawn from official agencies, which in turn have to rely on data provided by the individual countries, and are not necessarily accurate. The variables capturing the geographical distance between countries and the political system of the trade partners stem from research institutes.

\subsection{Relevance and wider implications}

\section{Greater welfare implications of rubber production}

In chapters two and three, only malfunctioning on the demand side of this market was scrutinised. When considering the supply side, the main failure might be constituted by negative externalities stemming from the monoculture production mode of rubber cultivation. These negative externalities have not been considered in this work, but are of crucial importance when assessing the overall welfare effects of rubber cultivation in Jambi. Some of them take effect on a local scale, such as 
loss of biodiversity and reduced functionality of ecoservices (Barnes et al., 2014, Rubiana et al. 2015), while others take effect on the global scale. Most notably, global scale effects include the decomposition of existing carbon pools due to exposure to aerobic conditions (Biagioni et al. 2015) as well as to erosion (Guillaume, 2015), reduced net primary production in above- and belowground tree biomass, as well as a reduction in the long time accumulation of carbon (Kotowska et al. 2015). The lowland peatlands of Southeast Asia are the largest in the tropics, and are currently under threat. Indonesia's handling of this situation has the potential to produce serious effects, and is also likely to send a signal to other countries in a similar position.

Since the costs are public, it is unlikely that the emissions which cause these costs are taken into account via the market mechanisms. Therefore, private and social costs fall apart, requiring an intervention from the government (Koester, 2011). The appropriate response to this market failure would be taxes on the externalities in order to reduce output to a welfare increasing level.

Two questions that emerge immediately at this point concern the valuation of a 'healthy environment': what is the individual's willingness to pay, and whose willingness to pay is considered? The first question refers to the problem that it is questionable whether the willingness to pay is actually an appropriate criterion for the valuation of nature. Due to the long-term nature of effects that are experienced far in the future, the current participants of the market may either not consider them in their decisions, or have time preferences that favour the present Coursey et al. 1987). The view on a larger scale leads to the second question that considers the temporal and geographical dimension of the individuals whose interests are taken into account. Members of future generations, for example, have interests that might be negatively affected by current decisions. Due to the global scale of environmental and climatic processes, decision making practices on this issue would also require the involvement of the global society.

Compared to other systems of political interventions (such as the one presented in chapter four), the question here can be answered easier: the maximum levels of pollution and usage of natural resources that enable future generations to offer every individual the opportunity to enjoy the same quality of life that the current generation has, are in fact known. Izrael and Semenov (2006) explain what is required to reach the two degree target which is, in turn, necessary to avoid irreversible changes of the climate, enabling future generations to live under similar (climatic) conditions under which the current one does.

In a globalised world of international competition in the majority of goods, the 
unilateral introduction of climate protecting regulations causes a competitive disadvantage. Therefore, as long as low environmental standards constitute a comparative advantage, countries are encouraged to engage in a race to the bottom for the lowest standards. In order to avoid this competition, the externalities that create effects on a global scale have to be regulated on an international level.

\section{Other instances of market malfunctioning}

In order to draw conclusions from past experiences such as the ones analysed in this thesis, it is important to identify markets to which the concepts developed in the individual papers of this thesis apply. The topics of market malfunctions that were touched upon in this dissertation are also relevant in other instances. For example, the analysis of possibly asymmetric transmission of prices can be used as an indicator of market power in other cases. Examples of cartels can be found on various levels. In the German food industry, from 2013 to 2014 alone, sanctions were imposed in the beer industry (Bundeskartellamt, 2014b), on sausage makers (Bundeskartellamt, 2014a), candy producers (Bundeskartellamt, 2013a), flour mills (Bundeskartellamt, 2013b) and in the sugar industry (Bundeskartellamt, 2014b). It would be interesting to see if any of these industries engaged in the asymmetric transmission of prices. If firms have a strong market power both on the supply and the demand side (for example the flour industry), challenges on a methodological level are also present.

\section{Other markets prone to preference erosion}

Preference erosion as discussed in chapter four can be a serious concern whenever external stakeholders enjoy preferential access to a protected market. There is a lot of scope for preference erosion due to multilateral trade negotiations in which countries participate that currently protect their markets via tariffs and also grant preferences. However, Francois et al. (2006) find that even if all tariffs were abolished, and preference erosion was expected to be maximal, the effects might not be strongly felt because of an underuse of the preferences currently granted for many products. The main reasons for this under-usage are the administrative challenges facing the export countries, such as fulfilling the rules of origin.

Considering the trade between Indonesia and the European Union, the erosion of other countries' preferences is a more likely scenario. Success of the currently ongoing negations concerning a free trade agreement between the EU and Indonesia (EU Commission: DG Trade, 2015) would cause preference erosion for ACP countries that currently export palm oil to the EU under preferential treatment; this is primarily because the EU prices have the potential to decrease. The EU, 
however, argues that the ACP countries do not have much to lose. Since the most favoured nation tariff is only $3.8 \%$, the current preference margin enjoyed by the ACP countries is relatively small (European Parliament, 2011, 2012).

Perhaps more relevant for Indonesia are the energy politics of the European Union, more specifically the Renewables Directive, which formulates targets for the minimum share of energy from renewable sources for each member state (European Parliament, 2009). In Germany, for example, this is realised via the Biofuel Quota Act (Bundesgesetzblatt, 2006), amongst other measures. This law requires the suppliers of car fuel to include a minimum amount of biofuel in the fuel they sell. This increases the demand for energy-rich plants, such as the oil palm.

Based on the considerations from chapter four, one could argue that this leads to the creation of production capacities in the palm oil sector that are only based upon this European regulation. If the European policy changed, the demand would decline and the production capacities would exceed this reduced demand.

However, since the central role of palm oil is one of an input in the production of processed food, and the share of palm oil for energy production is rather small, the overall impact of a changed energy policy would probably not cause too much harm. Besides that, the EU constitutes only a relatively small market for Indonesian Palm oil (in 2012, $14 \%$ of Indonesian palm oil exports went to the EU) ${ }^{5}$

\section{Policy under constraints}

The sugar case impressively shows the large number of policy constraints. For sugar, these constraints are external (such as WTO membership) and internal (such as limits with the European population's acceptance of the size of the EU budget and particularly its agricultural share). Under this consideration, it is intuitive that any market based intervention has the potential to conflict with one or several of these constraints, since these are exactly the two conditions that a policy has to fulfil in order to be acceptable: social acceptance, especially the distributional consequences, and compatibility with international agreements Constanza et al. 2001). Koester (2011) does not see these conditions as being fulfilled for many parts of the Common Agricultural Policy, which conserves the status quo rather than fostering innovation. The sugar policy in the timeframe under consideration is representative of this. In the CMO for sugar, the external constraints are primarily manifested by the introduction of a maximum amount of subsidised exports after the Uruguay round of multilateral trade negotiations. This was followed by the

\footnotetext{
${ }^{5}$ Figures from Worldbank World Integrated Trade Solution. http://wits.worldbank.org, accessed on 02.03 .2015
} 
lawsuit in which the WTO found the EU guilty of having trespassed this amount, and eventually the necessary adjustment of the intervention price.

In general, these results call for policy makers to put effort into identifying all stakeholders that are possibly affected by a planned intervention and do their best in predicting the effects on each group before implementation. Furthermore, all groups should be consulted before, and if possible included in the process of designing the policy. This is especially relevant in the current context of the Indonesian rubber market, when the failures described in chapters two and three are to be addressed by policy in the near future. 


\section{Bibliography}

Abbott, P. C. (2002). Tariff-rate quotas: failed market access instruments? European Review of Agriculture Economics, 29:109-130.

Adnan, N. A. and Atkinson, P. M. (2011). Exploring the impact of climate and land use changes on streamflow trends in a monsoon catchment. International Journal of Climatology, 31(6):815-831.

Agostino, M., Demaria, F., and Trivieri, F. (2010). Non-Reciprocal Trade Preferences and the Role of Compliance Costs in the Agricultural Sector: Exports to the EU. Journal of Agricultural Economics, 61(3):652-679.

Aker, J. C. (2010). Information from markets near and far: Mobile phones and agricultural markets in Niger. American Economic Journal: Applied Economics, 2:46-59.

Akiefnawati, R., Ayat, A., Alira, D., Suyitno, and Joshi, L. (2010). Enhancing rubber production in communities around a village forest in Bungo District, Jambi Province. In Leimona, B. and Joshi, L., editors, Eco-certified natural rubber from sustainable rubber agroforestry in Sumatra, Indonesia., pages 25-31. World Agroforestry Centre (ICRAF).

Anderson, J. E. (1979). A Theoretical Foundation for the Gravity Equation. American Economic Review, 69(1):106-116.

Anderson, J. E. and Van Wincoop, E. (2003). Gravity with Gravitas: A Solution to the Border Puzzle. American Economic Review, 93(1):170-192.

Anderson, J. E. and Yotov, Y. V. (2010). The changing incidence of geography. American Economic Review, 100(1):106-116.

Arifin, B. (2005). Supply-Chain of Natural Rubber in Indonesia. Jurnal Manajemen Agribisnis, 2(1):1-16.

Bain, J. S. (1956). Barriers to new competition: their character and consequences in manufacturing industries. 
Baldwin, R. and Taglioni, D. (2007). Trade Effects of the Euro: a Comparison of Estimators. Journal of Economic Integration, 22(4):780-818.

Barnes, A. D., Jochum, M., Mumme, S., Haneda, N. F., Farajallah, A., Widarto, T. H., and Brose, U. (2014). Consequences of tropical land use for multitrophic biodiversity and ecosystem functioning. Nature Communications, 5:5351.

Barnett, B. J., Barrett, C. B., and Skees, J. R. (2008). Poverty Traps and IndexBased Risk Transfer Products. World Development, 36:1766-1785.

Bates, D. M. and Watts, D. G. (1988). Nonlinear Regression Analysis and Its Applications. John Wiley \& Sons, New York, USA.

Battese, G. E. (1997). A Note on the Estimation of Cobb-Douglas Production Functions when some Explanatory Variables Have Zero Values. Journal of Agricultural Economics, 48:250-252.

Bendix, D., Danielzik, C.-M., Döll, J., Holzwarth, S., Juergensohn, J., Kiesel, T., Kontzi, K., and Philipp, C. (2013). Mit Kolonialen Grüßen. glokal e.V., Berlin, 2nd edition.

Bergstrand, J. H. (1985). The Gravity Equation in International Trade: Some Microeconomic Foundations and Empirical Evidence. The Review of Economics and Statistics, 67:474-481.

Berndt, E. R. (1996). The Practice of Econometrics: Classic and Contemporary. Addison Wesley, Boston, har/dskt edition.

Bertrand (1883). Book Review on "Théorie mathématique de la richesse sociale" and "Recherches sur les principes mathématiques de la richesse". Journal des Savants, pages 890-904.

Bhaskar, V., Manning, A., and To, T. (2002). Oligopsony and Monopsonistic Competition in Labor Markets. Journal of Economic Perspectives, 16(2):155174 .

Biagioni, S., Krashevska, V., Achnopha, Y., Saad, A., Sabiham, S., and Behling, H. (2015). 8000 years of vegetation dynamics and environmental changes of an unique inland peat ecosystem of the Jambi Province in Central Sumatra, Indonesia. Under Review.

Bloom, D. E. and Canning, D. (2005). Health and Economic Growth: Reconciling the Micro and Macro Evidence. Harvard School of Public Health, Cambridge, MA: Working Paper. 
Boisvert, R. N. (1982). The Translog Production Function - Properties, several Interpretations and Estimation Problems. Department of Agricultural Economics, Cornell Univ: Working Paper.

Bosquet, C. and Boulhol, H. (2014). Applying the GLM Variance Assumption to Overcome the Scale-Dependence of the Negative Binomial QGPML Estimator. Econometric Reviews, 33(7):772-784.

Bresnahan, T. F. (1982). The oligopoly solution concept is identified. Economics Letters, 10(1):87-92.

Bundesgesetzblatt (2006). Gesetz zur Einführung einer Biokraftstoffquote durch Änderung des Bundes-Immissionsschutzgesetzes und zur Änderung energie- und stromsteuerrechtlicher Vorschriften (Biokraftstoffquotengesetz - BioKraftQuG).

Bundeskartellamt (2013a). Bußgeldverfahren gegen Hersteller von Süßwaren. Technical report, Bonn.

Bundeskartellamt (2013b). Bußgeldverfahren gegen Unternehmen der Mühlenindustrie. Technical report, Bonn.

Bundeskartellamt (2014a). Bundeskartellamt imposes fines on sugar manufacturers. Technical report, Bonn.

Bundeskartellamt (2014b). Bußgelder gegen Bierbrauer wegen verbotener Preisabsprachen. Technical report, Bonn.

Burbidge, J. B., Magee, L., and Robb, A. L. (1988). Alternative Transformations to Handle Extreme Values of the Dependent Variable. Journal of the American Statistical Association, 83:123-127.

Burnham, K. and Anderson, D. (2002). Model selection and multimodel inference: a practical information-theoretic approach. Springer, Heidelberg, Germany.

Calì, M., Nolte, S., and Cantore, N. (2013). Sweet and sour changes in trade regimes. The World Economy, 36(6):786-806.

Cardwell, M. (2004). The European Model of Agriculture. Oxford University Press Oxford, New York.

Carrère, C., de Melo, J., and Tumurchudur, B. (2010). Disentangling market access effects of preferential trading arrangements with an application for ASEAN members under an ASEAN-EU FTA. The World Economy, 33:42-59. 
Cassels, J. M. (1937). Monopolistic Competition and Economic Realism. Canadian Journal of Economics, 3(3):376-393.

Chamberlin, E. H. (1958). The Theory of Monopolistic Competition - A Reorientation of the Theory of Value. Harvard University Press, Cambridge, 7th edition.

Chaplin, H. and Matthews, A. (2006). Coping with the Fallout for Preference Receiving Countries from EU Sugar Reform. The Estey Centre Journal of International Law and Trade Policy, 7(1):15-31.

Chen, B. and Li, Y. (2014). Analyzing Bilateral Trade Barriers under Global Trade Context: A Gravity Model Adjusted Trade Intensity Index Approach. Review of Development Economics, 18(2):326-339.

Chetty, R., Guren, A., Manoli, D., and Weber, A. (2011). Are Micro and Macro Labor Supply Elasticities Consistent? A Review of Evidence on the Intensive and Extensive Margins. The American Economic Review, 101(3):471-475.

Chua, C. L., Kew, H., and Yong, J. (2005). Airline Code-Share Alliances and Costs: Imposing Concavity on Translog Cost Function Estimation. Review of Industrial Organization, 26:461-487.

Cipollina, M., De Benedictis, L., Vicarelli, C., and Salvatici, L. (2013). Dummies for Policies or Policies for Dummies. A Montecarlo Gravity Experiment. Roma Tre University, Dipartimento di Economia: Working Paper.

Cipollina, M., Laborde, D., and Salvatici, L. (2014). The Tide That Does Not Raise All Boats. IFPRI Discussion Paper 01382.

Cipollina, M. and Salvatici, L. (2007). EU and developing countries: an analysis of preferential margins on agricultural trade flows. TradeAg Project: Working Paper 07/11.

Cipollina, M. and Salvatici, L. (2010). The trade impact of European Union agricultural preferences. Journal of Economic Policy Reform, 13(1):87-106.

Conforti, P., Ford, D., Hallam, D., Rapsomanikis, G., and Salvatici, L. (2007). The European Union preferential trade with developing countries. Total trade restrictiveness and the case of sugar. Università degli Studi del Molise, Economics E Statistics: Working Paper.

Constanza, R., Cumberland, J., Daly, H., Goodland, R., and Norgaard, R. (2001). Einführung in die Ökologische Ökonomik. Lucius and Lucius, Stuttgart. 
Conway, G. R. and Pretty, J. N. (1991). Unwelcome Harvest: Agriculture and Pollution. Routledge, London, 5th edition.

Coursey, D., Hovis, J., and Schulze, W. (1987). The disparity between willingness to accept and willingness to pay measures of value. The Quarterly Journal of Economics, pages 679-690.

Dauvergne, P. (1993). The politics of deforestation in Indonesia. Pacific Affairs, 66(4):497-518.

Easley, D. and Kleinberg, J. (2010). Networks, crowds, and markets: Reasoning about a highly connected world. Cambridge University Press, Cambridge.

Eilers, P. H. C. and Marx, B. D. (1996). Flexible smoothing with B-splines and penalties. Statistical Science, 11(2):89-102.

Ellis, F. (2000). The Determinants of Rural Livelihood Diversification in Developing Countries. Journal of Agricultural Economics, 51:289-302.

Engle, R. F. and Granger, C. W. J. (1987). Co-integration and Error Correction: Representation, Estimation, and Testing. Econometrica, 55(2):251-276.

Escribano, A. (2004). Nonlinear Error Correction: the Case of Money Demand in the United Kingdom (1878-2000). Macroeconomic Dynamics, 8:76-116.

EU Commission (2013). CAP Reform - an Explanation of the Main Elements. Technical report, Brussels.

EU Commission: DG Trade (2015). Countries and regions: Indonesia. Technical report, Brussels.

Euler, M., Krishna, V., Fathoni, Z., Hermanto, S., Schwarze, S., and Qaim, M. (2012). Ecological and Socioeconomic Functions of Tropical Lowland Rainforest Transformation Systems (Sumatra, Indonesia), Household Survey 2012. Göttingen, Germany; Jambi, Indonesia; Bogor, Indonesia; Georg-August University of Goettingen, Bogor Agricultural Uni.

European Parliament (2009). DIRECTIVE 2009/28/EC OF THE EUROPEAN PARLIAMENT AND OF THE COUNCIL on the promotion of the use of energy from renewable sources and amending and subsequently repealing Directives 2001/77/EC and 2003/30/EC. Official Journal of the European Union, 140(16).

European Parliament (2011). Parliamentary questions - Preference erosion in ACP countries. Technical report, Brussels. 
European Parliament (2012). Parliamentary questions - Answer given by Mr De Gucht on behalf of the Commission. Technical report, Brussels.

Fafchamps, M. and Gabre-Madhin, E. (2006). Agricultural markets in Benin and Malawi. The African Journal of Agricultural and Resource Economics, 1:67-94.

Fafchamps, M. and Hill, R. V. (2008). Price Transmission and Trader Entry in Domestic Commodity Markets. Economic Development and Cultural Change, 56(4):729-766.

Fafchamps, M. and Minten, B. (2002). Returns to social network capital among traders. Oxford economic papers, 54:173-206.

Fathoni, Z. (2009). Evaluation of Market System and Market Integration for Rubber Cultivation in Jambi Province - Indonesia. Masters Thesis, Bogor Agricultural Institute, Bogor, Indonesia.

Faust, H., Schwarze, S., Beckert, B., Brümmer, B., Dittrich, C., Euler, M., Gatto, M., Hauser-Schäublin, B., Hein, J., Holtkamp, A. M., Ibanez, M., Klasen, S., Kopp, T., Krishna, V., Kunz, Y., Lay, J., Muß hoff, O., Qaim, M., Steinebach, S., Vorlaufer, M., and M, W. (2013). Assessment of socio-economic functions of tropical lowland transformation systems in Indonesia - Sampling Framework and Methodological Approach. CRC990 Discusson Paper Series: Efforts Discussion Paper 1.

Feenstra, R. C. (2002). Border Effects and the Gravity Equation: Consistent Methods for Estimation. Scottish Journal of Political Economy, 49(5):491-506.

Feintrenie, L., Schwarze, S., and Levang, P. (2010). Are local people conservationists? Analysis of transition dynamics from agroforests to monoculture plantations in Indonesia. Ecology and Society, 15(4).

Fitzherbert, E. B., Struebig, M. J., Morel, A., Danielsen, F., Brühl, C. A., Donald, P. F., and Phalan, B. (2008). How will oil palm expansion affect biodiversity? Trends in Ecology and Evolution, 23(10):538-545.

Francois, J., Hoekman, B., and Manchin, M. (2006). Preference erosion and multilateral trade liberalization. World Bank Economic Review, 20:197-216.

Fugazza, M. and McLaren, A. (2014). Market Access, Export Performance and Survival: Evidence from Peruvian Firms. Review of International Economics, 22(3):599-624. 
Gabszewicz, J. and Thisse, J.-F. (2000). Microeconomic theories of imperfect competition. Cahiers d'économie politique, 37(1):47-99.

Gonzalo, J. (1994). Five alternative methods of estimating long-run equilibrium relationships. Journal of Econometrics, 60(1):203-233.

Gotor, E. (2009). The Reform of the EU Sugar Trade Preferences toward Developing Countries in Light of the Economic Partnership Agreements. The Estey Centre Journal of International Law and Trade Policy, 10(2):15-29.

Gourieroux, C., Monfort, A., and Trognon, A. (1984). Pseudo Maximum Likelihood Methods: Theory. Econometrica, 52(3):681-700.

Groenewegen, P. (2009). English Marginalism: Jevons, Marshall, and Pigou. In Samuels, W. J., Biddle, J. E., and Davis, J. B., editors, A Companion to The Hisotry of Economic Thought, chapter 16, pages 249-261. Blackwell, Malden, 4th edition.

Guillaume, T. (2015). Losses of soil carbon by converting tropical forest to plantations: Erosion and decomposition estimated by $\delta 13 \mathrm{C}$. Global Change Biology.

Hagedorn, K. (1983). Reflections on the methodology of agricultural policy research. European Review of Agricultural Economics, 10(4):303-323.

Hallet, G. (1981). The Economics of Agricultural Policy. Basil Blackwell, Oxford, 2nd edition.

Hansen, B. E. and Seo, B. (2002). Testing for two-regime threshold cointegration in vector error-correction models. Journal of Econometrics, Long Memory and Nonlinear Time Series, 110(2):293-318.

Hassouneh, I., Radwan, A., Serra, T., and Gil, J. M. (2012). Food scare crises and developing countries: The impact of avian influenza on vertical price transmission in the Egyptian poultry sector. Food Policy, 37:264-274.

Hassouneh, I., Serra, T., and Gil, J. M. (2010). Price Transmission in the Spanish Bovine Sector: The BSE Effect. Agricultural Economics, 41(1):33-42.

Head, K., Mayer, T., and Ries, J. (2009). How remote is the offshoring threat? European Economic Review, 53(4):429-444.

Henningsen, A. and Henning, C. H. C. A. (2009). Imposing regional monotonicity on translog stochastic production frontiers with a simple three-step procedure. Journal of Productivity Analysis, 32:217-229. 
Hirschman, A. (1964). The paternity of an index. The American Economic Review, $54: 761-762$.

Hoekman, B. and Howse, R. (2008). EC-Sugar. World Trade Review, 7(1):149-178.

Hornok, C. (2011). Gravity or Dummies? The Limits of Identification in Gravity Estimations. CeFig: Working Paper 11/09.

Ihle, R., Brümmer, B., and Thompson, S. R. (2012). Structural change in European calf markets: Decoupling and the blue tongue disease. European Review of Agricultural Economics, 39:157-179.

Ivanov, V. and Kilian, L. (2005). A Practitioner's Guide to Lag Order Selection For VAR Impulse Response Analysis. Studies in Nonlinear Dynamics 83 Econometrics, 9(1):1-36.

Izrael, Y. and Semenov, S. (2006). Critical levels of greenhouse gases, stabilization scenarios, and implications for the global decisions. In Schellnhuber, H. J., editor, Avoiding dangerous climate change, pages 3-7. Cambridge University Press, Cambridge.

Johansen, S. (1998). Likelihood-based inference in cointegrated vector autoregressive models. Oxford University Press, Oxford.

Kinnucan, H. W. and Forker, O. D. (1987). Asymmetry in Farm-Retail Price Transmission for Major Dairy Products. American Journal of Agricultural Economics, 69(2):285-292.

Koester, U. (2011). Grundzüge der landwirtschaftlichen Marktlehre. Franz Vahlen, Munich.

Kojima, K. and Ozawa, T. (1984). Micro-and Macro-Economic Models of Direct Foreign. Hitotsubashi Journal of Economics, 25(1):1-20.

Kopp, T., Alamsyah, Z., Fatricia, R. S., and Brümmer, B. (2014). Have Indonesian Rubber Processors Formed a Cartel? Analysis of Intertemporal Marketing Margin Manipulation. CRC990 Discussion Paper Series: Efforts Discussion Paper 3.

Kopp, T. and Brümmer, B. (2015). Moving Rubber to a Better Place - and Extracting Rents from Credit Constrained Farmers along the Way. CRC990 Discussion Paper Series: Efforts Discussion Paper 9. 
Kotowska, M., Leuschner, C., Antono, T., Meriem, S., and Hertel, D. (2015). Quantifying above- and belowground biomass carbon loss with forest conversion in tropical lowlands of Sumatra (Indonesia). Under Review.

Krivobokova, T., Kneib, T., and Claeskens, G. (2010). Simultaneous Confidence Bands for Penalized Spline Estimators. Journal of the American Statistical Association, 105(490):852-863.

Krueger, A. O. (1974). The Political Economy of the Rent-Seeking Society. The American Economic Review, 64:291-303.

Lloyd, T. A., McCorriston, S., Morgan, C. W., and Rayner, A. J. (2006). Food Scares, Market Power and Price Transmission: The UK BSE Crisis. European Review of Agricultural Economics, 33(2):119-147.

Mairesse, J. and Jaumandreu, J. (2005). Panel-data estimates of the production function and the revenue function: What difference does it make? Scandinavian Journal of Economics, 107:651-672.

Manitz, J. (2014). Statistical Inference for Propagation Processes on Complex Networks. Dissertation.

Marcuzzo, M. (2009). The "First" Imperfect Competition Revolution. In Samuels, W. J., Biddle, J. E., and Davis, J. B., editors, A companion to the history of economic thought, chapter 19. Blackwell, Malden, 4th edition.

Martini, E., Akiefnawati, R., Joshi, L., Dewi, S., Ekadinata, A., Feintrenie, L., and van Noordwijk, M. (2010). Rubber agroforests and governance at the interface between conservation and livelihoods in Bungo district, Jambi province, Indonesia. World Agroforestry Centre: Working Paper.

McCorriston, S., Morgan, C. W., and Rayner, A. J. (2001). Price transmission: the interaction between market power and returns to scale. European Review of Agricultural Economics, 28(2):143-159.

McMillan, M., Rodrik, D., and Welch, K. H. (2002). When Economic Reform Goes Wrong: Cashews in Mozambique. National Bureau of Economic Research: NBER Working Paper.

Medema, S. (2009). The economic role of government in the history of economic thought. In Samuels, W. J., Biddle, Jeff, E., and Davis, J. B., editors, A companion to the history of economic thought, chapter 27. Blackwell, Malden, 4th edition. 
Meyer, J. and von Cramon-Taubadel, S. (2004). Asymmetric Price Transmission: A Survey. Journal of Agricultural Economics, 55(3):581-611.

Morey, E. R. (1986). An Introduction to Checking, Testing, and Imposing Curvature Properties: The True Function and the Estimated Function. The Canadian Journal of Economics, 19(2):207-235.

Nedergaard, P. (2006). Market failures and government failures: A theoretical model of the common agricultural policy. Public Choice, 127:393-413.

Nicita, A. (2011). Measuring the relative strength of preferential market access. United Nations UNCTAD Policy Issues in International Trade and Commodities Study Series No $4 \%$.

Nicita, A. and Rollo, V. (2013). Tariff Preferences As A Determinant For Exports From Sub-Saharan Africa. United Nations UNCTAD Policy Issues in International Trade and Commodities Study Series No. 60.

Nolte, S., Buysse, J., and Van Huylenbroeck, G. (2012). Modelling the effects of an abolition of the EU sugar quota on internal prices, production and imports. In European Review of Agricultural Economics, volume 39, pages 75-94.

Osborne, T. (2005). Imperfect competition in agricultural markets: Evidence from Ethiopia. Journal of Development Economics, 76:405-428.

Peramune, M. R. and Budiman, A. (2007). A Value Chain Assessment of the Rubber Industry in Indonesia. U.S. Agency for International Development. Project Report, USAid.

Perloff, J. M., Karp, L. S., and Golan, A. (2007). Estimating Market Power and Strategies. Cambridge University Press, New York, USA.

Pigou, A. (1932). The Economics of Welfare. Macmillan, London, 4th edition.

Pitt, M. (1980). Alternative Trade Strategies and Employment in Indonesia. In Krueger, A. O., Lary, H. B., Monson, T., and Akrasanee, N., editors, Trade and Employment in Developing Countries, 1: Individual Studies. University of Chicago Press, Chicago.

Piyapromdee, S., Hillberry, R., and MacLaren, D. (2014). 'Fair trade' coffee and the mitigation of local oligopsony power. European Review of Agricultural Economics, 41(4):537-559. 
Pokhrel, D. M. and Thapa, G. B. (2007). Are marketing intermediaries exploiting mountain farmers in Nepal? A study based on market price, marketing margin and income distribution analyses. Agricultural Systems, 94:151-164.

Prehn, S., Brümmer, B., and Glauben, T. (2012). Structural gravity estimation \& agriculture. Department for Agricultural Economics and Rural Development: Working Paper.

Raimondi, V., Scoppola, M., and Olper, A. (2012). Preference erosion and the developing countries exports to the EU: a dynamic panel gravity approach. Review of World Economics, 148(4):707-732.

Regional Account and Statistical Analysis Division (2012). Jambi in Figures 2011. BPS Statistics of Jambi Province, Jambi, Indonesia.

Robilliard, A.-S. and Robinson, S. (2003). Reconciling household surveys and national accounts data using a cross entropy estimation method. Review of Income and Wealth, 49:395-406.

Robinson, J. (1959). The Economics of Imperfect Competition. Macmillan \& Company Limited, New York, 2nd edition.

Robinson, S. (1991). Macroeconomics, financial variables, and computable general equilibrium models. World Development, 19(11):1509-1525.

Rubiana, R., Rizali, A., Denmead, L. H., Alamsari, W., Hidayat, P. P., Hindayana, D., Clough, Y., Tscharntke, T., and Buchori, D. (2015). Agricultural Land Use Alters Species Composition but not Species Richness of Ant Communities. Under Review.

Runge, C. and Myers, R. (1985). Shifting foundations of agricultural policy analysis: welfare economics when risk markets are incomplete. Journal of Agricultural Economics, 67(5):1010-1016.

Ryan, D. L. and Wales, T. J. (2000). Imposing local concavity in the translog and generalized Leontief cost functions. Economics Letters, 67:253-260.

Santos Silva, J. M. C. and Tenreyro, S. (2006). The log of gravity. The Review of Economics and Statistics, 88(4):641-658.

Schmalensee, R. (1989). Inter-Industry Studies of Structure and Performance. In Handbook of Industrial Organization, volume 2, pages 952-1009. 
Serra, T., Gil, J. M., and Goodwin, B. K. (2006). Local Polynomial Fitting and Spatial Price Relationships: Price Transmission in EU Pork Markets. European Review of Agricultural Economics, 33(3):415-436.

Sraffa, P. (1926). The Laws of Returns under Competitive Conditions. The Economic Journal, 36:535-550.

Statistics of Jambi Province (2013). Jambi in Figures 2012. Regional Account and Statistical Analysis Division, Jambi.

Subramanian, A. and Qaim, M. (2011). Interlocked village markets and trader idiosyncrasy in rural India. Journal of Agricultural Economics, 62:690-709.

Sujarwo, R. M., Kopp, T., Nurmalina, R., Asmarantak, R. W., and Brümmer, B. (2014). Choice of Marketing Channels by Rubber Small Traders in the Jambi Province, Indonesia. Tropentag 2014: Conference Proceedings.

Tangermann, S. (1997). A Developed Country Perspective of the Agenda for the Next WTO Round of Agricultural Negotiations. Occasional Paper, page WTO Series Number 5.

Tinbergen, J. (1962). Shaping the World Economy; Suggestions for an International Economic Policy. Twentieth Century Fund, New York.

Varian, H. (1987). Intermediate microeconomics: a modern approach. Norton \& Company, New York, 1st edition.

von Cramon-Taubadel, S. (1998). Estimating asymmetric price transmission with the error correction representation: An application to the German pork market. European Review of Agricultural Economics, 25:1-18.

Vuong, Q. H. (1989). Likelihood ratio tests for model selection and non-nested hypotheses. Econometrica: Journal of the Econometric Society, 57:307-333.

Westerlund, J. and Wilhelmsson, F. (2011). Estimating the gravity model without gravity using panel data. Applied Economics, 43(6):641-649.

Wilhite, A. (2001). Bilateral trade and 'small-world'networks. Computational Economics, 18(1):49-64.

Wood, S. N. (2003). Thin plate regression splines. Journal of the Royal Statistical Society. Series B (Statistical Methodology), 65(1):95-114.

World Bank (2007). World Development Report 2008: Agriculture for Development. Oxford University Press, New York. 
Zellner, A., Kmenta, J., and Drèze, J. (1966). Specification and Estimation of Cobb-Douglas Production Function Models. Econometrica, 34:784-795. 



\section{Appendix}

\section{(1) Appendix to chapter two}

List of constraints imposed on the revenue function

Condition (a): Positive marginal products: $\frac{\delta(R e)}{\delta\left(x_{i}\right)}=\alpha_{i}+\alpha_{i i} \ln \left(x_{i}\right)+$ $\sum_{j=1}^{M}\left(\alpha_{i j} \ln x_{j}\right)>0$

(a.1) $\alpha_{1}+\alpha_{11} \ln x_{1}+\alpha_{12} \ln x_{2}+\alpha_{13} \ln x_{3}+\alpha_{14} \ln x_{4}+\alpha_{15} \ln x_{5}+\alpha_{16} \ln x_{6}>0$

(a.2) $\alpha_{7} 2+\alpha_{22} \ln x_{2}+\alpha_{12} \ln x_{1}+\alpha_{23} \ln x_{3}+\alpha_{24} \ln x_{4}+\alpha_{25} \ln x_{5}+\alpha_{26} \ln x_{6}>0$

$[\ldots]$

The $x_{i}$ enter as the sample mean. Since the variables are normalised, the mean is 1 , and the logarithm therefore 0 . This eliminates all the $\alpha_{i j} \ln x_{j}$ terms and leaves us with

(a.1) $\alpha_{1}>0$

(a.2) $\alpha_{2}>0$

$[\ldots]$

Condition (b): Diminishing marginal products: diagonals of the Hessian matrix $<0$ (Morey, 1986):

$\frac{\delta^{2}(R e)}{\delta^{2}\left(x_{i}\right)}=\left(\alpha_{i i}+\alpha_{i}\left(\alpha_{i-1}\right)\right)\left(\alpha_{i i}+\alpha_{i} \alpha_{i}\right) \ldots<0$

$(b .1):\left(\alpha_{11}+\alpha_{1}\left(\alpha_{1-1}\right)\right)<0$

$(b .2):\left(\alpha_{22}+\alpha_{2}\left(\alpha_{2-1}\right)\right)<0$

$[\ldots]$ 
Detailed results of production function estimation

\begin{tabular}{|c|c|c|}
\hline Elasticities at sample mean & Unconstrained & Constrained \\
\hline ln_x1_Rubber & $\begin{array}{c}1.0268^{* * *} \\
(0.0732)\end{array}$ & 1.0236 \\
\hline ln_x2_RespWork & $\begin{array}{c}0.0485^{* * *} \\
(0.0001)\end{array}$ & 0.0156 \\
\hline ln_x3_TranspCapacity & $\begin{array}{c}-0.0214 \\
(0.274)\end{array}$ & 0.0137 \\
\hline $\ln \_\mathrm{x} 4 \_$Distance & $\begin{array}{c}0.0105 \\
(0.4426)\end{array}$ & 0.0118 \\
\hline $\ln \_x 7 \_$Credit & $\begin{array}{l}0.0019^{*} \\
(0.0735)\end{array}$ & 0.0003 \\
\hline $\operatorname{ln\_ x1\_ square}$ & $\begin{array}{c}-0.014 \\
(0.3829)\end{array}$ & -0.0056 \\
\hline $\ln \_x 2 \_s q u a r e$ & $\begin{array}{c}0.013 \\
(0.3673)\end{array}$ & -0.0006 \\
\hline $\ln \_x 3 \_s q u a r e$ & $\begin{array}{c}0.0206^{*} \\
(0.0 .0909)\end{array}$ & -0.0048 \\
\hline $\ln \_x 4 \_s q u a r e$ & $\begin{array}{l}-0.0108 \\
(0.1225)\end{array}$ & -0.0027 \\
\hline $\ln \_x 7$ square & $\begin{array}{l}0.0001^{*} \\
(0.0698)\end{array}$ & -0.0001 \\
\hline ln_x1_ln_x2 & $\begin{array}{c}0.0082 \\
(0.3939)\end{array}$ & -0.0001 \\
\hline $\ln \_x 1 \_\ln \_x 3$ & $\begin{array}{c}0.0064 \\
(0.5154)\end{array}$ & 0.0005 \\
\hline $\ln \_x 1 \_\ln \_x 4$ & $\begin{array}{c}0.0011 \\
(0.9021)\end{array}$ & 0.0019 \\
\hline $\ln \_x 1 \_\ln \_x 7$ & $\begin{array}{c}0.0001 \\
(0.5940)\end{array}$ & 0.0001 \\
\hline $\ln \_x 2 \_\ln \_x 3$ & $\begin{array}{c}-0.0372^{* * *} \\
(0.0002)\end{array}$ & -0.0015 \\
\hline $\ln \_x 2 \_\ln \_x 4$ & $\begin{array}{c}-0.0123^{*} \\
(0.0002)\end{array}$ & -0.0002 \\
\hline $\ln \_x 2 \_\ln \_x 7$ & $\begin{array}{c}0.0001^{* * *} \\
(0.0001)\end{array}$ & 0.0001 \\
\hline
\end{tabular}




$\begin{array}{lcc}\text { ln_x3_ln_x4 } & 0.0028 & 0.0011 \\ & (0.7225 & \\ \text { ln_x3_ln_x7 } & 0.0001 & 0.0001 \\ & (0.0509) & \\ \text { ln_x4_ln_x7 } & 0.0001 & -0.0027 \\ & (0.3293) & \\ \text { dummy__x2 } & -00732 . & -0.502^{* * *} \\ & (0.3613) & (0.0001) \\ \text { dummy_x3 } & -0.0035 & 0.0252 \\ & (0.8839) & (0.4793) \\ \text { dummy_x4 } & -0.087^{*} & 0.0928 \\ & (0.0565) & (0.1154) \\ \text { dummy_x7 } & 1.276^{*} & -0.3314^{* * *} \\ & (0.0728) & (0.0001) \\ \text { Constant } & -1.274^{* * *} & 0.0764 \\ & (0.0732) & \end{array}$

Observations $209 \quad 209$

$\begin{array}{lll}\text { R-squared } & 0.987 & 0.986\end{array}$

$\mathrm{P}$ values in parentheses

*** $\mathrm{p}<0.01, * * \mathrm{p}<0.05, * \mathrm{p}<0.1$ 
(2) Appendix to chapter three

Error correction process (simple / symmetric adjustment)

\begin{tabular}{|c|c|c|c|}
\hline & $\begin{array}{l}\text { Johansen } \\
\text { D_ln_pSell }\end{array}$ & $\begin{array}{l}\text { Johansen } \\
\text { D_ln_pBuy }\end{array}$ & $\begin{array}{c}\text { Engle-Granger } \\
\text { Two-Step } \\
\text { D_ln_pBuy }\end{array}$ \\
\hline L.ect & $\begin{array}{c}-0.0153 \\
(0.511)\end{array}$ & $\begin{array}{c}-0.0593^{* * *} \\
(8.47 \mathrm{e}-08)\end{array}$ & $\begin{array}{c}-0.0583^{* * *} \\
(2.62 \mathrm{e}-05)\end{array}$ \\
\hline LD.ln_pBuy & $\begin{array}{l}-0.119 \\
(0.120)\end{array}$ & $\begin{array}{l}0.0548 \\
(0.134)\end{array}$ & $\begin{array}{l}0.0544 \\
(0.280)\end{array}$ \\
\hline L2D.ln_pBuy & $\begin{array}{l}0.0987 \\
(0.190)\end{array}$ & $\begin{array}{r}-0.0192 \\
(0.594)\end{array}$ & $\begin{array}{r}-0.0192 \\
(0.711)\end{array}$ \\
\hline L3D.ln_pBuy & $\begin{array}{r}-0.0879 \\
(0.223)\end{array}$ & $\begin{array}{l}0.0365 \\
(0.289)\end{array}$ & $\begin{array}{l}0.0365 \\
(0.372)\end{array}$ \\
\hline L4D.ln_pBuy & $\begin{array}{c}0.000486 \\
(0.994)\end{array}$ & $\begin{array}{c}0.130^{* * *} \\
(5.45 \mathrm{e}-05)(0.0400)\end{array}$ & $0.130^{* *}$ \\
\hline LD.ln_pSell & $\begin{array}{l}0.112^{* *} \\
(0.0151)\end{array}$ & $\begin{array}{c}0.155^{* * * *} \\
(0)\end{array}$ & $\begin{array}{c}0.157^{* * *} \\
(2.00 \mathrm{e}-08)\end{array}$ \\
\hline L2D.ln_pSell & $\begin{array}{l}-0.0818^{*} \\
(0.0776)\end{array}$ & $\begin{array}{c}0.138^{* * *} \\
(3.69 \mathrm{e}-10)\end{array}$ & $\begin{array}{c}0.139 * * * \\
(6.77 \mathrm{e}-06)\end{array}$ \\
\hline L3D.ln_pSell & $\begin{array}{l}0.0467 \\
(0.311)\end{array}$ & $\begin{array}{c}0.109^{* * *} \\
(7.39 \mathrm{e}-07)\end{array}$ & $\begin{array}{c}0.109 * * * \\
(5.06 \mathrm{e}-05)\end{array}$ \\
\hline L4D.ln_pSell & $\begin{array}{c}-0.0294 \\
(0.507)\end{array}$ & $\begin{array}{l}0.0360 * \\
(0.0883)\end{array}$ & $\begin{array}{l}0.0364 \\
(0.256)\end{array}$ \\
\hline Constant & $\begin{array}{c}0.000806 \\
(0.340)\end{array}$ & $\begin{array}{c}-0.000207 \\
(0.606)\end{array}$ & $\begin{array}{c}0.000500 \\
(0.247)\end{array}$ \\
\hline Observations & 701 & 701 & 701 \\
\hline
\end{tabular}


Results of tests for structural stability

Test Statistics and Estimated Asymptotic P-Values

Robust LM Statistics

SupLM $\quad 18.00196 \quad 0.058$

ExpLM $\quad 6.02526 \quad 0.05$

AveLM $\quad 8.969252 \quad 0.035$

Standard LM Statistics

SupLMs $41.01233 \quad 0$

ExpLMs $16.59242 \quad 0$

AveLMs $18.62208 \quad 0$ 


\section{(3) Questionnaire}

This is the questionnaire that was used for the data collection in Jambi, Indonesia. The survey was conducted with the Bahasa Indonesia version of this questionnaire. 


\section{Trader Field Questionnaire}

\section{Introduction:}

Good morning. Our names are and . We are doing a study on the role of traders in marketing of rubber and palm oil in Jambi province. The target of this study is to find out how the markets function on the local scale and to identify the deficiencies that constrain the business of all stakeholders involved. This will help us to increase the opportunities of everybody!

I would like to ask for your permission to participate in our questionnaire which will take around 120150 minutes. For taking your time we will give you this very nice T-Shirt when our questions are answered. You will also get this pen in the end.

All the information you provide will be treated confidentially. That means that the data will be anonymised: your personal information will be detached from your other answers, so nobody will know which are the answers you gave. If you are interested, we will provide you with a copy of the results of our study (ready in around two years). We use your phone number only if we have further questions and won't give it to anybody else.

Do you want to participate in the survey?

Are you interested in receiving the results?

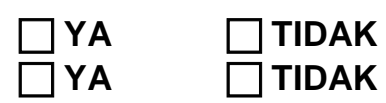

\section{Instructions for Enumerator:}

Please tick the according answer like this: $₫$

In case you ticked a wrong box please fill it completely like this:

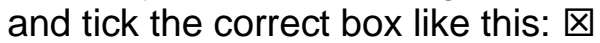

In case you filled a box completely but you want to tick it, please set a cross next to it, like this: $\times$

\section{If a trader is active in Palm Oil AND Rubber:}

Reply all questions that are marked "Weagen only concerning Rubber!

\section{Trader Identification and Enumerator Details}

\subsection{Respondent ID (from List):}

1.2. Name of respondent:

1.3. Name of village and district

1.4. Name of enumerator who filled out this questionnaire:

1.5. Name of other enumerator

1.6. Enumerator-Team:
$\square \mathrm{A}$
$\square \mathrm{B}$
$\neg \mathrm{C}$
$\square \mathrm{D}$

$\square \mathrm{E}$

1.7. Date of the interview:

1.8. Starting Time of Interview:

1.9. Gender of respondent: $\square$ MALE $\square$ FEMALE

1.10. Status of respondent: Pedagang Desa (all suppliers only from same village)

$\square$ Pedagang Kecamatan (suppliers from this Kecamatan)

$\square$ Pedagang Kabupaten (suppliers from the whole Kabupaten)

Distributor

Employee 
1.11. If Employed: by what kind of business?
$\square$ Pedagang Desa
Pedagang Kecamatan
Pedagang Kabupaten
Distributor
Factory
Farmers group

\section{If Employed: answer all the future questions for your employer unless stated otherwise.}

1.12. What is the name under which the business operates? (if Trader, write

Pedagang)

1.13. Contact Information:

Phone number.
Email Address:

1.14. Does the respondent represent somebody else?

$\square$ YA

$\square$ TIDAK

1.15. Jika $1.14=Y A:$ Who is represented?

1.16. Jika $1.14=Y A$ : Why is the originally selected trader not answering?

$\square$ Shop found, but trader could not be found

Shop found, but respondent refused

Shop found, but appears to be out of business

Shop not found

Others (specify)

\section{Characteristics of the Business}

\subsection{Ownership}

2.1.1. How many shareholders are in the business?

$\square$ Warung

$\square$ Toko

If there are more than one owner:

Which share do you own? ...\%

2.1.3. If there are more than one owner: How much do the other ones own (how many percent each)?
1: .....\% (Respondent)
2: .....\%
3: .....\%
4: ......\%
5: ......\%
6: ......\%
7: .....\%

2.1.4. Do you have a specific function in the village?

$\square$ YES $\quad \square$ TIDAK

2.1.5. Jika 2.1.4=YA: Which function?

2.1.6. What are your sources of income?

$\square$ trading $\quad: \square$ karet $\quad \square$ kelapa sawit $: \square$ masukan (Seperti: pupuk, atau benih, pestisida, etc.) $\square$ production : $\square$ karet $\square$ kelapa sawit $\square$ labour salary in this business:

$\square$ Lease out land (how many ha? ....)

$\square$ other1:

other2:

other3:

2.1.7. How much income do you generate with each activity per bulan?

Trading karet: Rp.

Trading kelapa Sawit Rp.

Trading inputs:

Produksi Karet: Rp.

Produksi Kelapa Sawit: Rp

Salary: Rp.

Warung: Rp

Toko: Rp.

Lease out land Rp......

Other1: Rp.

Other2: Rp.

Other3: Rp.

2.1.8. How much time do you spend for each activity per week?

Trading: K .... hours/day | ....... days/week

Trading: K.-S.... hours/day | ....... days/week

Trading: input.... hours/day $\mid . . . . .$. days/week

Produksi K.: .... hours/day | ....... days/week

Produksi K.-S:.... hours/day | ....... days/week

Salary: .......... hari | ......... jam / week

Warung: .... hours/day $\mid$....... days/week

Toko: .... hours/day | ....... days/week

Universitas Georg-August, Goettingen, 37073 Göttingen, Jerman 
Lease out land .... hours/day $\mid \ldots \ldots$.

Other2: .... hours/day $\mid$....... days/week days/week

Other1: .... hours/day | days/week

\subsection{Overview Trading Activities}

\section{(Instruction for enumerator: many questions in this section can be understood as related to the produksi. $\rightarrow$ always say that you are talking about the trading activities!)}

2.2.1. What type of product do you trade with?
$\square$ Karet
Kelapa sawit

2.2.2. What other products besides Rubber and Palm Oil do you market in your business? (not in warung)

Lainnya 1:

Lainnya 2:

2.2.3. How many tons per month do you produce?

$\square$ Karet .......ton

Kelapa sawit ...ton (lainnya1): .......ton (lainnya2): .......ton

2.2.4. How many tons per month do you buy from other producers / traders ? $\rightarrow$

$\square$ Karet .......ton

Kelapa sawit ...ton (lainnya1): ......ton (lainnya2): .......ton

2.2.5. How long in total have you been a trader

untuk karet?. years

untuk kelapa sawit? ........... years

2.2.6. Did you have any starting capital for your trading business?
$\square$ YA
$\checkmark$ TIDAK

2.2.7. What was the major source of start-up capital for this business?

$\square$ Personal savings

$\square$ Personal loan from family members

$\square$ Personal loan from non-family

members

$\square$ Loan from bank

Inherited

$\square$ BANSOS (Bantuan Social / Social

Help) (e.g. dari NGO)

$\square$ Help from the Government

$\square$ Other (specify):

2.2.8. If somebody wants to become a trader, what is the minimum of capital this person must have?

Rp.

2.2.9. Where does your liquidity for buying rubber or palm oil come from?

\author{
own funds \\ borrowed \\ $\square$ else (specify)
}

2.2.10. Where does your liquidity for giving credit to providers (farmers, other traders) come from?

own funds

borrowed

else (specify)

2.2.11. Do you keep written notes of the following activities?

Buying prices (Palm Oil/Rubber): 20

$\square$ every single transaction

$\square$ everything, aggregated

$\square$ less regular: ..... times per month $\square$ nothing at all

Selling prices (Palm Oil/Rubber): 2\%2

$\square$ every single transaction

$\square$ everything, aggregated

$\square$ less regular: ..... times per month

$\square$ nothing at all

Traded amounts (PalmOil/Rubber):

$\square$ every single transaction

$\square$ everything, aggregated

$\square$ less regular: ..... times per month

$\square$ nothing at all

Credits given:
$\square$ every single transaction
$\square$ everything, aggregated
$\square$ less regular: ..... times per month
$\square$ nothing at all

2.2.12. How many other traders are in the dusun?

Karet:

Sawit:

2.2.13. How many other traders are in the village?

Karet:

Sawit:

2.2.14. When was this village founded?

2.2.15. Is this a transmigrasi village?
$\square$ YA
$\square$ TIDAK 


\subsection{Human Capital:}

2.3.1. How many people work in the business (except of family members)? people

If more than five: fill out the following questions for the five most important ones

Person 1 activity:

Person 2 activity:

Person 3 activity:

Person 4 activity:

Person 5 activity:

2.3.2. In which part of your business is each of them employed?

Person 1:

$\square$ Production $\square$ Trading

Person 2:

$\square$ Production $\square$ Trading

Person 3:

$\square$ Production $\square$ Trading

Person 4:

$\square$ Production $\square$ Trading

Person 5:

$\square$ Production $\square$ Trading

2.3.3. How many hours do they work?

Person 1 : ...hours/week

Person 2 : ....hours/week

Person 3 : ....hours/week $\square$ Person 4 : ....hours/week

Person 5 : ....hours/week

2.3.4. How are the workers paid?:

Person 1: $\square$ Salary: ..... per day:

Share of profit: ....... \%

Share of harvest: ...... \%

Person 2: $\square$ Salary: ..... per day:

Share of profit: ....... \%

Share of harvest: ...... \%

Person 3: $\square$ Salary: ..... per day:

Share of profit: ...... \%

Share of harvest: ...... \%

Person 4: $\square$ Salary: ..... per day:

Share of profit: ....... \%

$\square$ Share of harvest: ...... \%

Person 5: $\square$ Salary: ..... per day:

Share of profit: ....... \%

Share of harvest: ...... \%

2.3.5. What did you spend on labour salary in the last week?

Person 1:

Person 2:

Person 3:

Person 4:

Person 5:

\subsection{Taking Credit}

2.4.1. Which institutions are in your village where you can take a loan from? (multiple answers possible)
$\square$ None
Bank
Microfinance scheme
(Informal) money lender
Warehouse
Government program
KUD
Else (specify)

2.4.2. Specification of all the credits you took during the last 6 months 


\begin{tabular}{|l|l|l|l|l|l|l|l|}
\hline $\begin{array}{l}\text { Loan- } \\
\text { No: }\end{array}$ & $\begin{array}{l}\text { When did } \\
\text { you take } \\
\text { this loan? }\end{array}$ & $\begin{array}{l}\text { What was } \\
\text { the } \\
\text { purpose } \\
\text { of the } \\
\text { loan? }\end{array}$ & $\begin{array}{l}\text { Which was } \\
\text { the size of } \\
\text { this loan? }\end{array}$ & $\begin{array}{l}\text { Who } \\
\text { provided } \\
\text { this loan? } \\
\text { } \text { l* }\end{array}$ & $\begin{array}{l}\text { When did } \\
\text { you pay it } \\
\text { back? }\end{array}$ & $\begin{array}{l}\text { How much } \\
\text { did you } \\
\text { have to pay } \\
\text { back? }\end{array}$ & $\begin{array}{l}\text { How much } \\
\text { interest did } \\
\text { you pay? }\end{array}$ \\
\hline A & & & & & & & \\
\hline B & & & & & & & \\
\hline C & & & & & & & \\
\hline D & & & & & & & \\
\hline E & & & & & & & \\
\hline
\end{tabular}

1) Purchase Rubber / Palm Oil

2) Purchase pick- up or lorry for business

**

1) Bank

2) Microfinance scheme

3) (Informal) money lender

4) Warehouse

2.4.3. (question deleted)

2.4.4. (question deleted)

2.4.5. (question deleted)

2.4.6. How much time is there in general for you between asking for a credit and receiving it?

$$
\square \text { hari / } \square \text { bulan }
$$

2.4.7. When you have taken a credit from a potential buyer, do you then always have to sell to him?

$\square$ YA $\square$ TIDAK

$\square$ Not, if
3) Expand or improve business premises
4) Give credit to providers
5) Purchase inputs
6) Other (specify)
5) Input seller
6) Government program
7) KUD
8) Else (specify)

2.4.8. What are the preconditions you need to meet when taking a credit from a buyer?

Big number of transactions per year

$\square$ Providing collateral

If yes: what?

Positive references from other people

Other (specify)

2.4.9. Legislation of credits

$\square$ Written contracts

Verbal contracts

Written records of the credit

Possibility to re-negotiate

Requirement of down-payment?

Else? (specify)

\subsection{Physical Capital:}

2.5.1. How many computers do you own?

2.5.2. If there are computers, do you use them for your business?

$$
\square \text { YA } \square \text { TIDAK }
$$

2.5.3. In your house and storage house / warehouse, how many $\mathrm{kg}$ can you store in total?

Karet:
Kelapa sawit:

2.5.4. If your storage space is full, Do you have further possibilities of storage? $\square$ YA $\square$ TIDAK Specify:

2.5.5. If you use another storage space, how much do you have to pay for it?

Rp. 
2.5.6. Do you rent any vehicle on a regular basis? $\square$ YA $\square$ TIDAK

2.5.7. Do you own any motorized vehicle? $\square$ YA $\square$ TIDAK

2.5.8. Information on vehicles that you own:

\begin{tabular}{|c|c|c|c|c|c|c|c|c|}
\hline NO & $\begin{array}{l}\text { Type of } \\
\text { vehicle } \\
\text { (name: } \\
\text { Motorbike, } \\
\text { car, truck, } \\
\text { etc..) and } \\
\text { brand. }\end{array}$ & $\begin{array}{l}\text { Type of } \\
\text { vehicle* }\end{array}$ & $\begin{array}{l}\text { Capacity } \\
\text { of this } \\
\text { vehicle } \\
\text { (tons) } \\
\text { (if not for } \\
\text { load: } \\
\text { write } \\
\text { "only } \\
\text { people") }\end{array}$ & $\begin{array}{l}\text { When } \\
\text { was it } \\
\text { bought? }\end{array}$ & $\begin{array}{l}\text { For how long } \\
\text { more can you } \\
\text { approximately } \\
\text { use it? }\end{array}$ & $\begin{array}{l}\text { What } \\
\text { would } \\
\text { be the } \\
\text { price of } \\
\text { selling } \\
\text { this } \\
\text { vehicle } \\
\text { right } \\
\text { now? } \\
\text { (market } \\
\text { value?) }\end{array}$ & Purpose: & $\begin{array}{l}\text { Do you } \\
\text { rent it } \\
\text { out? } \\
\text { If yes: for } \\
\text { how } \\
\text { many } \\
\text { Rp/day? }\end{array}$ \\
\hline 1 & & & & & & & & \\
\hline 2 & & & & & & & & \\
\hline 3 & & & & & & & & \\
\hline 4 & & & & & & & & \\
\hline 5 & & & & & & & & \\
\hline 6 & & & & & & & & \\
\hline 7 & & & & & & & & \\
\hline 8 & & & & & & & & \\
\hline 9 & & & & & & & & \\
\hline
\end{tabular}

*.

1) Motorcycle

2) Private Car

3) Pick Up

4) Truck

$\star \star$.

1: picking up palm oil

2: picking up rubber

3: delivering palm oil

4: delivering rubber

5: picking up inputs

6: delivering inputs

7: others (specify):

\subsection{Land}

2.6.1. How much land do you own?

ha

2.6.2. Is it in one piece or fragmented?
$\square$ one piece
$\square$ fragmented

2.6.3. If fragmented, how many pieces:

Universitas Georg-August, Goettingen, 37073 Göttingen, Jerman 
2.6.4. Information on the fields

\begin{tabular}{|c|c|c|c|c|c|c|c|c|}
\hline $\begin{array}{c}\text { Field } \\
\text { NO }\end{array}$ & $\begin{array}{l}\text { Size } \\
\text { (ha) }\end{array}$ & $\begin{array}{l}\text { Do you have } \\
\text { a land } \\
\text { certificate } \\
\text { for this? ( } \mathrm{Y} / \\
\mathrm{N} / \text { ) }\end{array}$ & $\begin{array}{l}\text { What is } \\
\text { the land } \\
\text { used } \\
\text { for? } \\
\text { * }\end{array}$ & $\begin{array}{l}\text { Is this land } \\
\text { already } \\
\text { producing? }\end{array}$ & $\begin{array}{l}\text { Since } \\
\text { when do } \\
\text { you have } \\
\text { it? } \\
\text { (month / } \\
\text { year) }\end{array}$ & $\begin{array}{l}\text { How } \\
\text { did } \\
\text { you } \\
\text { get it? } \\
\star \star\end{array}$ & $\begin{array}{l}\text { What } \\
\text { would be } \\
\text { the price of } \\
\text { selling this } \\
\text { field right } \\
\text { now? }\end{array}$ & $\begin{array}{l}\text { Who is } \\
\text { working } \\
\text { on the } \\
\text { land? } * * *\end{array}$ \\
\hline 1 & & & & & & & & \\
\hline 2 & & & & & & & & \\
\hline 3 & & & & & & & & \\
\hline 4 & & & & & & & & \\
\hline 5 & & & & & & & & \\
\hline 6 & & & & & & & & \\
\hline 7 & & & & & & & & \\
\hline 8 & & & & & & & & \\
\hline
\end{tabular}

*.
1) Kelapa Sawit
2) Karet

**:

1) Bought
2) Inhereted

$\star \star \star$ :

\section{1) Family members \\ 2) Labourers}

2.6.5. Do you lease out any land?

$\square$ YA $\quad \square$ TIDAK

Since when? ........ months

How much? ..............ha

2.6.6. Do you have any sharecropping arrangements in place?
$\square$ YA
$\square$ TIDAK

2.6.7. Jika 2.6.6=YA: since when are are they in place?

Since ......... years

2.6.8. Jika 2.6.6=YA: How many ha and with how many people?

ha

orang

Is this included in the table above?

$\square$ YA $\quad \square$ TIDAK
3) Rice

4) Lainnya (specify)

3) Transmigrasi

4) Else (specify)

3) Else (specify)

4) Respondent

2.6.9. Jika 2.6.6=YA: Who takes the decision concerning:

What is cultivated?

$\square$ Respondent $\square$ Petani

How to cultivate?

$\square$ Respondent $\square$ Petani

When to sell?

$\square$ Respondent $\square$ Petani

Whom to sell?

$\square$ Respondent $\square$ Petani

2.6.10. Do you "offer" new sharecropping contracts?
$\square$ YA
$\square$ TIDAK

2.6.11. Are you allowed to use land in communal area (forest e.g.)?

$\square$ YA $\quad \square$ TIDAK

How much? ............ ha 


\section{Business activities I}

\subsection{Palm Oil / Rubber Trade (towards downstream, i.e. buyers)}

3.1.1. Rubber: What do you understand by KKK ("Kader Kering Karet”) and „Basi“? KKK:

Basi:

3.1.2. palm oil: What do you understand by "rendemin sawit"? rendomen

3.1.3. Information on the firms that are your most important buyers of

\begin{tabular}{|c|c|c|}
\hline & \multicolumn{2}{|c|}{ Three most important buyers } \\
\hline & 1 & 3 \\
\hline \multicolumn{3}{|l|}{ a) Type of buyer * } \\
\hline \multicolumn{3}{|l|}{$\begin{array}{l}\text { b) Name of buyer (if factory / } \\
\text { warehouse:name of factory / warehouse) }\end{array}$} \\
\hline \multicolumn{3}{|l|}{$\begin{array}{l}\text { If gudang: is it acting as commission agent } \\
\text { (facilitates, get's share of traded value), or as } \\
\text { a trader (buying \& selling)? }\end{array}$} \\
\hline \multicolumn{3}{|l|}{$\begin{array}{l}\text { What is the name of the person who you } \\
\text { talk to? }\end{array}$} \\
\hline \multicolumn{3}{|l|}{$\begin{array}{l}\text { What is the status of this person? } \\
\text { - agen komisi } \\
\text { - employee of the business named above } \\
\text { - owner of the business named above } \\
\text { - self-employed (toke) } \\
\text { - self-employed (pedagang lebih besar) }\end{array}$} \\
\hline \multicolumn{3}{|l|}{$\begin{array}{l}\text { What is the ethnic group of this person? } \\
\text { 1: Jambi Kota } \\
\text { 2a: Jambi Desa } \\
\text { 2b: Jawa } \\
\text { 3: Cina } \\
\text { 4: Lainnya: ... }\end{array}$} \\
\hline \multicolumn{3}{|l|}{$\begin{array}{l}\text { Is this person employedor self-employed) ( } \\
\text { E / S.-E.) }\end{array}$} \\
\hline \multicolumn{3}{|l|}{$\begin{array}{l}\text { t) Are you registered in this institution as a } \\
\text { trader }(Y / T)\end{array}$} \\
\hline \multicolumn{3}{|l|}{$\begin{array}{l}\text { u) Is the institution that you deliver to also } \\
\text { the institution where you get the money } \\
\text { from? }(Y / T)\end{array}$} \\
\hline \multicolumn{3}{|l|}{ c) When did the business relationship start? } \\
\hline \multicolumn{3}{|l|}{ d) When did it end? (leave blank if ongoing) } \\
\hline \multicolumn{3}{|l|}{ e) Where ist the firm located? } \\
\hline \multicolumn{3}{|l|}{ 1. In the same village $(\mathrm{Y} / \mathrm{N})$} \\
\hline \multicolumn{3}{|l|}{ 2. Jambi City $(\mathrm{Y} / \mathrm{N})$} \\
\hline \multicolumn{3}{|l|}{ 3. Country (If not in Indonesia) } \\
\hline \multicolumn{3}{|l|}{ 4. Province (If not in Jambi) } \\
\hline \multicolumn{3}{|l|}{ 5. Regency (Kabupaten) } \\
\hline 6. District (kecamatan) & & \\
\hline
\end{tabular}




\begin{tabular}{|c|c|c|c|}
\hline 7. Village & & & \\
\hline 8. Dusun & & & \\
\hline $\begin{array}{l}\text { h) Within how many days do you get paid? } \\
\text { (Y="immediately") }\end{array}$ & & & \\
\hline $\begin{array}{l}\text { i) Does the quality that you get paid vary } \\
\text { every week? (Quality for rubber: basi } \\
\text { content, KKK, etc., quality for oil palm: age of } \\
\text { palm) }(\mathrm{Y} / \mathrm{T})\end{array}$ & & & \\
\hline $\begin{array}{l}\text { j) Does the quality that you get paid vary } \\
\text { only between rainy and dry season? }(\mathrm{Y} / \mathrm{T})\end{array}$ & & & \\
\hline $\begin{array}{l}\text { k) Do you always get paid the same quality? } \\
(\mathrm{Y} / \mathrm{T})\end{array}$ & & & \\
\hline $\begin{array}{l}\text { I) What price did you recive last week? } \\
\text { (Rp./kg) }\end{array}$ & & & \\
\hline $\begin{array}{l}\text { m) What price did you recive three months } \\
\text { ago? (Rp./kg) }\end{array}$ & & & \\
\hline $\begin{array}{l}\text { n) Is there a difference in price whether } \\
\text { rubber has been stored in box or sack? (Ya / } \\
\text { Tidak) }\end{array}$ & & & \\
\hline $\begin{array}{l}\text { 0) How many tons of Rubber/ Palm Oil did } \\
\text { you sell to this firm in total in the last } \\
\text { September? }\end{array}$ & $\begin{array}{l}\text { K: .... ton } \\
\text { K.-S.: ..... ton }\end{array}$ & $\begin{array}{l}\text { K: .... ton } \\
\text { K.-S.: ..... ton }\end{array}$ & $\begin{array}{l}\mathrm{K}: \ldots . . \text { ton } \\
\mathrm{K} . \mathrm{S} .: \ldots . . . \text { ton }\end{array}$ \\
\hline $\begin{array}{l}\text { How many rupiahs did you get paid for this } \\
\text { amount? }\end{array}$ & $\begin{array}{l}\text { K: Rp..... } \\
\text { K.-S.: Rp. ..... }\end{array}$ & $\begin{array}{l}\text { K: Rp..... } \\
\text { K.-S.: Rp. ..... }\end{array}$ & $\begin{array}{l}\text { K: Rp..... } \\
\text { K.-S.: Rp. ..... }\end{array}$ \\
\hline $\begin{array}{l}\text { p) How many separate deliveries of Palm } \\
\text { Oil / Rubber did you execute to this firm } \\
\text { within september? }\end{array}$ & $\begin{array}{l}\text { K: } \ldots \ldots \text { kali } \\
\text { K.-S........ kali }\end{array}$ & $\begin{array}{l}\mathrm{K}: \ldots \ldots \text { kali } \\
\mathrm{K} . \mathrm{S} . . \ldots \ldots \ldots \text { kali }\end{array}$ & $\begin{array}{l}\text { K: } \ldots \ldots \text { kali } \\
\text { K.-S.:..... kali }\end{array}$ \\
\hline What was the quality of these deliveries? & $\begin{array}{l}\mathrm{K}: \ldots \ldots \ldots \ldots \ldots \\
\mathrm{K} . \mathrm{S} . \mathrm{A} \ldots \ldots \ldots \ldots\end{array}$ & $\begin{array}{l}\text { K: } \ldots \ldots \ldots \ldots \ldots \\
\text { K.-S.: } \ldots \ldots \ldots \ldots \ldots\end{array}$ & K: $\ldots \ldots \ldots \ldots \ldots \ldots$ \\
\hline $\begin{array}{l}\text { q) In which ones of the last } 6 \text { months have } \\
\text { you been indebted to this buyer? }\end{array}$ & & & \\
\hline $\begin{array}{l}\text { r) Which arrangements do you have with this } \\
\text { buyer? }^{* *} \text { (multiple answers possible) }\end{array}$ & & & \\
\hline 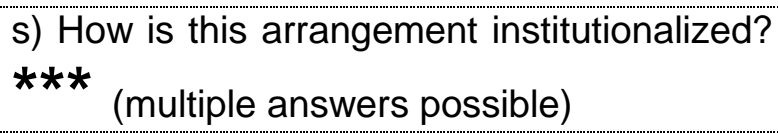 & & & \\
\hline
\end{tabular}

1) Other trader

2) Warehouse (gudang)
3) Factory
4) Pasar lelang (Auction Market)
5) else (specify)

$\star \star$

1) Sales guarantees

2) Price guarantees

3) Quantities delivered
4) Arrangements on delivering goods

5) Arrangements on picking up goods

6) Arrangements on paying of transport 
7) Other (specify)

\section{$\star \star \star$}

1) Written contract

5) Meeting at least once a week

2) Verbal contract

6) Meeting at least once a month

3) Can be re-negotiated

7) Meeting at least once in three months

4) Meeting daily

3.1.4. If you're not selling directly to a factory: Why do you not sell directly to the factory? "Wa

\section{The following replies are written in Formular Number 1:}

3.1.5. How many tons of Palm Oil / Rubber have you delivered in each of the last 12 month to the three buyers mentioned above?
3.1.6. How many Rupiah did you get for each of these deliveries?

\subsection{Transaction costs of selling palm oil / rubber}

Introduction: Now I would like you to describe the costs you face in delivering a normal order of Palm Oil / Rubber to your current most important buyer that you identified earlier. I will ask you about a series of payments you might need to make related to transporting the Palm Oil / Rubber order from your business to the buyer.

3.2.1. What is the exact size of a normal (average) delivery of Palm Oil / Rubber to one buyer? (How many $\mathrm{kg}$ ?)

3.2.5. Do you buy karet / kelapa Sawit in the whole village or only in some parts?

$\square$ in the whole village

n.m.

3.2.2. (question deleted)

3.2.6. If 3.2.5=NO: why?

3.2.3. Where is the location of the transaction? (IF Auction Market: Write,PL")

3.2.7. Are there traders who are active in the other parts?

$\square$ YA $\square$ TIDAK

3.2.4. How much do you pay for benzin to transport one delivery of Palm Oil / Rubber to the buyer? (and how many liters?)

3.2.8. What happens if one trader starts doing business in the part of another one?

\subsection{Other Costs}

3.3.1. When delivering kelapa sawit/karet, how often do you have to pay retribusi in average per trip? times
3.3.2. How much each time in average?

\section{gera}

Rp.

3.3.3. Who is responsible for paying them?

$\square$ responden 
buyer

Transporter

else (specify)

3.3.4. Do you pay any other fees or taxes for your Rubber / Palm Oil order? For example, to local authorities, district authorities, or the central revenue authority? Other examples might include an annual license fee or market dues.

$\square$ YA $\square$ TIDAK

3.3.5. Is there a fee you have to pay to the factory / warehouse?

$\square$ YA $\square$ TIDAK

3.3.6. IF 3.3.5=YA: How much?

Rubber:

$\square$ matrai: Rp.
Palm Oil:

warehouse comission: Rp. ...

buruh: Rp. ........ / kg

unloading vehicle: Rp. ...

else:

matrai: Rp

$\square$ warehouse comission: Rp. ...

$\square$ buruh: Rp. ........ / kg

$\square$ unloading vehicle: Rp. ...

$\square$ else:

3.3.7. Is there a person you have to pay at the factory?

$\square$ YA $\square$ TIDAK

3.3.8. If 3.3.7=YA: How much?

3.3.9. Is there anything else you have to pay for your delivery which was not mentioned yet?

3.3.10. How many \% of all palm oil / rubber deliveries were picked up by the buyer at your place in the last half year?

$\%$

3.3.11. How many \% of all your palm oil / rubber deliveries did you deliver to the buyer yourself in the last half year?

............. \%

3.3.12. Of all the palm oil / rubber deliveries that you delivered up yourself, what was the most common way of transport during the last half year?

\begin{tabular}{|c|c|c|c|c|c|c|}
\hline \multirow{2}{*}{$\begin{array}{l}\text { ID of } \\
\text { vehicle } \\
*\end{array}$} & \multirow{2}{*}{$\begin{array}{l}\text { How often } \\
\text { is this } \\
\text { vehicle } \\
\text { used? }\end{array}$} & \multirow{2}{*}{$\begin{array}{l}\text { Which } \\
\text { Product is } \\
\text { it used } \\
\text { for? (K.-S. } \\
\text { or K.) }\end{array}$} & \multirow{2}{*}{$\begin{array}{l}\text { How much } \\
\text { do you } \\
\text { pay per } \\
\text { ton to } \\
\text { have it } \\
\text { loaded up } \\
\text { the } \\
\text { vehicle? }\end{array}$} & \multicolumn{3}{|c|}{ If hired / public: } \\
\hline & & & & $\begin{array}{l}\text { Capacity of this } \\
\text { vehicle } \\
\text { /load) }\end{array}$ & $\begin{array}{l}\text { What are the } \\
\text { daily costs of } \\
\text { hiring this } \\
\text { transportation? }\end{array}$ & $\begin{array}{l}\text { Who pays for } \\
\text { it? }\end{array}$ \\
\hline & & & & & & \\
\hline & & & & & & \\
\hline & & & & & & \\
\hline & & & & & & \\
\hline & & & & & & \\
\hline & & & & & & \\
\hline
\end{tabular}

*
\#) from Question 2.5.8 (put in which number)
P) Public (specify
R) Rented
O) Other (specify)

3.3.13. How many $\mathrm{kg}$ were delivered in total during the last half year? Kelapa sawit: ............ Karet: .......

3.3.14. How many rupiah are the transport costs in the rainy season higher than in the dry season? Rp. 


\section{Trading activities II}

\subsection{Palm Oil / Rubber Trade (from upstream, i.e. farmers or other traders)}

4.1.1. Do all providers deliver the same quality?

$\square$ YA $\square$ TIDAK

4.1.2. If Karet: Do all providers deliver the same grade of cleanness

("kebesihan")?

$\square$ YA $\square$ TIDAK

4.1.3. Quality: How do you measure quality of rubber (KKK, Basi, etc.) / palm oil (rendemin)?

4.1.4. Has all the incoming rubber been treated with the same coagulant? $\square$ YA $\square$ TIDAK

4.1.5. If 4.1.3=YA: which one?

4.1.6. Do all farmers get the same price per kg.?

$\square$ YA $\square$ TIDAK

4.1.7. Does the quality, the cleanness and the coagulant used impact the payment?

Kualitas: $\quad \square$ YA $\square$ TIDAK

Kebersihan: $\square$ YA $\square$ TIDAK

Koagulan: $\square$ YA $\square$ TIDAK

4.1.8. If one of the above (4.1.7)=YES: how is this happening?

4.1.9. Do you have the freedom to set the base-prices alone?

$\square$ YA $\square$ TIDAK

4.1.10. JIGA 4.1.9.=TIDAK: Who sets the price?

4.1.11. JIGA 4.1.9.=YA: Do you talk with anybody about the next price? $\square$ YA $\square$ TIDAK

4.1.12. JIGA 4.1.11=YA: Is it possible to say who are the possible people to discuss the next price with?

\author{
friends \\ family members \\ other traders \\ warehouse \\ other (specify)
}

4.1.13. JIGA 4.1.11.=YA: How often do you do this?

.......... times $\square$ per week / $\square$ per month

4.1.14. Within how many days after delivery do you pay?

(Y="immediately, right at the spot")?

............... days

4.1.15. JIGA 4.1.14=Y, where do YOU get the liquidity for the purchase from? respondent's own savings buyer further downstream other (specify)

4.1.16. Is it possible for a farmer to get a cash advance from you?
$\square$ YA $\quad \square$ TIDAK

4.1.17. What is the maximum amount of this? Rp. $\%$ of average delivery

4.1.18. Do you sometimes pay in inkind?
$\square$ YA
$\square$ TIDAK

4.1.19. If 4.1.18=Ya: Which?
$\square$ Sepeda
$\square$ Sepeda Motor
$\square$ Motor
$\square$ TV
$\square$ telpon selular
$\square$ Lainnya (Specify):

4.1.20. Is there a difference in the price depending on the rubber being stored in a sack or in a box?

$\square$ YA $\square$ TIDAK

4.1.21. [Show the list of Farmers Survey] $\rightarrow$ Do you buy rubber/sawit from two of them?

And who are the most important farmers / middlemen from whom you buy Rubber / Palm Oil? 32. If active in Rubber and Sawit, only talk about Karet!

If two from the list are known: put their names in column $1 \& 2$ and the two most important provider in column 3.

Universitas Georg-August, Goettingen, 37073 Göttingen, Jerman 
If only one is known: Put his/her name in column $\mathbf{1}$ and the two most important providers in column 2 \& 3.

If none is known: Put the names of the three most important providers in column $\mathbf{1}, \mathbf{2}, \mathbf{\&} \mathbf{3}$.

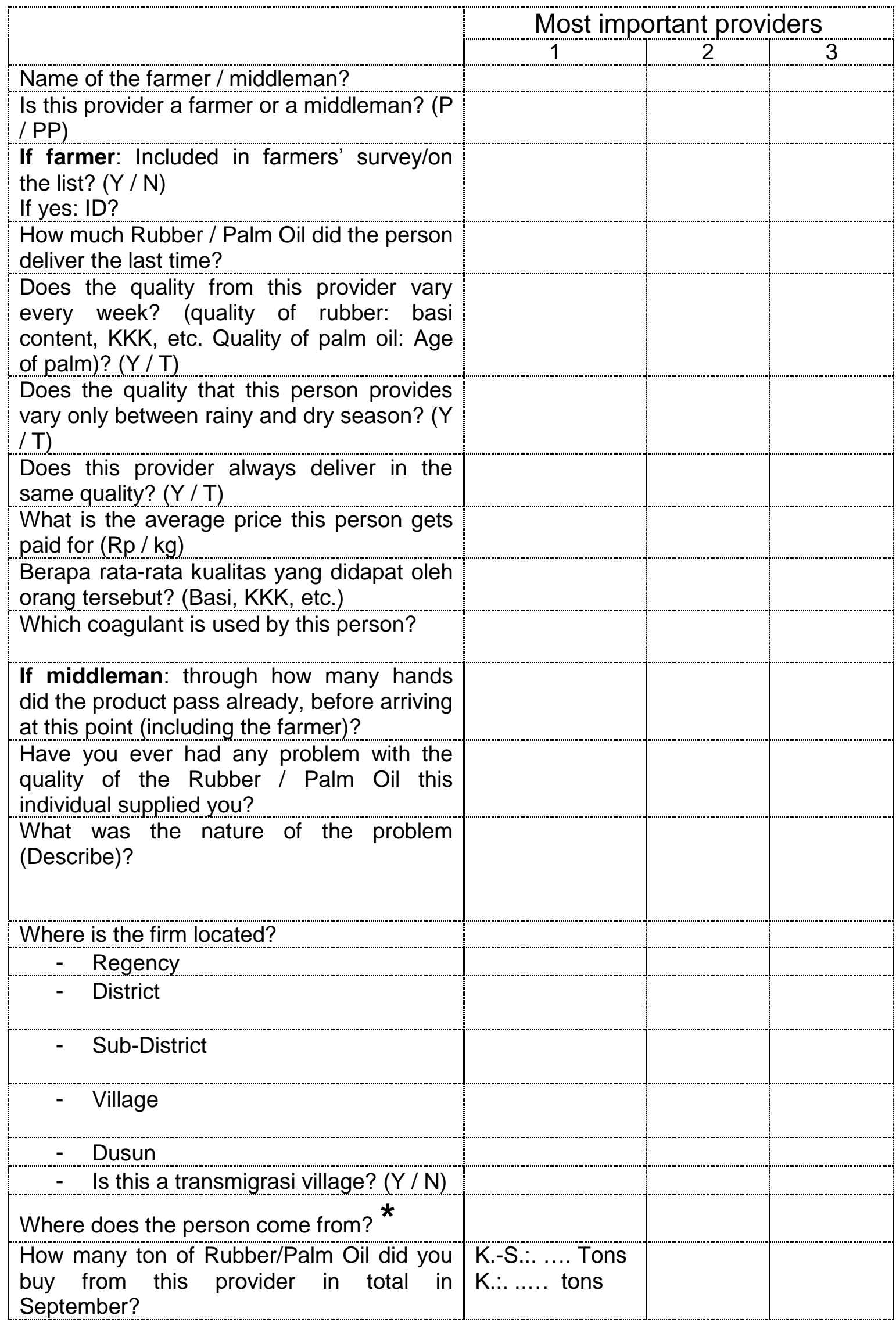




\begin{tabular}{|c|c|c|c|}
\hline $\begin{array}{l}\text { What did you pay to the provider of Rubber } \\
\text { / Palm Oil in total during September? }\end{array}$ & $\begin{array}{l}\text { K.-S: Rp. } \ldots . \\
\text { K.: Rp. }\end{array}$ & & \\
\hline $\begin{array}{l}\text { How many separate deliveries did you } \\
\text { receive from this provider in Rubber/Palm } \\
\text { Oil in September? }\end{array}$ & $\begin{array}{l}\text { K.-S.: } \ldots \text { times } \\
\text { K.: ...times }\end{array}$ & & \\
\hline What was the quality of these deliveries? & $\begin{array}{l}\text { K.-S.: } \\
\ldots \ldots \ldots \ldots \ldots \ldots \ldots \\
\ldots \ldots \ldots \ldots \ldots \ldots \ldots \ldots \ldots \\
\text { K.: } \ldots \ldots \ldots \ldots \ldots \ldots \\
\ldots \ldots \ldots \ldots \ldots \ldots \ldots \ldots \ldots\end{array}$ & & \\
\hline $\begin{array}{l}\text { If Palm Oil: Is this farmer a plasma farmer? } \\
(\text { YA / TIDAK) }\end{array}$ & & & \\
\hline $\begin{array}{l}\text { Which arrangements do you have with this } \\
\text { pruducer? }^{* \star} \text { (multiple answers possible) }\end{array}$ & & & \\
\hline $\begin{array}{l}\text { How is this arrangement institutionalized? } \\
\star \star \star \star \quad \text { (multiple answers possible) }\end{array}$ & & & \\
\hline \multicolumn{4}{|l|}{$\begin{array}{l}\text { How much input has been sold to the } \\
\text { providers per month? }\end{array}$} \\
\hline 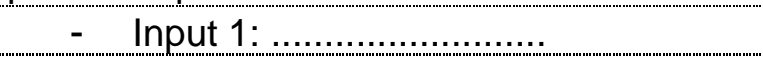 & Rp.: $\ldots \ldots \ldots$ & $R p .: \ldots \ldots$ & Rp.:.......... \\
\hline - $\quad$ Input $2:$......................... & Rp.: .......... & Rp.:.......... & Rp.:............ \\
\hline - Input 3: $\ldots \ldots \ldots \ldots \ldots \ldots \ldots \ldots \ldots \ldots$ & Rp.: ........... & Rp.:....... & Rp.:....... \\
\hline
\end{tabular}

1) Village where she / he is living at right now

2) From another village in Jambi

$\star \star$

1) Sales guarantees

2) Price guarantees

3) Quantities delivered

4) Arrangements on delivering goods

$\star \star * *$

1) Written contract

2) Verbal contract

3) Can be re-negotiated

4) Meeting daily
3) Transmigrant

4) other (Specify)

5) Arrangements on picking up goods

6) Arrangements on paying of transport

7) Provision of inputs

4.1.22. Which amount of Palm Oil / Rubber have you received from these 4 farmers / other traders in total at every month during the last 12 montsh? FORMULAR NUMBER 2

4.1.23. How much money has been paid to these 4 farmers / other traders at every month during the last 12 month for the respective amounts? FORMULAR NUMBER 2 \%

\subsection{Transaction costs of buying Palm Oil / Rubber}

Introduction: I would now like you to describe the costs you face in buying a normal order of Palm Oil / Rubber from your most important providers (farmers or other middlemen) that you identified earlier. I will ask you about a series of payments you might need to make related to transporting the Palm Oil / Rubber order from the farmer to your business.

4.2.1. What is the exact size of a normal $\mathrm{kg}$.

(average) delivery of Palm Oil / Rubber from your most important provider? (How many kg?))

6) Meeting at least once a month

7) Meeting at least once in three months 
4.2.3. Where is the location of the transaction? (IF Auction Market: write,PL")

4.2.4. Road fees: Are there any paying road fees at traffic stops, road blocks, or weigh bridges during the transport of the Palm Oil / Rubber delivery to you? 2xa
$\square$ YA
$\square$ TIDAK

4.2.5. How many are there usually?

4.2.6. Who is responsible for paying them?

$\square$ responden

$\square$ seller

$\square$ Transporter

$\square$ else (specify)

4.2.7. How much do you pay for road fees for your Palm Oil / Rubber order in total in transporting it from the provider to your business?

4.2.8. Where do the transporters load the order? rex
Collection point in village

At individual farmers

At individual traders

Other (Specify)

4.2.9. Do you pay any other fees or taxes for your Rubber / Palm Oil order? For example, to local authorities, district authorities, or the central revenue authority? Other examples might include an annual license fee or market dues..
$\square$ YES
$\square \mathrm{NO}$

4.2.10. Jika 4.2.9.=YA: Please specify: how much is to be paid where?

4.2.11. How often do you have to pay retribusi in average per trip? times

4.2.12. How much each time in average? Rp.

4.2.13. How many \% of all palm oil / rubber purchases was delivered to you by the produsen / pedagang lain in the last half year?

.............. \%

4.2.14. How many \% of all your palm oil / rubber purchases did you pick up at the produsen / pedagang lain in the last half year?

..............\%

4.2.15. Of all the palm oil / rubber purchases that you picked up yourself, what was the most common way of transport during the last half year?

\begin{tabular}{|c|c|c|c|c|c|c|c|}
\hline \multirow{2}{*}{$\begin{array}{l}\text { ID of } \\
\text { vehicle } \\
\star\end{array}$} & \multirow{2}{*}{$\begin{array}{l}\text { What } \\
\text { percentage } \\
\text { of the } \\
\text { TOTAL } \\
\text { amount was } \\
\text { transported } \\
\text { with this } \\
\text { vehicle? }\end{array}$} & \multirow{2}{*}{$\begin{array}{l}\text { How } \\
\text { often } \\
\text { is it } \\
\text { used? }\end{array}$} & \multirow{2}{*}{$\begin{array}{l}\text { Do you } \\
\text { pesonally } \\
\text { go with } \\
\text { the } \\
\text { vehicle to } \\
\text { pick up } \\
\text { the } \\
\text { rubber? }\end{array}$} & \multirow{2}{*}{$\begin{array}{l}\text { How much } \\
\text { do you pay } \\
\text { per kg to } \\
\text { have it } \\
\text { loaded up or } \\
\text { down from a } \\
\text { truck? }\end{array}$} & \multicolumn{3}{|c|}{ If hired / public } \\
\hline & & & & & $\begin{array}{l}\text { Capacity } \\
\text { of this } \\
\text { vehicle } \\
\text { (kg / } \\
\text { road) }\end{array}$ & $\begin{array}{l}\text { What are the } \\
\text { daily costs of } \\
\text { hiring this } \\
\text { transportation? }\end{array}$ & $\begin{array}{l}\text { Who } \\
\text { pays for } \\
\text { it? }\end{array}$ \\
\hline & & & & & & & \\
\hline & & & & & & & \\
\hline & & & & & & & \\
\hline & & & & & & & \\
\hline & & & & & & & \\
\hline & & & & & & & \\
\hline
\end{tabular}

\#) from Question 2.5.11

P) Public (specify

R) Rented

O) Other (specify) 
4.2.16. What is the minimum amount of $\mathrm{kg}$ of palm oil / rubber per delivery that you accept? $\mathrm{kg}$ \%es

4.2.17. How many single transactions of buying palm oil / rubber do you execute per month?

4.2.18. How many incidents of bad quality delivered did you encounter last month?

खथ ............... times

\section{Providing credit}

\subsection{General}

5.1.1. Do you provide rubber/palm oil farmers with credit?

$\square$ YA $\square$ TIDAK

IF 5.1.1=TIDAK: CONTINUE WITH SECTION 6 !
5.1.2. Do you provide farmers with credit in order to buy inputs from you?

$\square$ YA $\quad \square$ TIDAK

5.1.3. Do you provide farmers with credit that is not used for purchasing inputs from you?

\subsection{Preconditions for getting a credit from you}

5.2.1. Can everybody who wants get a credit from you?

$\square$ YA $\square$ TIDAK

5.2.2. If 5.2.1=TIDAK: Does a farmer have to sell their Rubber / Palm Oil to you when he wants to take a credit from you?

$\square$ YA $\quad \square$ TIDAK

5.2.3. For how long must one have been a good business partner to get a credit from you?

$\square$ Minimum of weeks of selling Rubber

/ Palm Oil to you (time):

Minimum of Rubber / Palm Oil sales to you (amount):

$\square$ No waiting time
5.2.4. Providing collateral?

$$
\square \text { YA } \square \text { TIDAK }
$$

5.2.5. Jika 5.2.4=YA: What can be used as collateral?

Land: $\square$ YA $\square$ TIDAK

Lainnya:

5.2.6. Fill in forms?
$\square$ YES $\square$ NO

5.2.7. Others? (specify)

5.2.8. Is there a maximum time until the credit has to be paid back?

$\square$ YA $\quad \square$ TIDAK

5.2.9. If 2.7.14=YA: How long? 
5.2.10. Has there been any conflict concerning credit within the last half year? (Both ongoing conflicts and solved ones)

$\square$ YA $\square$ TIDAK

5.2.11. If $0=Y E S$ : Types of conflicts:

\begin{tabular}{|c|c|c|l|}
\hline $\begin{array}{c}\text { Conflict } \\
\text { No. }\end{array}$ & $\begin{array}{c}\text { How } \\
\text { often } \\
\text { occured } \\
\text { this? }\end{array}$ \\
\hline 1 & & Reason for conflict (non payment / other) & What was done in case of \\
each type of conflict *
\end{tabular}

*

1) With third party as mediator / arbitrator

2) Solving directly face to face?

3) Keeping the collateral?

4) Stop deliveries?

5) Go to the police?

6) Go to court?

7) Take a lawyer?

8) What else can be done?

\subsection{Size of Credits (All in Formular Number 3)}

5.3.1. How much credit (in the form of cash AND inputs) was given to the 4 farmers/other traders from Question 4.1.21 in every month during the last 12 months (how many rupiah in total)?

5.3.2. How much will not be repaid? What do you think, who will not repai within the next 6 months?

\section{4. (Interest and) repayment}

5.4.1. Explain: Many traders whom we've talked to before said that they also have to pay interest to the people who provide them with liquidity. Others said they don't think so, but were not sure. Do you know how much interest you are paying?

$\square$ YA $\square$ TIDAK

5.4.2. If 5.4.1.=YA: How much is it?

5.4.4. Explain: There are traders who take interest on the credit (implicitly) by reducing the estimated Dry Rubber Content (KKK). What are you doing?

(Hinweis für enumerator:

$\square$ Ya $\square$ Tidak)

5.4.3. Explain: Of course it is difficult to expect farmers to pay interest to you when they have borrowed money. But of course you somehow have to get back the interest you pay (implicitly) to somebody else. How do you do that? 
5.4.5. If YES: How much do you decrease the Dry Rubber Content (KKK) in the following cases?

\begin{tabular}{|c|c|c|c|c|}
\hline & \multicolumn{3}{|c|}{ Debt } \\
\hline & & $\begin{array}{l}\text { Rp. } \\
100.000\end{array}$ & $\begin{array}{l}\text { Rp. } \\
1 / 2 \text { juta }\end{array}$ & $\begin{array}{l}\text { Rp. } \\
1 \text { juta }\end{array}$ \\
\hline \multirow{3}{*}{$\begin{array}{c}\text { Delivered } \\
\text { Amount }\end{array}$} & $\begin{array}{l}50 \\
\mathrm{~kg}\end{array}$ & & & \\
\hline & $\begin{array}{c}200 \\
\mathrm{~kg}\end{array}$ & & & \\
\hline & $\begin{array}{c}500 \\
\mathrm{~kg}\end{array}$ & & & \\
\hline
\end{tabular}

5.4.6. If No: If the farme does not repay his debt in time: what do you think would be a fair interest rate? $\%$

5.4.7. Do you get payback of the credit as share of the harvest to pay the debt?
a) Share of Harvest: $\square$ YA $\square$ TIDAK

b) Fixed amount: $\quad \square$ YA $\square$ TIDAK

5.4.8. Jika 5.4.7a)=YA: How much is this share? ...........\%

5.4.9. Jika 5.4.7b)=YA: How much is this amount? tons

5.4.10. What forms of repayment do you accept?
Substract sum from selling sum of

Rubber or Palm Oil (von

Verkaufssumme abziehen beim

Handel)

$\square$ Processed foodstuff

$\square$ Handicrafts

$\square$ Labour

$\square$ Other (specify)

5.4.11. In which case can the loan be increased?

Crop failure?

Other reasons?

5.4.12. In which case can debt be forgiven?

Crop failure?

Other reasons?

5.4.13. If a farmer/other trader is owing you money, can they sell their produce to another trader? $\square$ YA $\square$ TIDAK

Ya,

if

5.4.14. Is it generally possible for a farmer without debt to sell to another trader than you?

$\square$ YA $\square$ TIDAK, because

\section{Information gathering}

6.1. On which things (that determine prices) do you get information?

$\square$ World market

Policies abroad

Policies at home

Harvests abroad

Harvests at home

NO

6.2. If any of $6.1=$ YES: Where do you get

this kind of information from? prices of input, outputs and services, as well as price-forecasts)

\author{
6.3.1. Media \\ Newspaper \\ Radio \\ Television \\ Internet (websites apa?)
}

6.3.2. Human sources

Friends

Own farming experience

downstream buyers

Input dealers

Government agency 
NGO project

Other (Specify)

\subsubsection{How (human sources)?}

$\square$ meeting (formal)

meeting (informal)

Email

Mobile phone (call)

Mobile phone (sms)

Mobile phone (other?

6.4. Do you own a smartphone /

blackberry?
$\square$ YA
$\square$ TIDAK

6.5. Do you own a USB-Modem? $\square$ YA $\quad \square$ TIDAK

6.6. Is there mobile phone reception in your village?

$\square$ YES $\square$ NO

6.7. Do you know the prices of your competitors?

$\square$ YA $\quad \square$ TIDAK

6.8. Do you know your farmers' costs?

$\square$ YA $\quad \square$ TIDAK

6.9. Do you know your buyers' revenue?

$\square$ YA $\quad \square$ TIDAK

6.10. Do you know your buyers' profit?
$\square$ YA
TIDAK

\section{Characteristics of Respondent (Part II)}

7.1. Age of respondent?

7.2. Religion?

years

7.3. Household size (including yourself)? people

7.4. Where have you been born?

7.5. What is your ethnicity?

$\square$ Jambi

$\square$ Jawa

Cina

lainnya:

7.6. Where has your father been born?

7.7. What is his ethnicity?
$\square$ Jambi
Jawa
Cina
$\square$ lainnya:

7.8. Where has your mother been born?

7.9. What is her ethnicity?
$\square$ Jambi
Jawa
Cina
$\square$ lainnya:

7.10. Are you transmigrasi?

$$
\text { YA } \square \text { TIDAK }
$$

7.11. For long have you lived in this place? ........... years

7.12. If you don't live here:
Where do you live?

Village:

Sub-District:

District:

How often do you come to this place? times / week

7.13. Education: What is your highest level attained?

$\square$ Never went to school

$\square$ Less than 2 years

$\square$ More than 2 years primary school

but didn't complete

Completed primary

Some secondary

Completed secondary

Post-secondary:

College:

7.14. Are you active in any village group? (E.g. Farmers-, Youth-, WomenGroup)

7.15. Are you member of any association? $\square$ YA $\square$ TIDAK

7.16. If yes: Which one?

7.17. How much did your house cost

(without land)?

House: Rp.

Land: Rp. 


\section{Business perspective}

\subsection{Information on buyers}

8.1.1. How many other traders do you know?

Karet:

Di RT:

Di Dusun:

Di Desa:

Di Kecamatan:

Sawit:

Di RT:

Di Dusun:

Di Desa:

Di Kecamatan:

8.1.2. Karet-traders di Desa ini:

12 months ago:

18 months ago:

24 months ago:

30 months ago:

36 months ago:

8.1.3. Sawit-traders di Desa ini:

12 months ago:

18 months ago:

24 months ago:

30 months ago:

36 months ago:

8.1.4. What do you think how will this number develop over the next years?
8.1.5. SHOW LIST OF RESPONDENTS: do you know any trader who is active in this village who is not on the list (including ones that don't live here) What are their names?

8.1.5.a. how much do you buy in this village (from list of respondents)? $\mathrm{kg} /$ month

8.1.6. How many buyers is delivered to?

8.1.7. How many buyers are there for you to choose from?

8.1.8. What do you have to do when you stop selling to one buyer?

8.1.9. What do you have to do when you start selling to another buyer?

8.1.10. Types of buyers

\begin{tabular}{|c|l|}
\hline & $\begin{array}{l}\text { Considering all your Palm Oil } \\
\text { Rubber sales in the last 52 weeks, } \\
\text { what percentage was sold to this kind } \\
\text { of buyer? }\end{array}$ \\
\hline Local Trader & R: \\
& P.-O.: \\
\hline $\begin{array}{c}\text { Warehouse } \\
\text { (Gudang) }\end{array}$ & R: \\
& P.-O.: \\
\hline
\end{tabular}




\begin{tabular}{|l|l|}
\hline Factories & R: \\
& P.-O.: \\
\hline Exporters & R: \\
& P.-O.: \\
\hline Others & Specify: \\
& $1: \ldots \ldots \ldots \ldots \ldots$ \\
& R: \\
& P.-O.: \\
& $2: \ldots \ldots \ldots \ldots \ldots$ \\
& R: \\
& P.-O.: \\
\hline
\end{tabular}

\subsection{Location of buyers}

8.2.1. Of the total amount of Palm Oil / Rubber you bought in the last 52 weeks, what proportion was sold to firms in this village?

$\%$

8.2.2. What proportion was sold to firms in this district?

$$
\%
$$

8.2.3. What proportion was sold to firms in districts neighbouring this one?
8.2.4. What proportion was sold to firms in other parts of Indonesia? ............\%

8.2.5. What proportion was sold to firms in other countries? $\%$

8.2.6. Which countries?

\subsection{Information on farmers / providers}

8.3.1. How many Palm Oil / Rubber providers do you buy from?

Farmers:

Other traders:

8.3.2. Would you like to have more?

$\square$ YES $\square$ NO

8.3.3. Do you always source from the same providers?
$\square$ YES
$\square \mathrm{NO}$

8.3.4. If 8.3.3.=NO: How much do they change?

Between two months $80 \%$ overlap

Between two months 50\% overlap

Between two months $30 \%$ overlap

8.3.5. What do you have to do when you start buying from a new provider (farmer / other trader)?

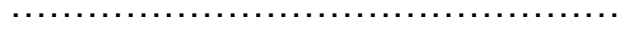

8.3.6. When you buy commodities, are you the only trader in the area?
8.3.7. Do you have any objection to see another trader at the same time in the same area?

$\square$ YES $\quad \square$ NO

8.3.8. Is it possible that they could disturb the normal procedure of your business?

$$
\square \text { YES } \square \text { NO }
$$

8.3.9. When there was any other trader active at the same time of your business, have you ever asked him to leave the area?

$\square$ YES $\square$ NO

8.3.10. Has it ever happened that another trader left by your request?

$\square$ YES $\square$ NO

8.3.11. Have you ever used any other instrument to encourage somebody to leave?

$\square$ YES $\square$ NO

8.3.12. If 8.3.11=YA: What did you do?

$\square$ YES $\square$ NO 
8.3.13. Types of farmers and providers

\begin{tabular}{|l|l|l|}
\hline & $\begin{array}{l}\text { Considering all of your Palm Oil / } \\
\text { Rubber purchases in the last half } \\
\text { year, what percentage was from each } \\
\text { type of providers? }\end{array}$ & $\begin{array}{l}\text { What was the typical amount of } \\
\text { Palm Oil / Rubber you bought } \\
\text { from this kind of provider in a } \\
\text { single transaction? }\end{array}$ \\
\hline $\begin{array}{l}\text { Plasma smallholder } \\
\text { farmers (less than 5 ha) }\end{array}$ & & \\
\hline $\begin{array}{l}\text { Free smallholder } \\
\text { farmers (less than 5 ha) }\end{array}$ & & \\
\hline $\begin{array}{l}\text { Smallholders producing } \\
\text { jungle rubber? }\end{array}$ & & \\
\hline $\begin{array}{l}\text { Smallholders producing } \\
\text { in a small rubber } \\
\text { plantation? }\end{array}$ & & \\
\hline $\begin{array}{l}\text { Large- scale farmers/ } \\
\text { plantations }\end{array}$ & & \\
\hline Farmers' groups? & & \\
\hline Other traders & & \\
\hline $\begin{array}{l}\text { NGO, government, or } \\
\text { other projects }\end{array}$ & & \\
\hline Others & & \\
\hline
\end{tabular}

\subsection{Location of sellers}

8.4.1. Of the total amount of Palm Oil / Rubber you bought in the last 52 weeks, what proportion was bought from providers in this village? ..................\%

8.4.2. What proportion was bought from providers in this district?

\begin{abstract}
8.4.3. What proportion was bought from providers in neighbouring districts? $\%$
\end{abstract}

8.4.4. What proportion was bought from providers in other parts of Indonesia? $\%$

\subsection{Development Perspectives}

8.5.1. How much profit did you make by trading one ton of rubber last week, after substracting all costs? Rp.
8.5.2. Is there an auction market in this village?

$\square$ YES $\square$ NO

\section{Final remarks}

9.1. Is there anything else you would like to share with us?

9.2. Are you interested in the results of this survey? (If he has an email address)

$$
\square \text { YES } \square \text { NO }
$$

9.3. Do yo have demands towards the researchers? 
CRC $-990-$ C01 - WP2

\section{ENDING TIME OF THE INTERVIEW:}

GPS Data (filled in by Tom): S.:

E.:

\section{Notes:}


CRC $-990-$ C01 - WP2

Instructions for Enumerator:

Please thank the respondent for the time he or she spent to answer these questions.

Now go out of the house and take a picture of him, together with you.Make sure the GPS works! If not: Switch off the camera, switch it on again, wait a little.

- Give respondend a T-Shirt

- Pay Rp. 50.000

- Let sign the following statement:

I, participating in this survey

have received the sum of $\mathrm{Rp} .50 .000$ as compensation of

Signature

Place

Date

Now go out of the house and take a picture of him, together with you. Make sure the GPS has a signal! If not: Switch off the camera, switch it on again, wait a little.

Name of enumerator: 
Form 1: Selling Rubber / Palm Oil

Respondent ID

Respondent Name

Date of Interview

Name of enumerator:

Is the information provided based on written notes $(\mathrm{N})$ or recall $(\mathrm{R})$ ?

If fotographs of books are available: Timestamp of the first picture:

4.1.5. How many tons of Palm Oil / Rubber have you delivered in each of the last 12 month to the three buyers mentioned above? (in ton)

\begin{tabular}{|c|c|c|c|c|c|c|c|c|c|c|c|c|c|}
\hline & This Month & $\begin{array}{c}1 \text { month } \\
\text { ago }\end{array}$ & $\begin{array}{c}2 \text { months } \\
\text { ago }\end{array}$ & 3 & 4 & 5 & 6 & 7 & 8 & 9 & 10 & 11 & 12 \\
\hline Buyer 1 & & & & & & & & & & & & & \\
\hline Buyer 2 & & & & & & & & & & & & & \\
\hline Buyer 3 & & & & & & & & & & & & & \\
\hline
\end{tabular}

4.1.6. How many Rupiah did you get for each of these deliveries? (in Rupiah)

\begin{tabular}{|c|c|c|c|c|c|c|c|c|c|c|c|c|c|}
\hline & This Month & $\begin{array}{c}1 \text { month } \\
\text { ago }\end{array}$ & $\begin{array}{c}2 \text { months } \\
\text { ago }\end{array}$ & 3 & 4 & 5 & 6 & 7 & 8 & 9 & 10 & 11 & 12 \\
\hline Buyer 1 & & & & & & & & & & & & & \\
\hline \multicolumn{14}{|l|}{ Buyer 2} \\
\hline Buyer 3 & & & & & & & & & & & & & \\
\hline
\end{tabular}




\section{Form 2: Buying Rubber and Palm Oil}

$\square$ Palm Oil

$\square$ Rubber

Is the information provided based on written notes $(\mathrm{N})$ or recall $(\mathrm{R})$ ?

If fotographs of books are available: Timestamp of the first picture:

5.1.22. Which amount of Palm Oil / Rubber have you received from these 4 farmers / other traders in total at every month during the last 12 montsh? (in tons)

\begin{tabular}{|c|c|c|c|c|c|c|c|c|c|c|c|c|c|}
\hline & This Month & $\begin{array}{c}1 \text { month } \\
\text { ago }\end{array}$ & $\begin{array}{c}2 \text { months } \\
\text { ago }\end{array}$ & 3 & 4 & 5 & 6 & 7 & 8 & 9 & 10 & 11 & 12 \\
\hline Provider 1 & & & & & & & & & & & & & \\
\hline Provider 2 & & & & & & & & & & & & & \\
\hline Provider 3 & & & & & & & & & & & & & \\
\hline Provider 4 & & & & & & & & & & & & & \\
\hline
\end{tabular}

5.1.23. How much money has been paid to these 4 farmers / other traders at every month during the last 12 month for the respective amounts? (in Rupiah)

\begin{tabular}{|c|c|c|c|c|c|c|c|c|c|c|c|c|c|}
\hline & This Month & $\begin{array}{c}1 \text { month } \\
\text { ago }\end{array}$ & $\begin{array}{c}2 \text { months } \\
\text { ago }\end{array}$ & 3 & 4 & 5 & 6 & 7 & 8 & 9 & 10 & 11 & 12 \\
\hline Provider 1 & & & & & & & & & & & & & \\
\hline Provider 2 & & & & & & & & & & & & & \\
\hline Provider 3 & & & & & & & & & & & & & \\
\hline Provider 4 & & & & & & & & & & & & & \\
\hline
\end{tabular}




\section{Form 3: Credit}

6.3.1. How much credit (in the form of cash AND inputs) was given to the 4 farmers/other traders from Question 4.1 .18 in every month during the last 12 months (how many rupiah in total)? (In Rupiah)

\begin{tabular}{|c|c|c|c|c|c|c|c|c|c|c|c|c|c|}
\hline & This Month & $\begin{array}{c}1 \text { month } \\
\text { ago }\end{array}$ & $\begin{array}{c}2 \text { months } \\
\text { ago }\end{array}$ & 3 & 4 & 5 & 6 & 7 & 8 & 9 & 10 & 11 & 12 \\
\hline Provider 1 & & & & & & & & & & & & & \\
\hline Provider 2 & & & & & & & & & & & & & \\
\hline Provider 3 & & & & & & & & & & & & & \\
\hline Provider 4 & & & & & & & & & & & & & \\
\hline
\end{tabular}

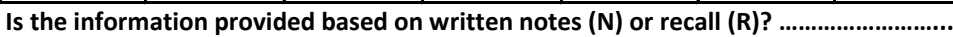

If fotographs of books are available: Timestamp of the first picture: .

6.3.2. How much will not be repaid? (in Rupiah)

\begin{tabular}{|c|c|c|c|c|c|c|c|c|c|c|c|c|c|}
\hline & This Month & $\begin{array}{c}1 \text { month } \\
\text { ago }\end{array}$ & $\begin{array}{c}2 \text { months } \\
\text { ago }\end{array}$ & 3 & 4 & 5 & 6 & 7 & 8 & 9 & 10 & 11 & 12 \\
\hline Provider 1 & & & & & & & & & & & & & \\
\hline Provider 2 & & & & & & & & & & & & & \\
\hline Provider 3 & & & & & & & & & & & & & \\
\hline Provider 4 & & & & & & & & & & & & & \\
\hline
\end{tabular}

Is the information provided based on written notes $(\mathrm{N})$ or recall $(\mathrm{R})$ ? .

If fotographs of books are available: Timestamp of the first picture: 


\section{Curriculum Vitae}

\section{Personal Information}

Name: $\quad$ Thomas Kopp

Date of birth: $\quad 03.12 .1983$

Place of birth: Gräfelfing

Nationality: German

\section{Education}

since 02/2012 PhD student at Georg-August-Universität Göttingen

09/2011 Master of Science in Agricultural Economics

10/2006-09/2011 Student of Agricultural Economics at Georg-August-Universität Göttingen

08/2009 Bachelor of Arts in Area Studies of Asia and Africa

10/2006-09/2009 Student of Area Studies of Asia and Africa at Humboldt Unversität zu Berlin

10/2004-09/2005 Student of Environmental Engineering at Technische Universität Berlin

06/2003 Abitur 